\title{
WestVirginiaUniversity
}

THE RESEARCH REPOSITORY @ WVU

Graduate Theses, Dissertations, and Problem Reports

2011

\section{Friction and Leakage Characteristics of Inflatable Structures in Tunnels}

Joshua J. Sill

West Virginia University

Follow this and additional works at: https://researchrepository.wvu.edu/etd

\section{Recommended Citation}

Sill, Joshua J., "Friction and Leakage Characteristics of Inflatable Structures in Tunnels" (2011). Graduate Theses, Dissertations, and Problem Reports. 4790.

https://researchrepository.wvu.edu/etd/4790

This Thesis is protected by copyright and/or related rights. It has been brought to you by the The Research Repository @ WVU with permission from the rights-holder(s). You are free to use this Thesis in any way that is permitted by the copyright and related rights legislation that applies to your use. For other uses you must obtain permission from the rights-holder(s) directly, unless additional rights are indicated by a Creative Commons license in the record and/ or on the work itself. This Thesis has been accepted for inclusion in WVU Graduate Theses, Dissertations, and Problem Reports collection by an authorized administrator of The Research Repository @ WVU. For more information, please contact researchrepository@mail.wvu.edu. 


\title{
Friction and Leakage Characteristics of Inflatable Structures in Tunnels
}

\author{
Joshua J. Sill \\ Thesis submitted to the \\ College of Engineering and Mineral Resources \\ at West Virginia University \\ in the partial fulfillment of the requirements \\ for the degree of
}

\author{
Master of Science \\ in \\ Mechanical Engineering \\ Kenneth Means, Ph.D., Chair \\ Wade Huebsch, Ph.D. \\ Eduardo Sosa, Ph.D.
}

Department of Mechanical and Aerospace Engineering

Morgantown, West Virginia

2011

Keywords: friction; leakage; fabrics; inflatables; tunnels; plugs

Copyright 2011 Joshua J. Sill 


\title{
Abstract \\ Friction and Leakage Characteristics of Inflatable Structures in Tunnels
}

\author{
Joshua J. Sill
}

Inflatable technology has become a popular alternative for replacing conventional ways of building structures. Inflatable structures offer the benefits of being lightweight and portable while maintaining needed rigidity and reducing production costs. These benefits have prompted the use of inflatables in confined spaces such as pipes and tunnels to act as barriers with minimal infrastructure modification. This work focuses on using these inflatables, or plugs, in transportation subway tunnels as a way to mitigate threats such as floods.

In order to stop the flow of water, the plug must be capable of being pressurized and apply enough pressure on the tunnel walls so that it does not move while being acted upon by an opposing force. A small scale test bed was constructed in which a plug could be inflated inside of a pipe representing a tunnel with one closed end. This closed space between the closed tunnel end and the plug could then be pressurized with water applying an opposing force on the plug trying to push it out of the tunnel. The plug was set at different pressures while the tunnel pressure was raised to the plug pressure until slippage of the plug occurred. This pressure differential between the plug and tunnel was recorded and used to calculate a friction coefficient. Friction coefficients were calculated for three different materials lining the tunnel so a comparison could be made. These friction coefficients were also compared to laboratory friction machine testing of the same lining materials. This comparison showed that the tunnel and plug friction coefficients were much lower than the laboratory friction machine tests.

Rates of water leakage around the plug were also studied. The leakage rates were recorded for several different plug pressures while varying the tunnel pressure accordingly. It was observed that as pressure differential decreased between the plug and tunnel, the leakage rate increased. The leakage rates were also compared to the friction tests and indicated that an increased leakage rate caused a decrease in the friction coefficient. Leakage rates were also scaled and estimated for a larger plug and tunnel diameter. 


\section{Acknowledgements}

I would like to thank my committee members, Dr. Wade Huebsch and Dr. Eduardo Sosa, for their help through the course of this project. I would also like to thank my advisor, Dr. Kenneth Means, for his guidance, leadership, and kind nature throughout my graduate studies.

The slippage and leakage tests performed for this thesis would have not been possible without the help of my good friends, Christopher Griffin, Jared Grim, and Perry (P.J.) Spaur. Thanks to all of you for your help. Also, thanks to Kevin Peil for performing the friction machine testing.

Thanks to my wonderful girlfriend, Renae, who is always there to help, encourage, and support me in all that I do. Thank you for everything you do for me. A special thanks to my great family for always believing and encouraging me to do my very best in all that I do. 


\section{Table of Contents}

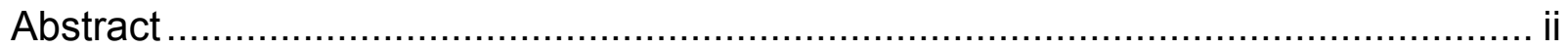

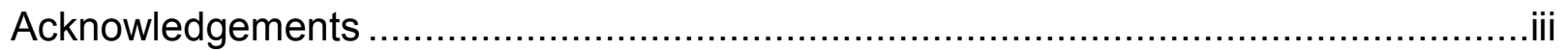

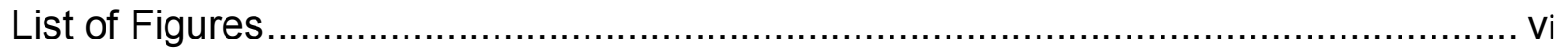

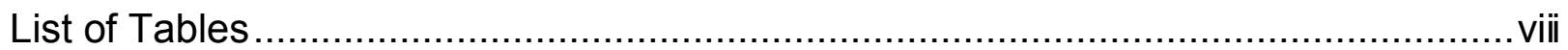

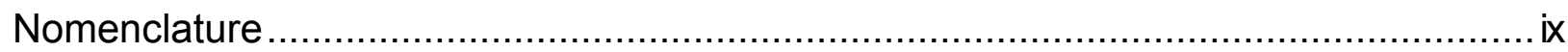

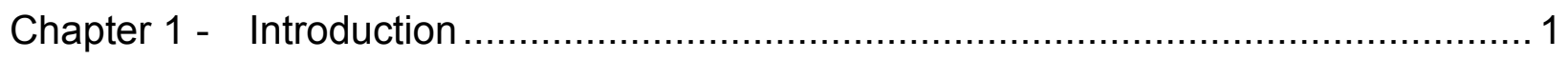

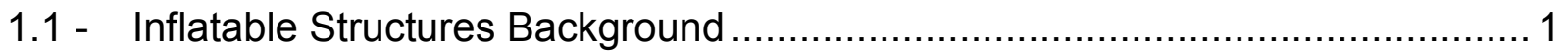

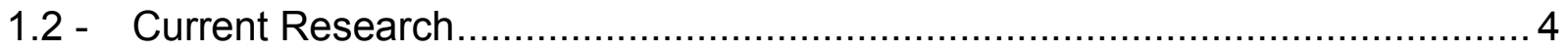

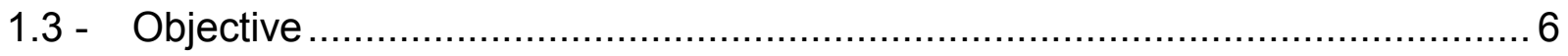

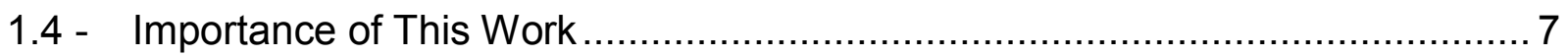

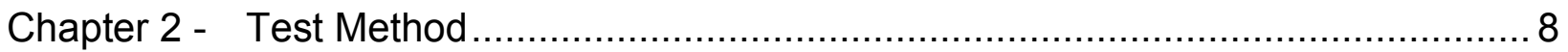

2.1 - Test Setup

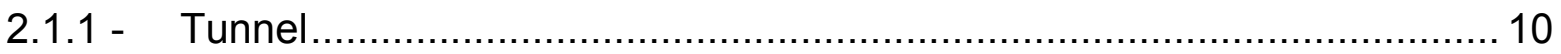

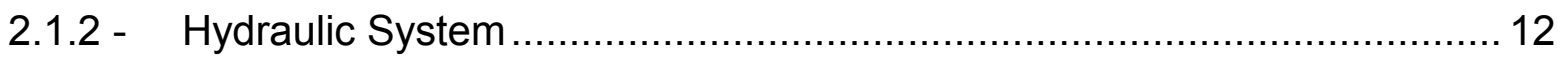

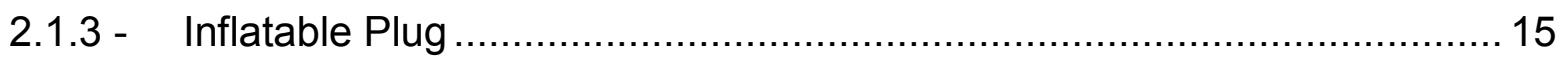

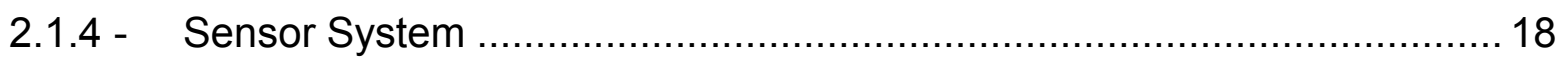

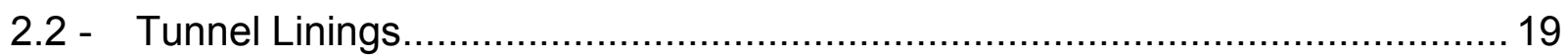

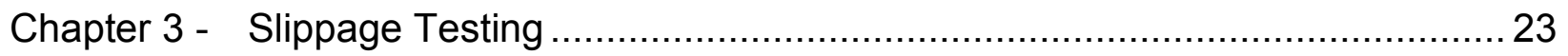

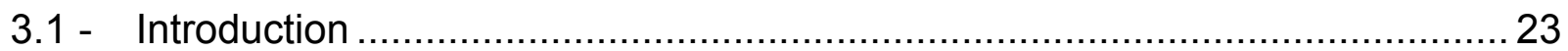

3.2 - Friction Tests Using A Friction Testing Machine …................................... 23

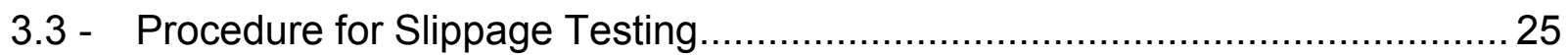

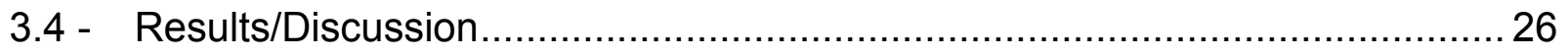

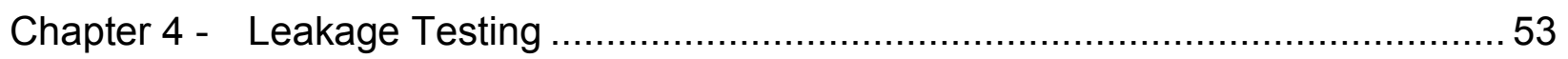

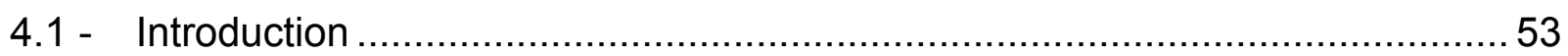




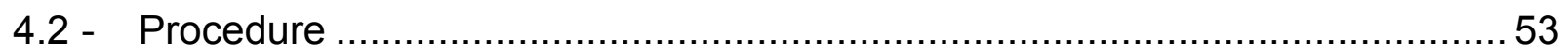

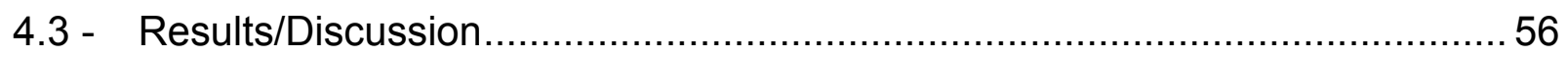

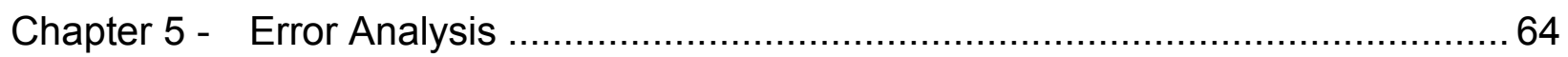

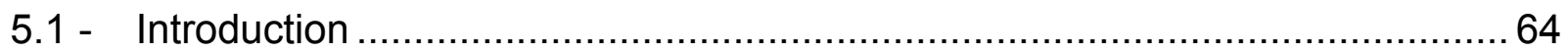

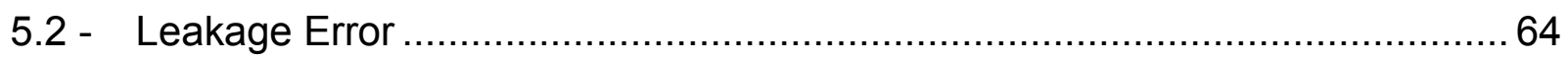

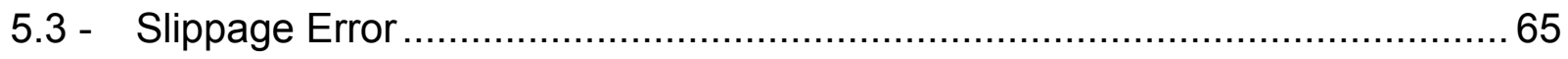

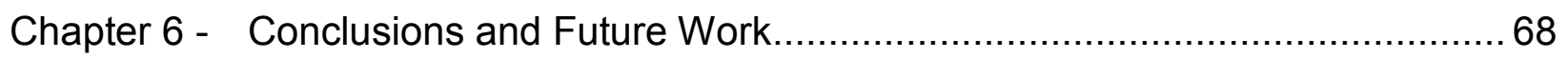

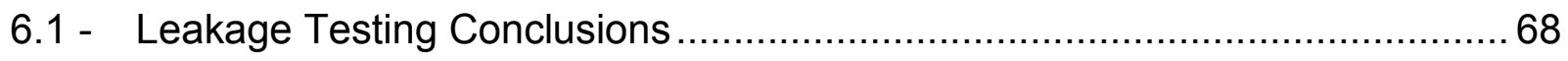

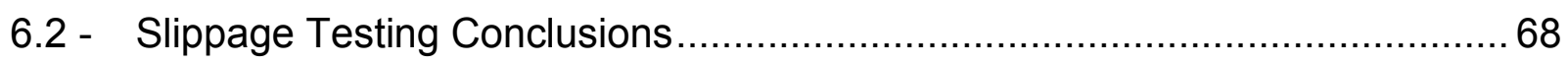

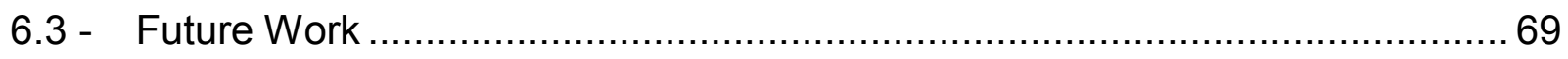

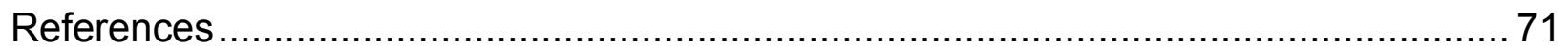

Appendix A - Pressure Transducer Documentation ................................................. 74

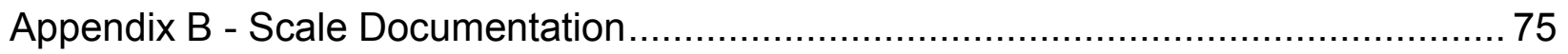

Appendix C - Pump Curve Documentation.............................................................. 76

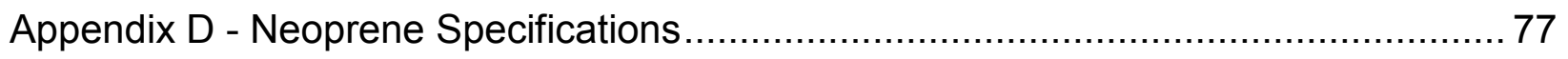

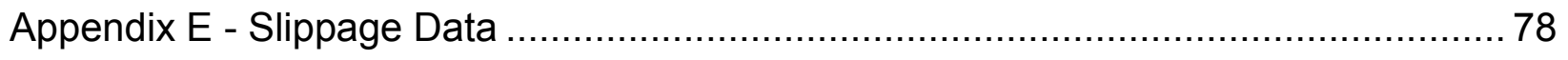




\section{List of Figures}

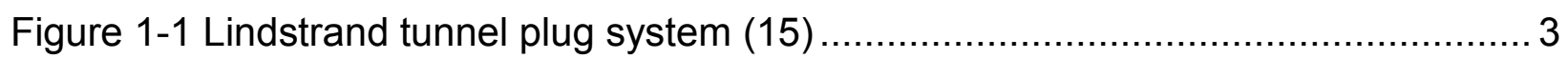

Figure 1-2 Proof of concept testing at WMATA (19) …........................................... 5

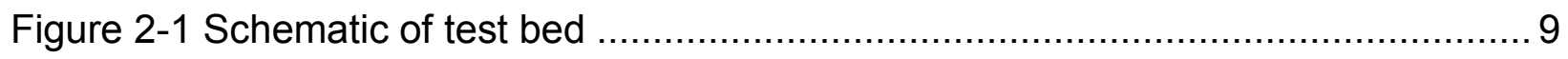

Figure 2-2 Cross-section of tunnel and plug setup ............................................... 9

Figure 2-3 Tunnel dimensions and connections ................................................ 11

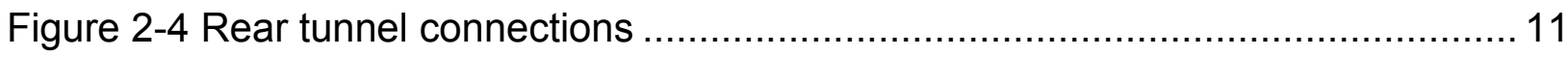

Figure 2-5 3000 gallon water supply with outlet hoses to pumps .............................. 13

Figure 2-6 Pump system for filling and pressurization........................................... 14

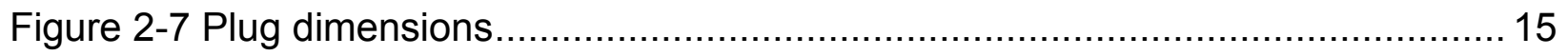

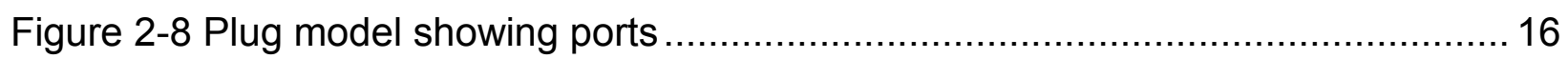

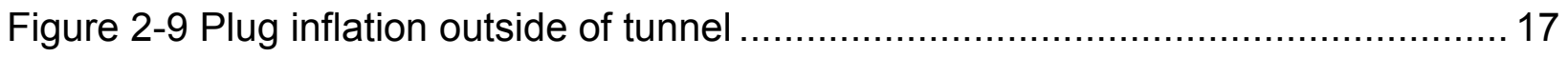

Figure 2-10 Plug inflated inside the tunnel with low pressure air.............................. 17

Figure 2-11 LabVIEW data collection program.................................................. 18

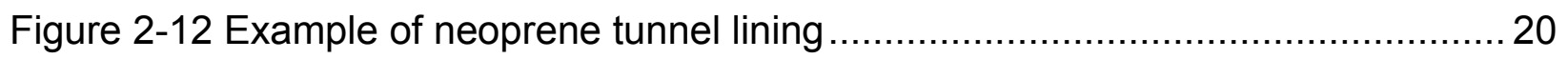

Figure 2-13 Detailed view of tunnel linings: (A) Concrete, (B) Neoprene, and (C) Vinyl 22

Figure 3-1 Friction testing machine used in previous friction testing (20).................... 24

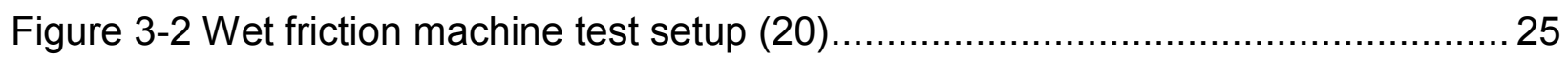

Figure 3-3 Example of slippage point for at 20 psi plug pressure .............................. 30

Figure 3-4 Example of slippage point location compared to the plug displacement ...... 30

Figure 3-5 Slippage point for 10 psi plug pressure with concrete lining .......................31

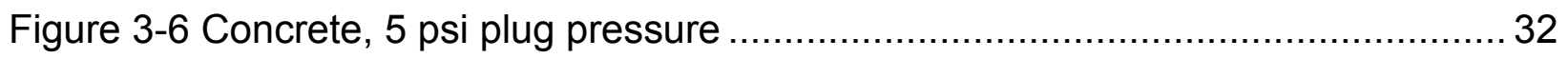

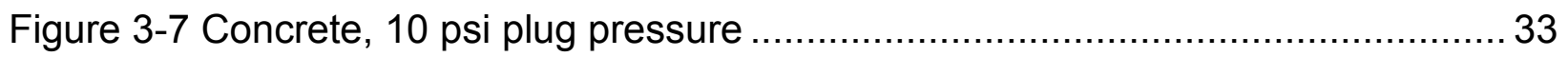




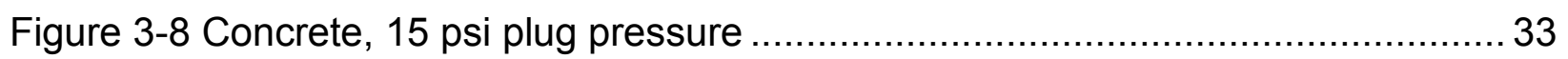

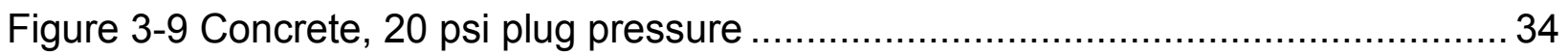

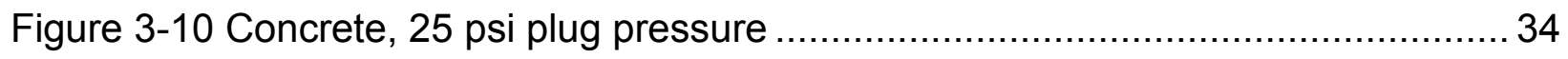

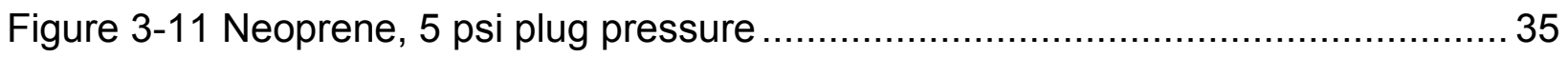

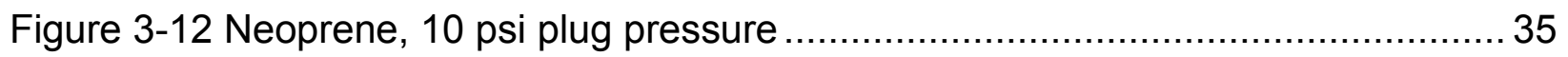

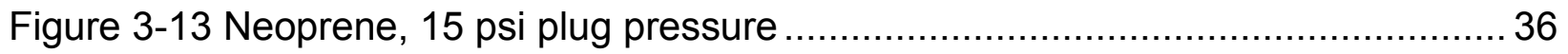

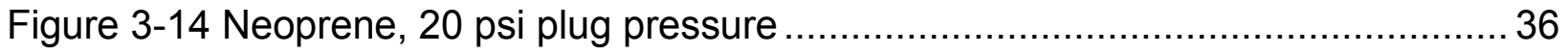

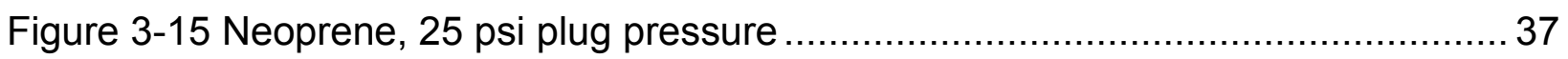

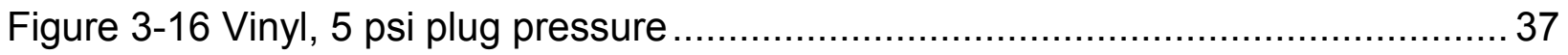

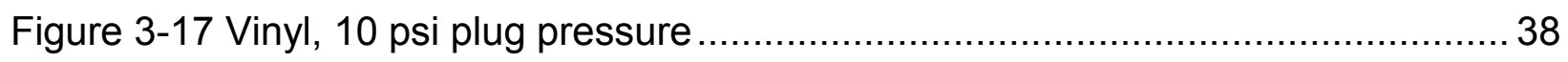

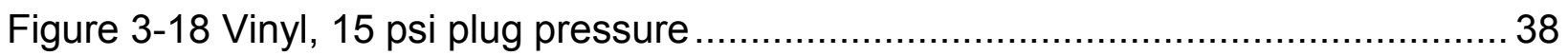

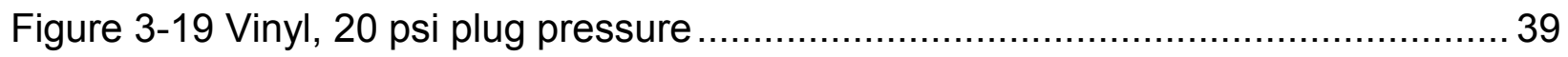

Figure 3-20 Plug pressure vs pressure differential .............................................. 40

Figure 3-21 Force balance and dimensions of tunnel and plug............................... 41

Figure 3-22 Hydrostatic pressure distribution on the plug ..................................... 42

Figure 3-23 Plug pressure vs. tunnel pressure for each tunnel lining.........................48

Figure 3-24 Leakage rate vs. friction coefficient...................................................... 50

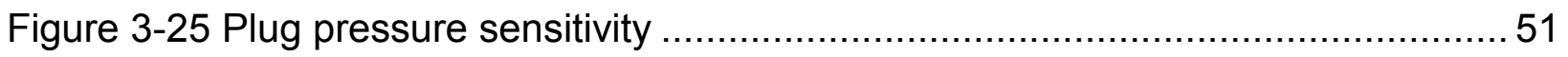

Figure 4-1 Pressure differential vs. leakage rate for concrete .................................. 58

Figure 4-2 Pressure differential vs. leakage rate for neoprene..................................58

Figure 4-3 Pressure differential vs. leakage rate for vinyl....................................... 59

Figure 4-4 Tunnel pressure vs. leakage rate for concrete lining ................................6 60

Figure 4-5 Leakage rates from $4 \mathrm{ft}$ and $16 \mathrm{ft}$ tunnels at a plug pressure of $20 \mathrm{psi}$.......... 62 


\section{List of Tables}

Table 3-1 Desired and actual plug pressure error ............................................... 27

Table 3-2 Slippage data for different tunnel linings .............................................. 28

Table 3-3 Friction coefficients for different tunnel linings........................................ 47

Table 3-4 Comparison of friction values for different testing methods ......................... 49

Table 3-5 Relationship between friction coefficient and leakage rate..........................50

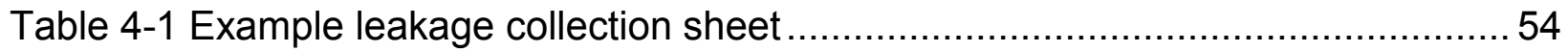

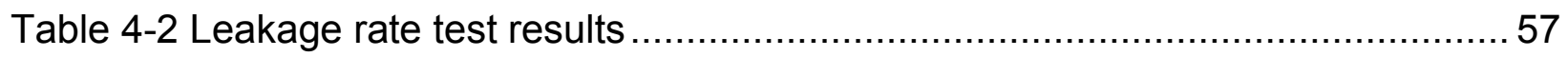

Table 4-3 Estimated leakage rates for a $16 \mathrm{ft}$ diameter tunnel .................................. 63

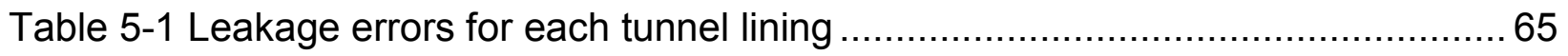

Table 5-2 Friction coefficient error for each tunnel lining ......................................... 66 


\section{Nomenclature}

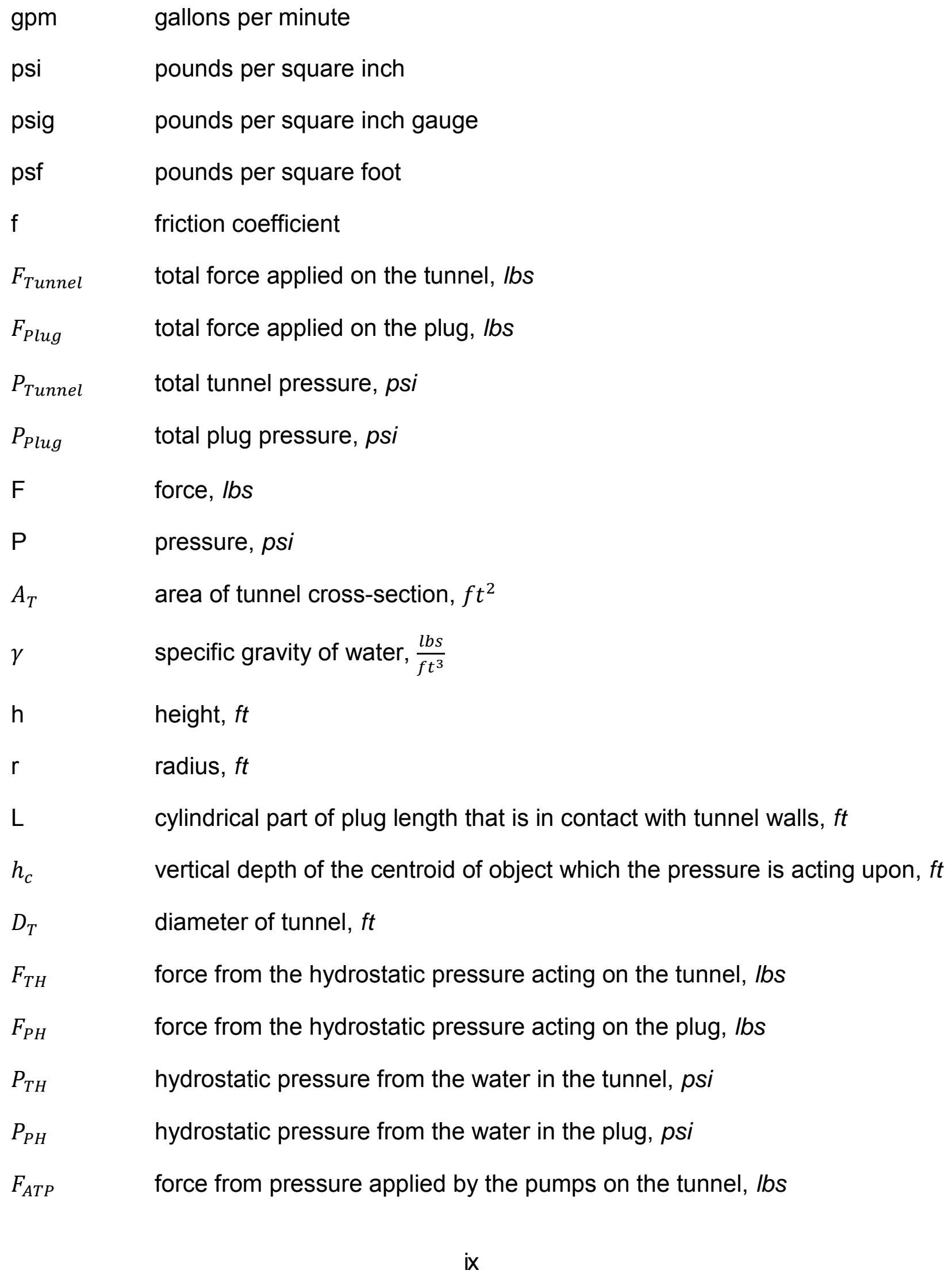


$F_{A P P} \quad$ force from pressure applied by the pumps on the plug, Ibs

$P_{A T P} \quad$ pressure applied by the pumps on the tunnel, psi

$P_{A P P} \quad$ pressure applied by the pumps on the plug, $p s i$

W weight, lbs

$T$

Time, seconds

VDC volts direct current 


\section{Chapter 1 - Introduction}

\section{1 - Inflatable Structures Background}

For many years inflatable structures have continued to gain popularity throughout the world. Space exploration prompted much of the research in this area starting in the early 1970's with companies beginning to design and test inflatable space structural systems (1) (2). This research has continued and now offers many inflatable structures that can be seen in a wide variety of industries. Space exploration still plays a large role in the development of inflatable designs with examples such as flexible containment covers for the Hubble Telescope and impact landing airbag systems for the Mars Exploration missions (3). Military applications include items such as lightweight portable buildings and tents that act as barriers against chemical and biological agents (4) (5). More recognizable examples include airships (6) and even the roofs of stadiums and buildings such as the Metrodome (7) and Carrier Dome (8).

Inflatable structures used as plugs are also being used in the repair of pipe systems. Even though this technique has been evolving since the early 1920's with patents dating as early as 1949 (9), recent technology improvements have allowed significant product innovations to make it far more effective and successful (10). In the past many methods have been used to prevent the flow of substances in confined spaces. Traditional ways most commonly include the use of valves in pipes or the use of flood gates in tunnels and waterways. Other methods, such as injecting concrete or grouts into pipes, have been used to seal sections which have failed. These permanent seals then require the flow to be permanently rerouted. 
An example of a situation in which inflatable plugs could have been useful is in the Great Chicago Flood of 1992. In this event, a breach in a freight tunnel connected to over 100 buildings caused the river to flood into city building basements. The tunnels were originally designed to transport goods to different buildings to relieve traffic congestion but were later used for running fiber optic cables. The water caused the city to be shut down and the Chicago Loop was declared a federal emergency. Engineers were tasked with the cleanup and removal of water and then installed permanent plugs to prevent any future disaster (11).

By using inflatable structures, one or more plugs can be inserted into pipes and then inflated to seal off certain sections so that repairs can be performed (12). Once repairs are finished, the plugs can be deflated and removed so the pipe can resume normal operation. This method is common when fixing sewage pipes that have deteriorated or been damaged. This technique is also used in many production plant environments where fluid systems must be repaired but the entire system cannot be shut down. In special cases the plugs can even be filled with a variety of different liquids. For example, when a diesel line must be repaired, the plug can be filled with diesel so if the plug does leak, the lines are not contaminated with a foreign substance (13).

Breakthroughs in material strengths and manufacturing methods also allow inflatable plugs to be applied in much larger scales to seal tunnels in the event of an accident. Underground mines, subway tunnels, and automobile tunnels are a few examples of large scale situations where accidents can occur. These large plugs can be used to block smoke, fire, and water. 
Lindstrand Technologies has developed inflatable tunnel plugs for use in the London Underground Victoria Line subway system. In 1987 a disastrous fire engulfed an old wooden escalator at the King's Cross underground station killing thirty one people (14). In order to help prevent another disaster, the Lindstrand tunnel plugs are installed at pre-positioned 100 meter intervals and inflated by remote control when needed. These plugs seal the tunnel thus cutting off the flow of oxygen that a fire needs to burn. They also inhibit the spread of smoke and other harmful agents in the air (15). An example of the plugs developed by Lindstrand is shown in Figure 1-1.

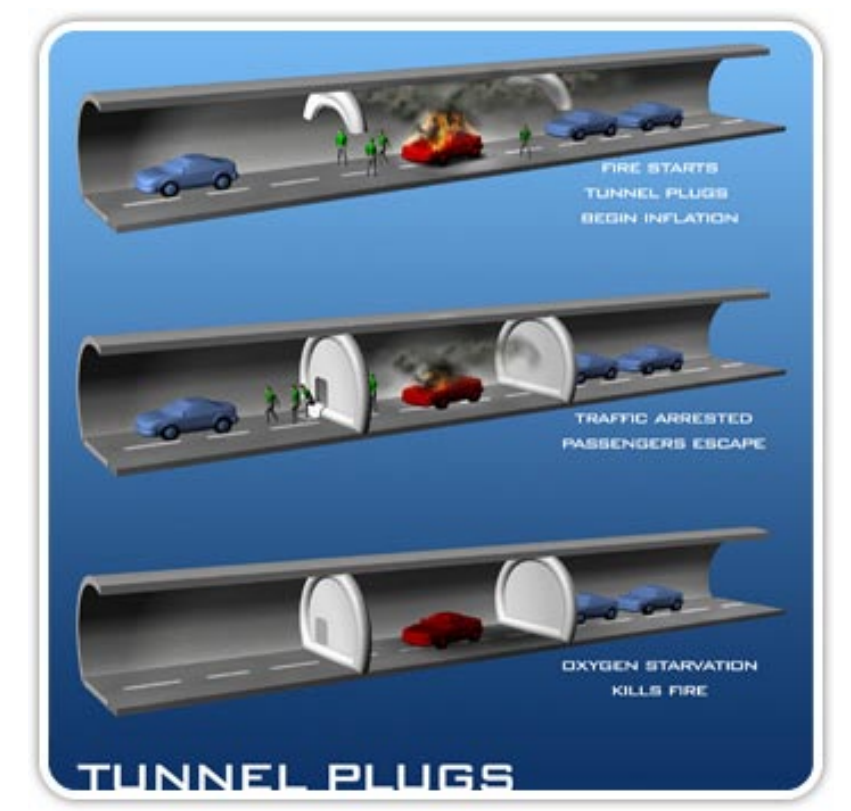

Figure 1-1 Lindstrand tunnel plug system (15)

Petersen, which has extensive knowledge with pipe plugs, has recently performed some very large operations to stop mine flooding. In 2008, the Cigar Lake Uranium Mine in Canada developed a large leak which stopped work. A plug that was seven meters ( 23 feet) in diameter was constructed and placed in the tunnel using a 
remote operated vehicle. The plug was then filled first with water to check position and then with grout to form a permanent seal to stop the leak (16).

These inflatable plugs have several advantages over other methods. Minimal infrastructure modification is necessary in order to install and deploy the plugs. They can be installed quickly and can function independently of other systems. Comparable structures to the plugs such as a flood gate or other system require extensive modifications that could take years to install. Inflatable structures also offer the advantage of being lightweight when compared to equivalent structures made from other materials. This aids in the ease of transportation and also lowers manufacturing costs. Since the material is pliable, plugs can be folded into compact packages and inserted into very small openings and then inflated to fill large spaces. These advantages are making inflatable structures a popular and ingenious alternative to protect underground transportation infrastructure.

\section{2 - Current Research}

Currently, West Virginia University (WVU) is doing research in the area of inflatable structures which is focused on tunnel plugs. Several organizations are involved in the Resilient Tunnel Project (RTP) to help create a tunnel plug that is capable of blocking underground transportation tunnels in case of a disaster. This project aims to address post-9/11 concerns that terrorists will target vulnerable tunnels causing catastrophic damages (17). The plug(s) could be installed at key points in tunnels and deployed in the event of flooding, fire, smoke or other disaster (18). 
The RTP has conducted several phases of testing, the first being a full scale proof of concept test demonstrated in the Washington Metropolitan Area Transit Authority (WMATA) tunnel system (18). This test is shown in Figure 1-2.

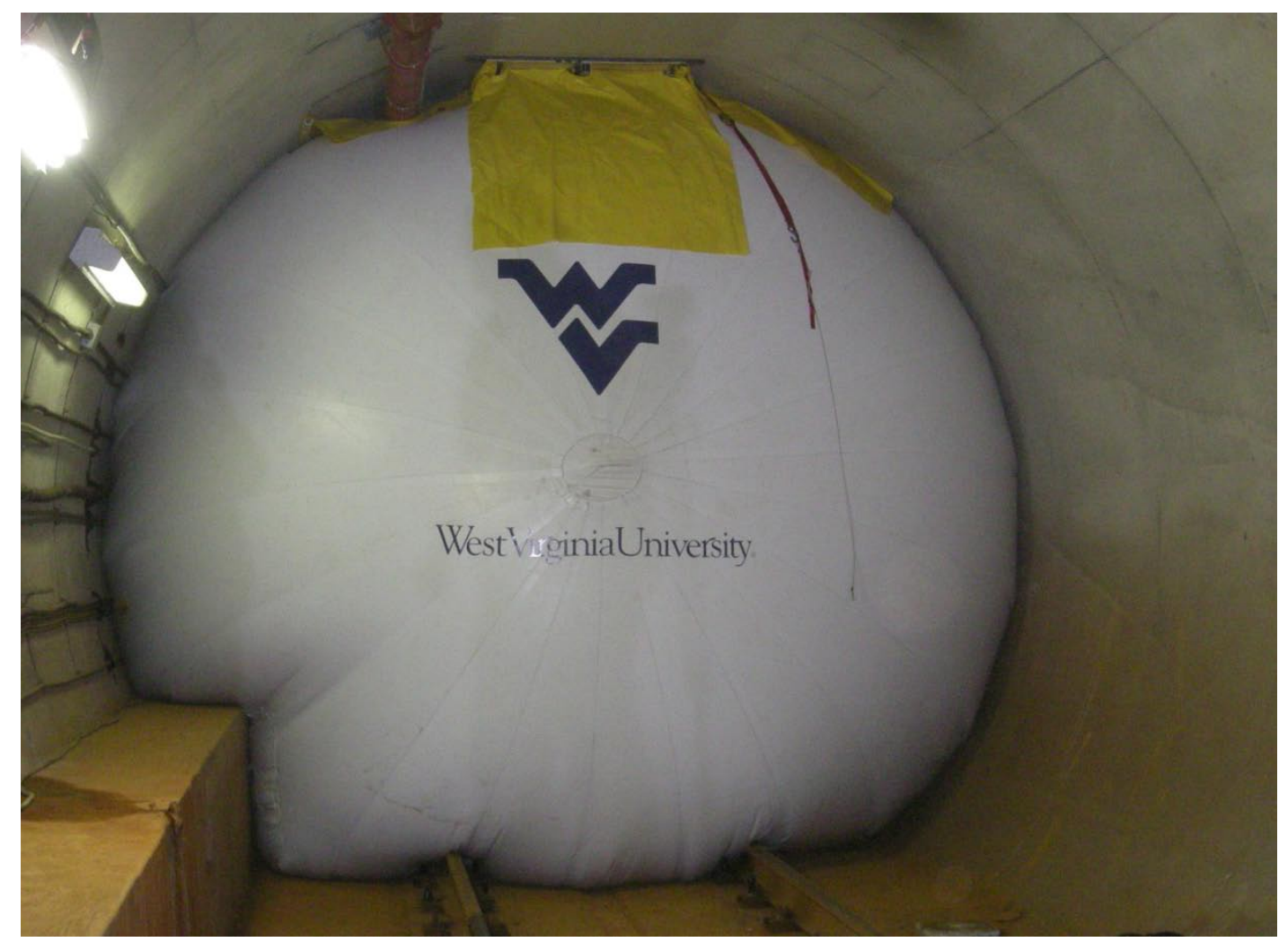

Figure 1-2 Proof of concept testing at WMATA (19)

These full scale low pressure air tests were then followed by one-quarter scale testing with high pressures using water. The small scale testing was performed with water filling both the plug and also pressurizing a space behind the plug to see if it could withstand the applied pressure. By applying pressure behind the plug, friction coefficients and leakage rates were obtained to further enhance plug design and optimization. 
Materials testing of the fabric used to manufacture the tunnel plugs was also conducted. Since it may be necessary for the plugs to be inflated for extended periods of time, the long term loading properties of the material were studied so they could be better understood. Some aspects that were studied were the prediction of creep failure times given an applied stress in the fabric and also quasi-static testing to provide the ultimate strength and Young's modulus (20). A laboratory method of studying fabric friction was also introduced with minor modifications to the standard ASTM D1894 (21). This method used a friction testing machine to obtain the friction coefficient between fabric and different surfaces using small samples of fabric (20)(22).

\section{3 - Objective}

The main objective of this thesis is to determine an experimental friction coefficient between an inflatable plug and a tunnel surface lined with different materials using water as the inflation medium. This is determined by finding the pressure differential at which the plug slips when acted upon by a longitudinal opposing head pressure that is applied behind the plug. This friction coefficient from the plug-tunnel tests can then be compared to laboratory friction tests performed on plug material with a friction testing machine.

A secondary objective includes measuring the leakage rate of water flowing around the plug when it is pressurized within the tunnel. The leakage rate will be measured for different pressure differentials between the plug and tunnel to determine common trends. 


\section{4 - Importance of This Work}

Even though friction coefficients between the plug and tunnel can be calculated using friction testing machines, these results cannot take into account other factors that may be present. The data obtained from the plug and tunnel friction tests presented in this work will be very important in future plug design. The friction coefficients will allow designers to know how the plug performs under actual test conditions.

The leakage rates measured during testing will also be important in later plug design and implementation. The rates will allow the tunnel operators to be aware of how much water they must be able to handle and dispose of during an event. The data collected will ultimately aid in the design and construction of a full scale inflatable plug for implementation in tunnel systems.

Even though there has been numerous tests and designs for inflatable structures using air as the inflation medium, very limited work has been published using water for inflation. The results presented in this work will also help gain a better understanding of the testing techniques used and equipment needed for this type of inflation. 


\section{Chapter 2 - Test Method}

\section{1 - Test Setup}

This test bed was made up of four main components: an inflatable plug, a concrete pipe representing a tunnel, a hydraulic pump system, and a sensor system. The total system was designed for a maximum pressure of 36 psig with a factor of safety of 1.5 . Because of the compressibility of gases, air was avoided as the inflation medium and water was used instead. An air compressor capable of providing the needed volume and pressure was not as cost effective nor as safe as using pumps and water. Minimal energy is dissipated in bursts with high pressures of water.

A 3000 gallon water storage tank was used as the water source so that the water could be recycled for multiple tests. A schematic of the test bed is shown in Figure 2-1. Arrows indicate the flow of water during testing. Water is pumped from the water tank to both the plug and tunnel through the plug pumps and the tunnel pumps to fill and pressurize the respective volumes. Any leakage that flows around the plug is caught in the collection trough and pumped back into the water tank.

Each test required both the plug and the space between the plug and the end of the tunnel to be filled and pressurized with water. Figure 2-2 provides a conceptual representation of the how the plug was inflated in the tunnel and the pressure being applied by the volume of water behind it. 


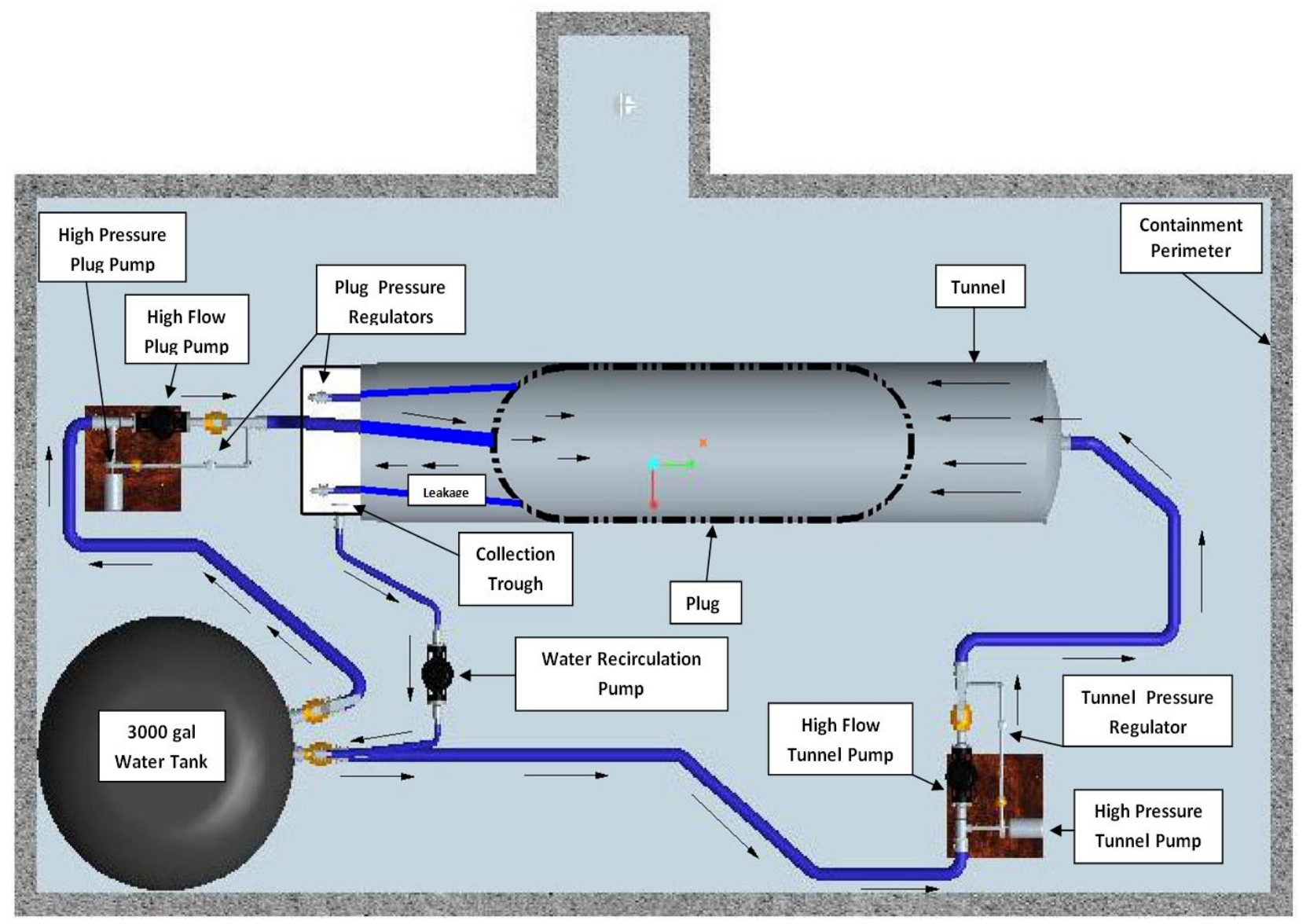

Figure 2-1 Schematic of test bed

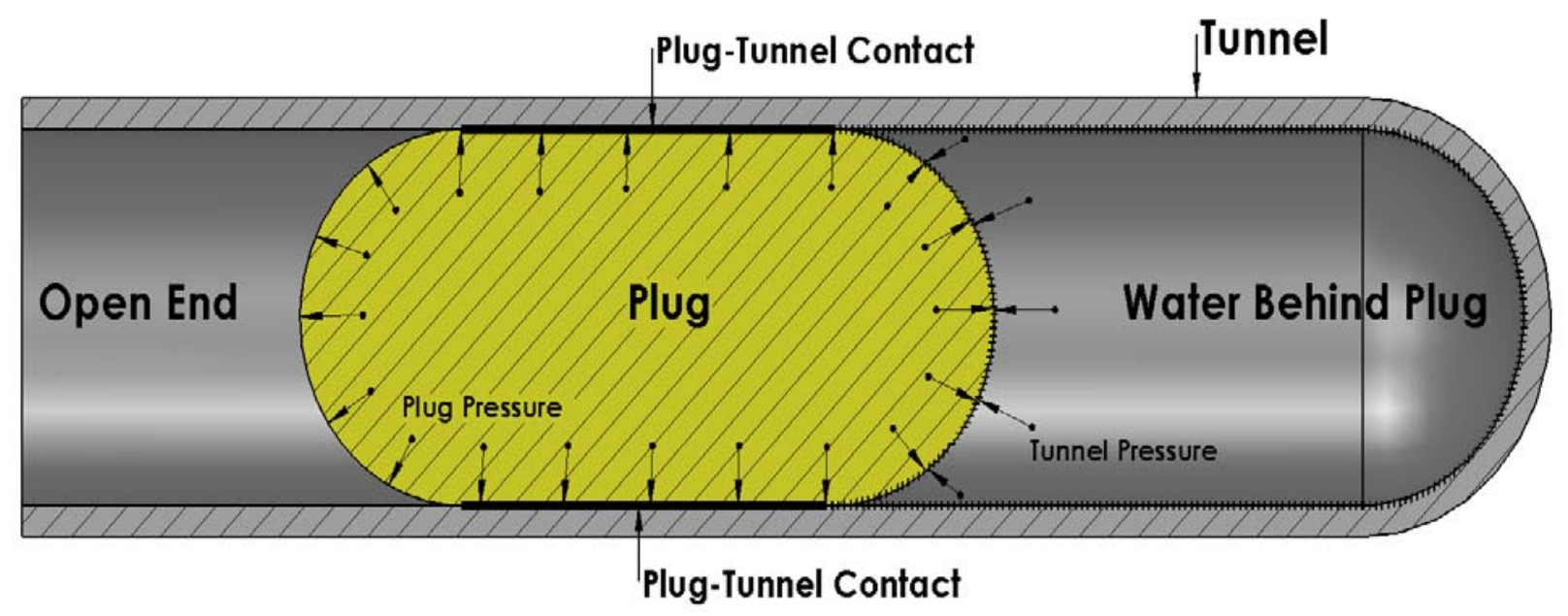

Figure 2-2 Cross-section of tunnel and plug setup 
The tunnel volume behind the plug is referred to as the tunnel pressure, $P_{\text {Tunnel }}$. The plug volume is also filled with pressurized water and referred to as the plug pressure, $P_{\text {Plug }}$.

The following basic test sequence was followed for each test:

1. Insert deflated plug approximately 6 feet into open end of the tunnel.

2. Attach hoses to plug for inflation and pressure readings.

3. Inflate plug until full but not pressurized and turn off pumps.

4. Fill space between the plug and the closed end of the tunnel. While the tunnel is filling with water, air is being displaced and must escape through the air outlet in the top of the tunnel.

5. Once the tunnel is full, the pumps are shut off and the air outlet is closed.

6. The plug and tunnel can then be pressurized to the desired pressures.

It is important to note that the plug pressure was kept above the tunnel pressure to avoid plug slippage unless specific slippage tests were performed. Detailed descriptions of each component making up the test bed are provided in the subsequent sections.

\subsection{1 - Tunnel}

The tunnel dimensions are shown in Figure 2-3. One end of the tunnel was sealed and contained connections to fill the tunnel, release pressure, and measure pressure. These connections are shown in Figure 2-4. 


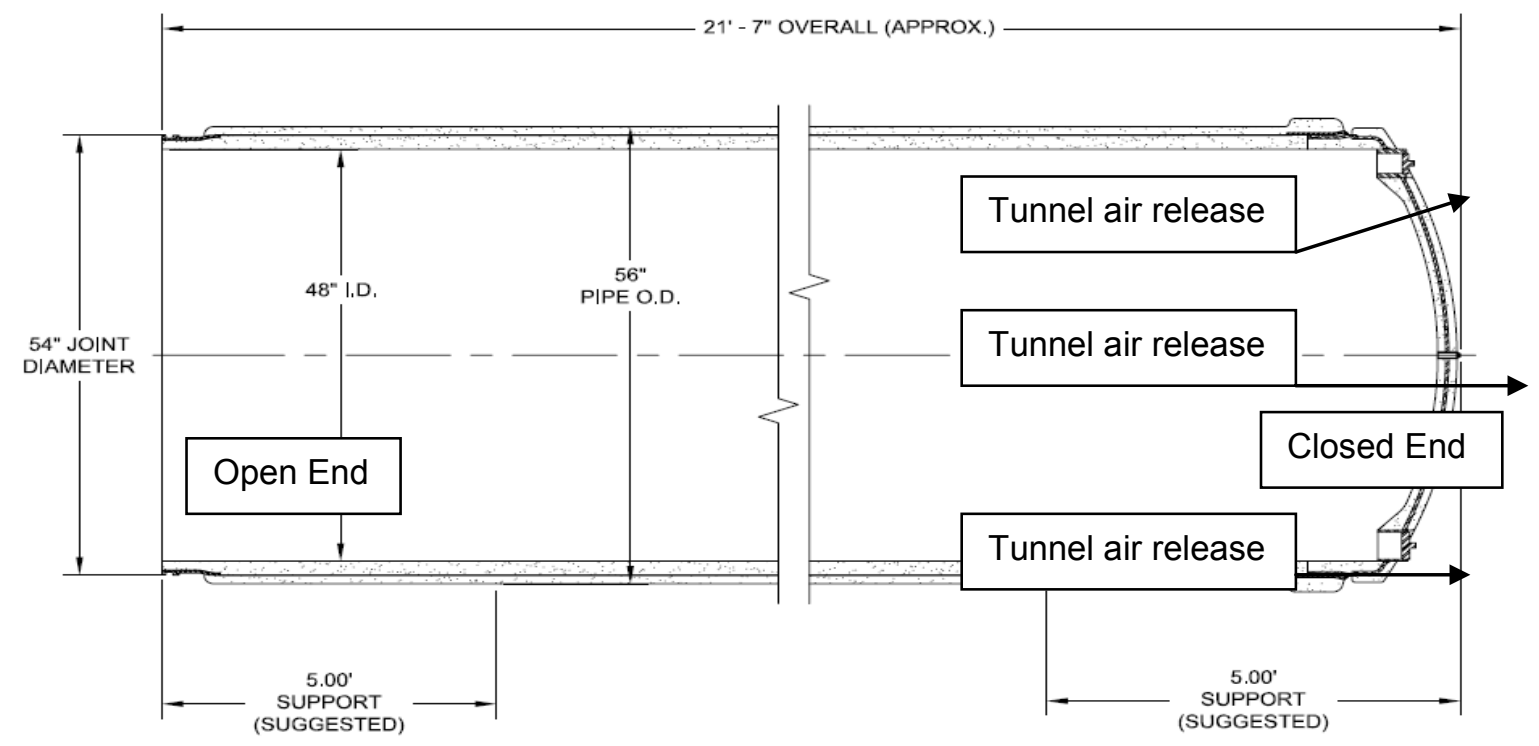

Figure 2-3 Tunnel dimensions and connections

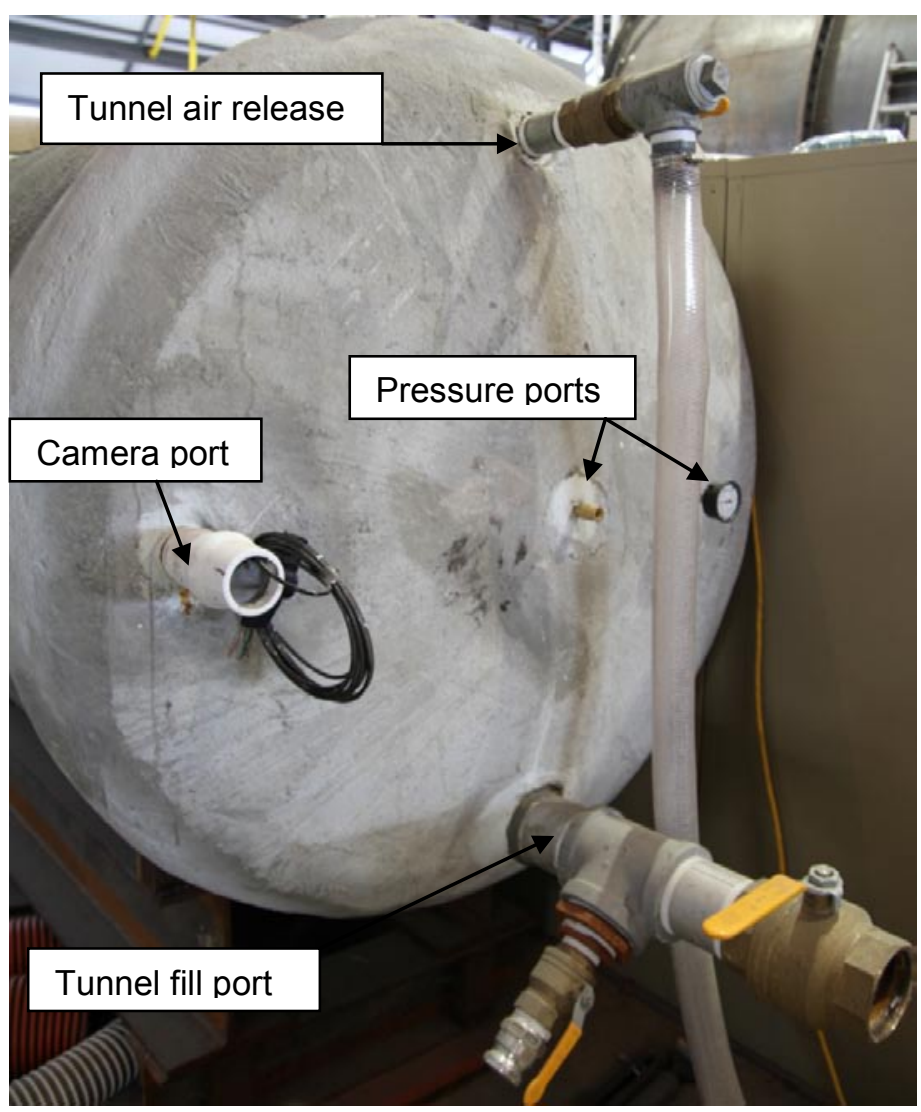

Figure 2-4 Rear tunnel connections 
The tunnel was constructed of steel rings with a concrete inner and outer layer. The tunnel was designed to withstand at least a maximum of 60 psi. The concrete inner layer was prepared so the friction characteristics mimicked those that can be expected in an actual tunnel. A support structure was designed using I-beams so that deflection in the tunnel in the longitudinal direction could be minimized to reduce the risk of cracking or damage. The interior of the tunnel is capable of being lined with different materials using an adhesive to attach them to the walls.

\subsection{2 - Hydraulic System}

This system contains a 3000 gallon water supply that is capable of filling both the plug and the tunnel. This water supply is connected to 4 inch hoses that are rated to 75 psig. These hoses are then routed to the pumps for inflation. The water supply and outlet hoses are shown in Figure 2-5. 


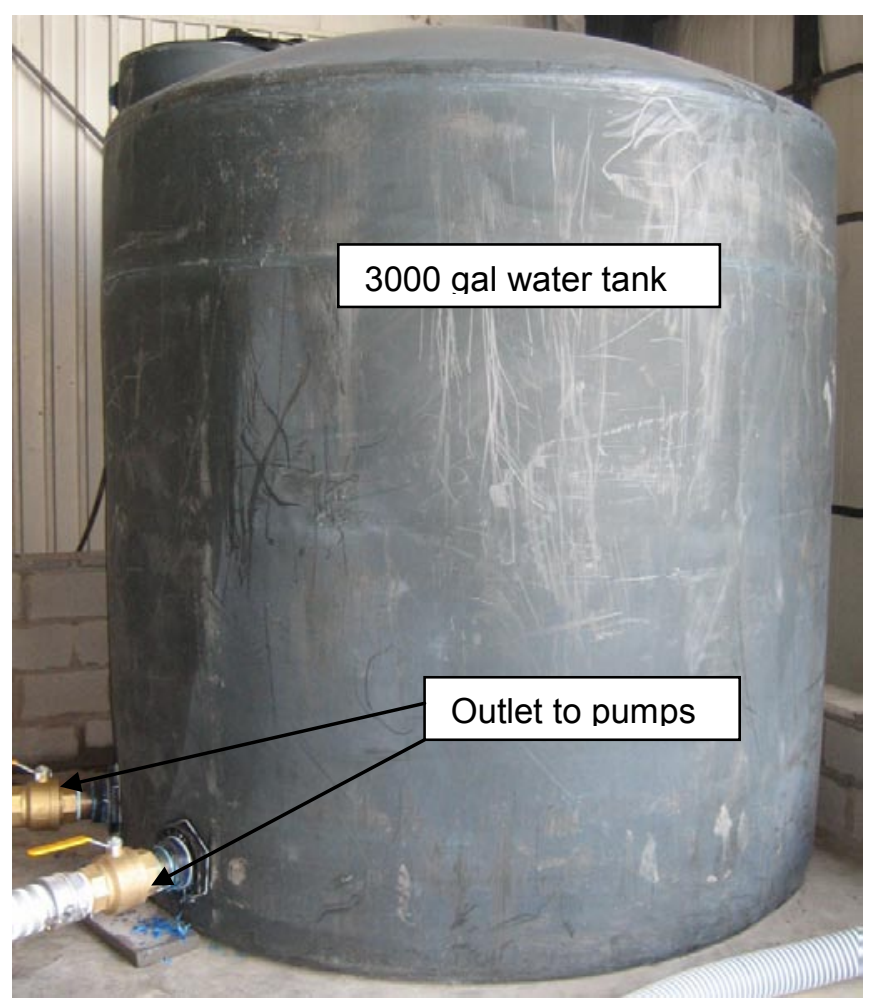

Figure 2-5 3000 gallon water supply with outlet hoses to pumps

Both the tunnel and the plug had a dual pump system for inflation. A high flow, low pressure pump and a low flow, high pressure pump were connected in parallel for maximum efficiency. This pump system is shown in Figure 2-6. The high flow pump filled the large volumes quickly and were then shut off. The high pressure pumps were then activated to pressurize the volume. Both the tunnel and the plug pump systems had a pressure regulator located downstream to control the pressures. The plug also had an upstream pressure regulator to aid the downstream regulator for precise control of the plug pressure. The downstream pressure regulators were capable of adjusting the pressure between 5 and $35 \mathrm{psi}$. Adapters were also added to the pump system so that the municipal water supply could also be used as a pressure source if desired. The 
high flow pump was capable of a flow rate of $200 \mathrm{gpm}$ and a head pressure of $21 \mathrm{psi}$. The high pressure pump was capable of a flow rate of $65 \mathrm{gpm}$ and a head pressure of 53 psi. The pump curves can be found in Appendix C.

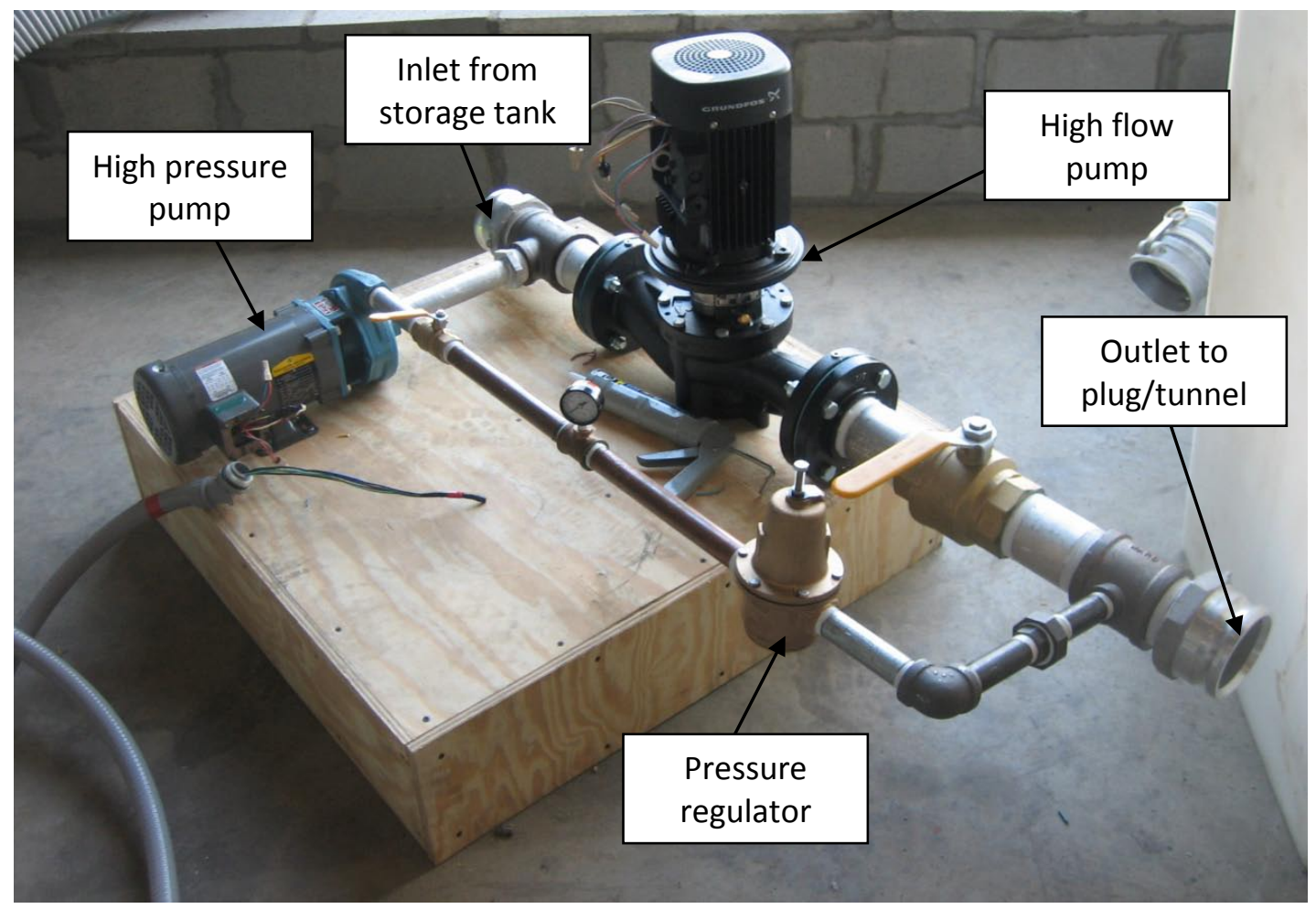

Figure 2-6 Pump system for filling and pressurization

A collection trough was positioned at the open end of the tunnel to catch and recycle any water that leaked out from testing. Another high flow pump was connected to this trough and acted as the recirculation pump to return the water to the 3000 gallon supply tank. All pumps were controlled manually with a switchboard. Only the recirculation pump had a depth gauge which switched it on automatically once the trough was full. 


\subsection{3 - Inflatable Plug}

The plug was constructed from a fabric made of Vectran fibers. The Vectran fabric was protected with a urethane coating on both the inside and outside of the plug. This coating was important on the inside to provide water proofing characteristics and important on the outside to help protect the fabric from abrasion.

The plug had an outer diameter of 50 inches. This is slightly oversized to the tunnel's 48 inch diameter in order to ensure maximal contact between the tunnel and plug. The total length from end cap to end cap was 110 inches. It was designed for a maximum inflation pressure of 40 psig with a factor of safety of 3 . It has a volume of approximately 800 gallons. The dimensions are shown in Figure 2-7.
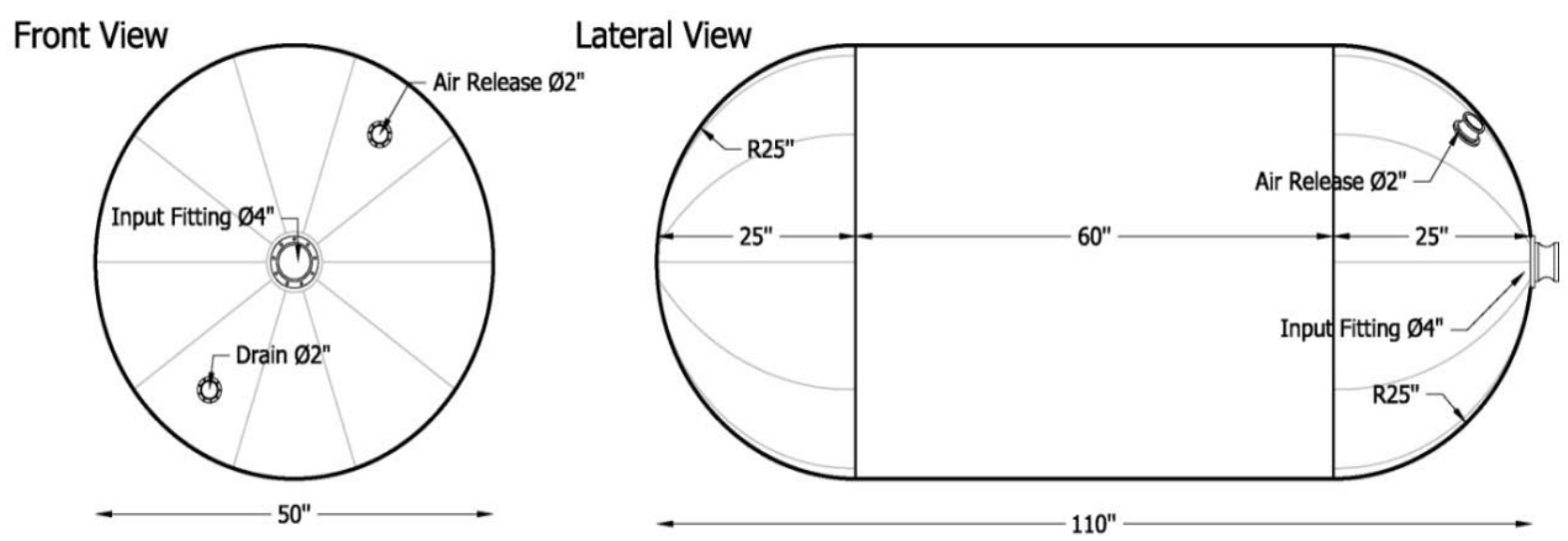

Figure 2-7 Plug dimensions

The plug had a total of three ports on the front end cap. These ports are shown in the plug model in Figure 2-8. The air purge outlet at the top of the plug is used to evacuate the air that is displaced when filled with water. The pressure transducer used 
to measure the plug pressure was connected to the drain port. Figure 2-9 shows an inflation outside of the tunnel. This inflation was used to check for leaks and defects in the plug fabric. Figure 2-10 also shows the plug inflated inside the tunnel with air at low pressure.

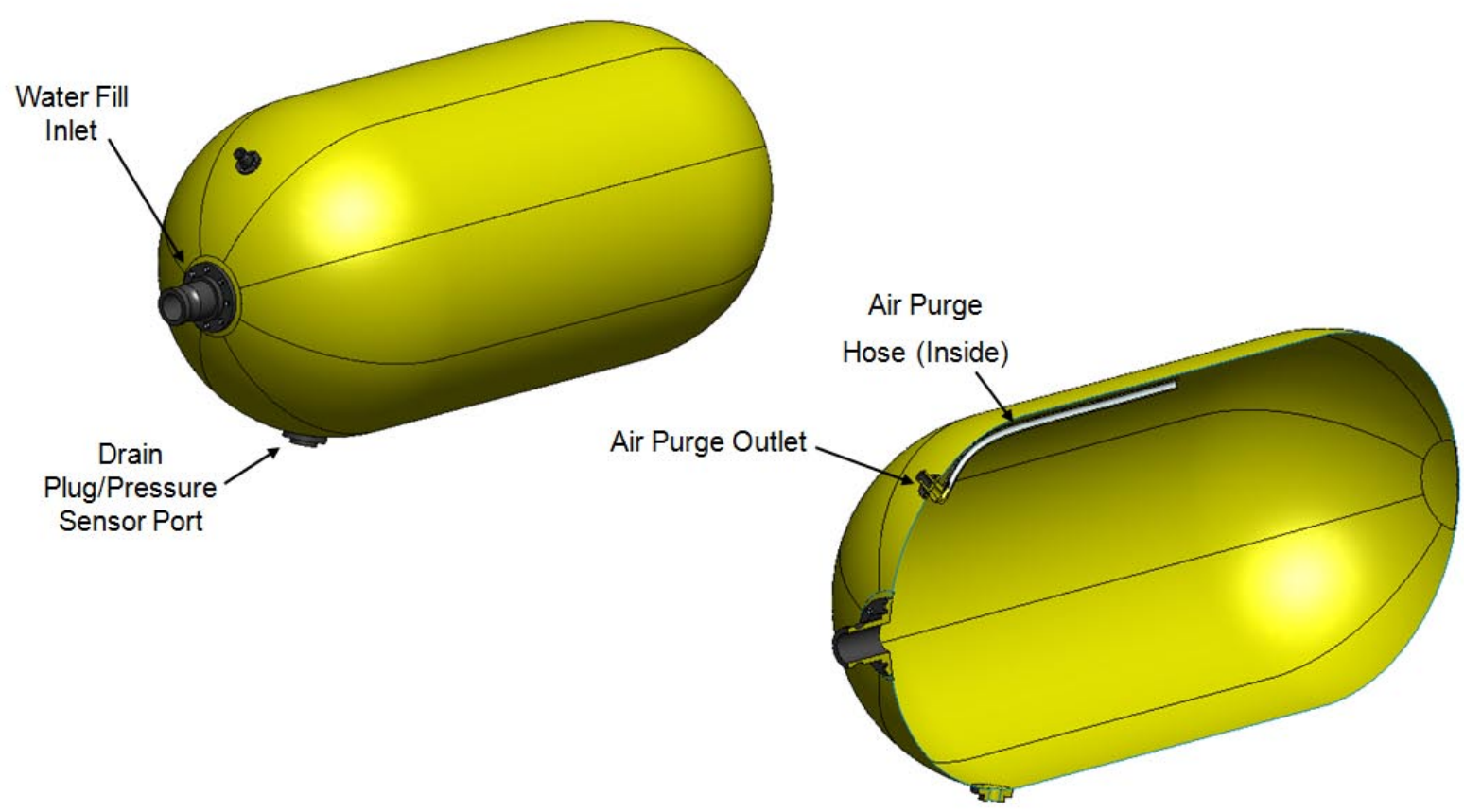

Figure 2-8 Plug model showing ports 


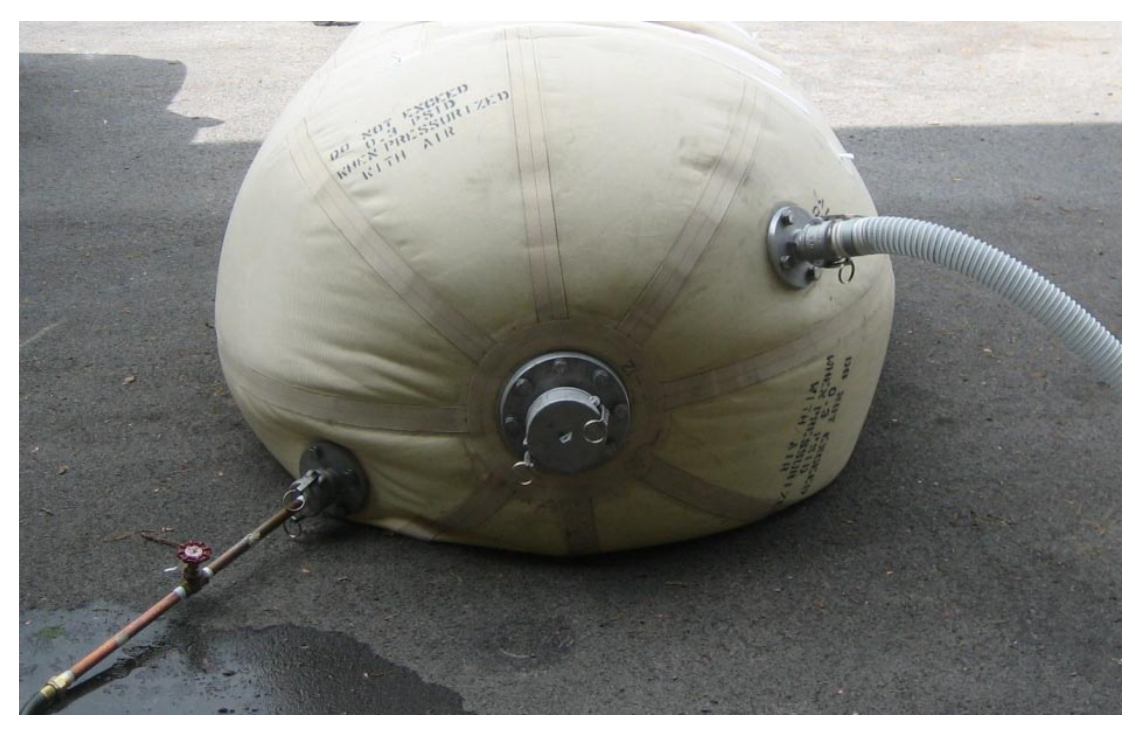

Figure 2-9 Plug inflation outside of tunnel

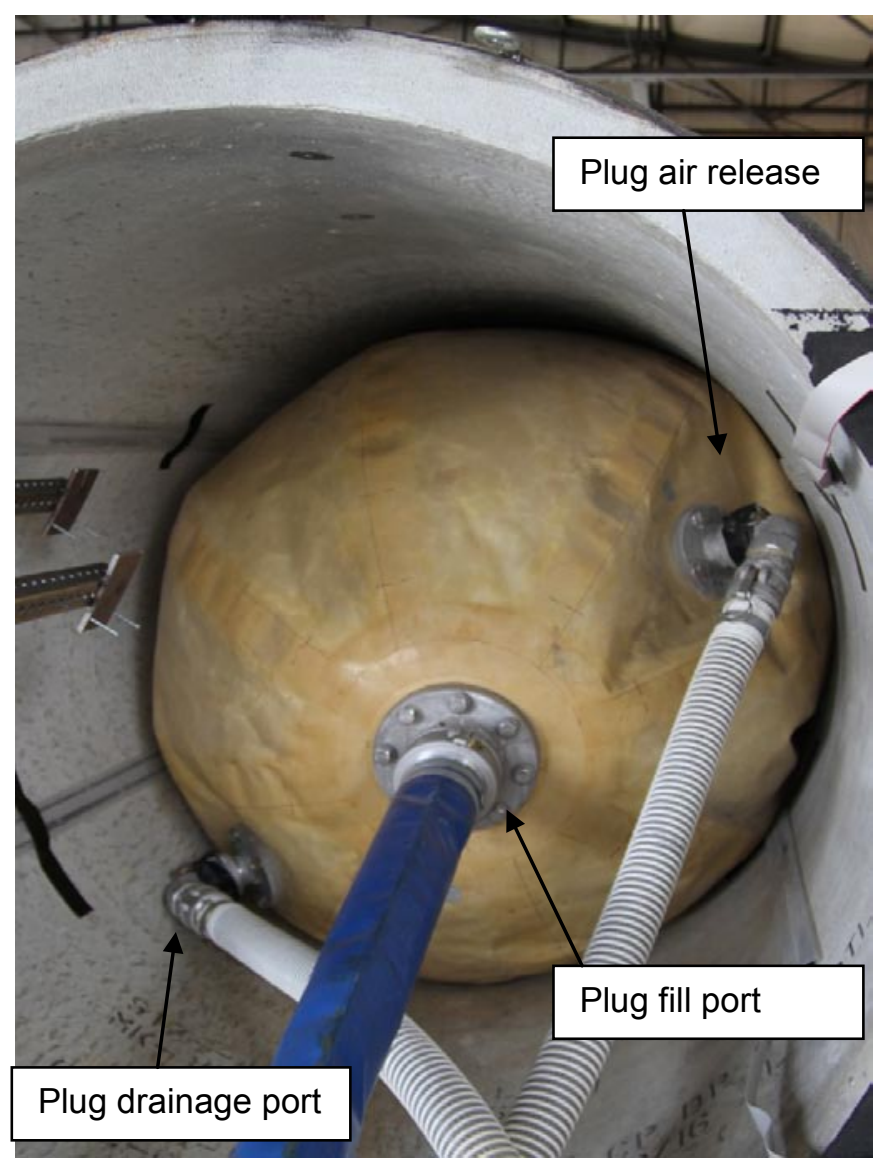

Figure 2-10 Plug inflated inside the tunnel with low pressure air 


\subsection{4 - Sensor System}

A sensor system was implemented in order to collect data from the plug. Digital pressure transducers were connected to measure the tunnel and plug pressures. These pressure transducers had a pressure range of $0-50$ psi with an output of $0-5$ VDC. Both of the transducers were at the same height for both the tunnel and plug to keep their readings consistent. The sensor specifications can be seen in Appendix A. A displacement sensor was also attached to the plug to measure movement. For the leakage data a digital scale, model Ohaus D31P300BX, was used for flow rate calculations.

The sensors were attached to a 16 bit data acquisition board and used a LabVIEW program to collect the data. A screen shot of the LabVIEW program is shown in Figure 2-11.

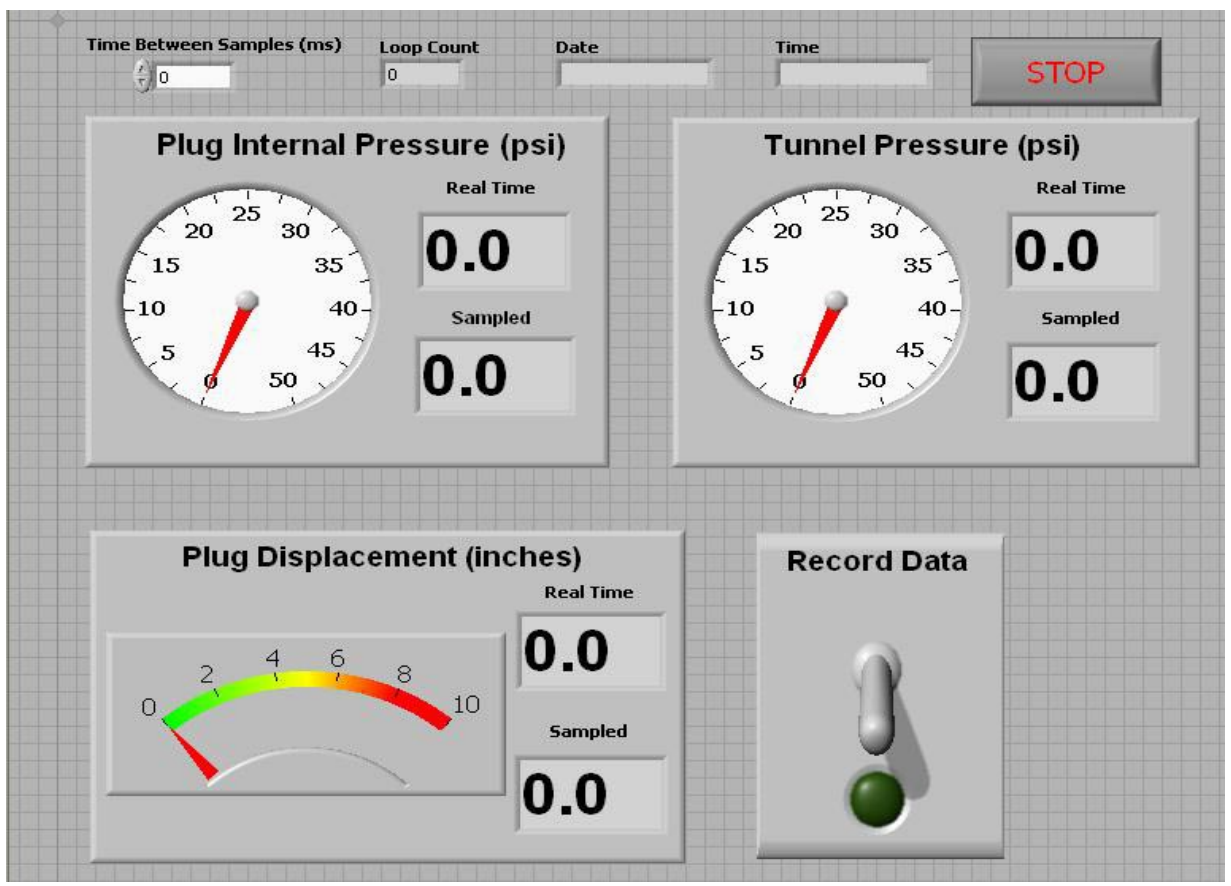

Figure 2-11 LabVIEW data collection program 
For the friction testing performed, data was sampled at one second intervals, taking readings for plug pressure, tunnel pressure, and plug displacement simultaneously. The data was stored in Microsoft Excel.

\section{2 - Tunnel Linings}

In addition to the original concrete interior of the tunnel, two more materials were used to line the inside of the tunnel. These included a soft neoprene rubber and also a vinyl floor coating. There were several factors that influenced the selection of these materials such as roughness, compressibility, ease of application, and potential application in full scale prototypes. The materials chosen could be installed easily in a full scale application if they prove to provide benefits. The most significant determining factor was choosing materials that would not cause abrasion to the plug material. Since the plug would be serving for other tests not covered in the topic of this thesis, special care had to be taken to ensure its protection. Due to this limitation, rough or potentially damaging materials were avoided. The liner materials were attached to the tunnel using removable adhesive tape. This removable adhesive allowed the liners to be removed so another could be installed or to expose the original concrete. The liners were installed a length of 8 feet along the tunnel which ensured the entire plug-tunnel contact area was covered. Figure 2-12 shows a portion of installed neoprene inside the tunnel. The vinyl floor covering was installed in the same manner. 


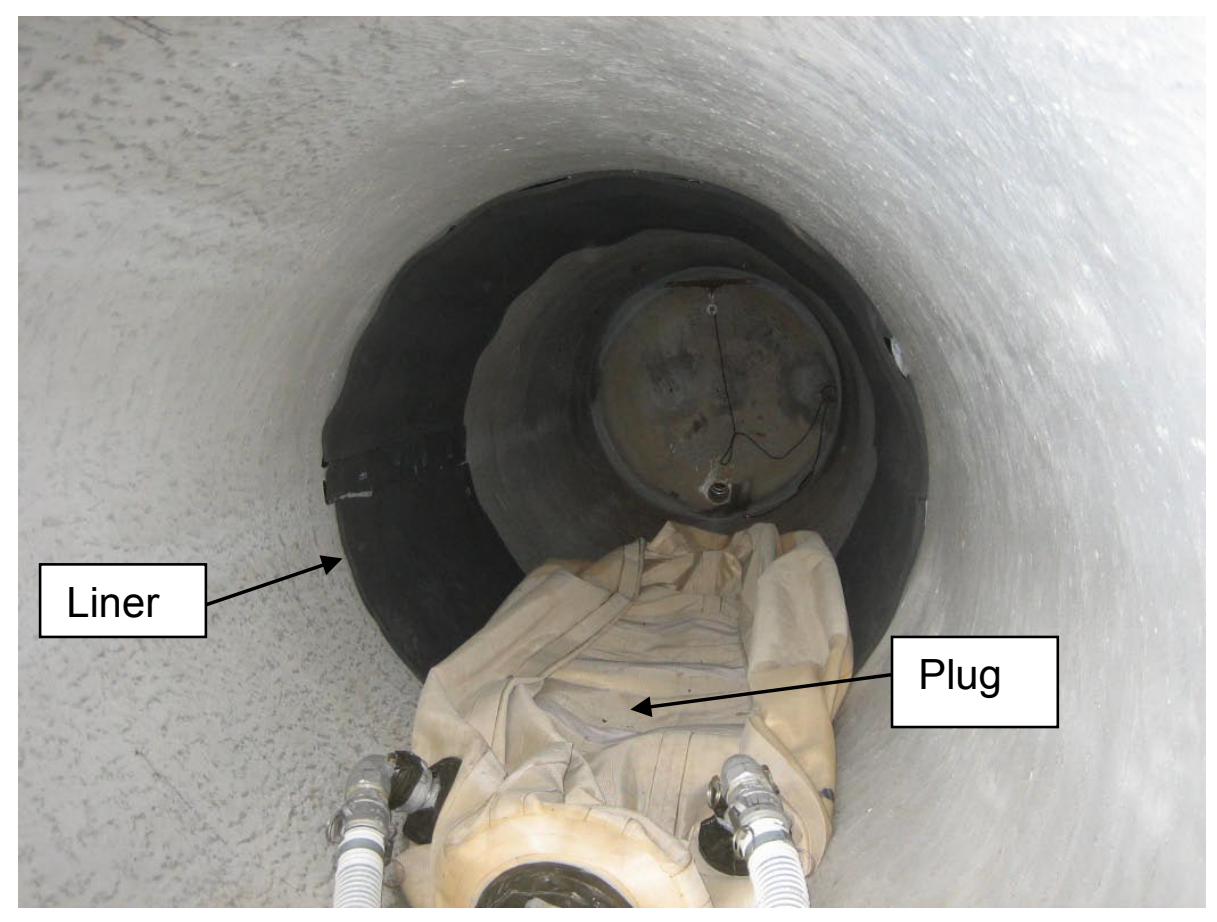

Figure 2-12 Example of neoprene tunnel lining

For all tests it was also assumed that the tunnel linings were wet. Additional reasons for selection and material properties are explained in the following sections.

\section{Concrete}

Concrete was used because it most accurately simulates a potential finished surface that would be used in underground structures such as subways. Both friction and leakage data was desired for this surface. The concrete surface used in this situation was smooth to help minimize abrasions when testing with the plug. It is classified as ICRI-CSP \#1 smooth concrete (23). A detailed view of the concrete in the tunnel is shown in Figure 2-13 (A). 


\section{Neoprene Rubber}

Leakage rates coming from around the plug was one of the main topics of concern. Leakage occurs around the plug when water passes through small wrinkles or imperfections in the plug-tunnel contact area that cannot be observed. This prompted a hypothesis of limiting leakage using a material that would conform and expand into voids between the plug and the tunnel wall. The compressibility and non-abrasive properties of neoprene seemed to meet the requirements necessary. Even though the primary focus of neoprene was to study leakage, friction testing was also performed to gain additional information.

The neoprene was $1 / 2$ inch thick and lined the tunnel along the full plug-tunnel contact length. It has a density of $4-8 \mathrm{lbs} / \mathrm{ft}^{3}$ and a firmness of $2-5 \mathrm{psi}(25 \%$ deflection). More mechanical properties are shown in Appendix D. A detailed view of the neoprene is shown in Figure 2-13 (B).

\section{Vinyl Floor Coating}

The vinyl floor coating was chosen as a lining that would produce a more slippery surface as opposed to concrete and neoprene. This would give a wider variety of testing surfaces so they could be compared with each other for the friction coefficients. The vinyl coating was also studied in the leakage tests to see if any significant differences were present as compared to the other linings.

The vinyl floor coating possessed a smooth, slick, plastic like surface. It had a thickness of 0.0625 inch. The surface was completely uniform with no protruding features. A detailed view of the vinyl is shown in Figure 2-13 (C). 

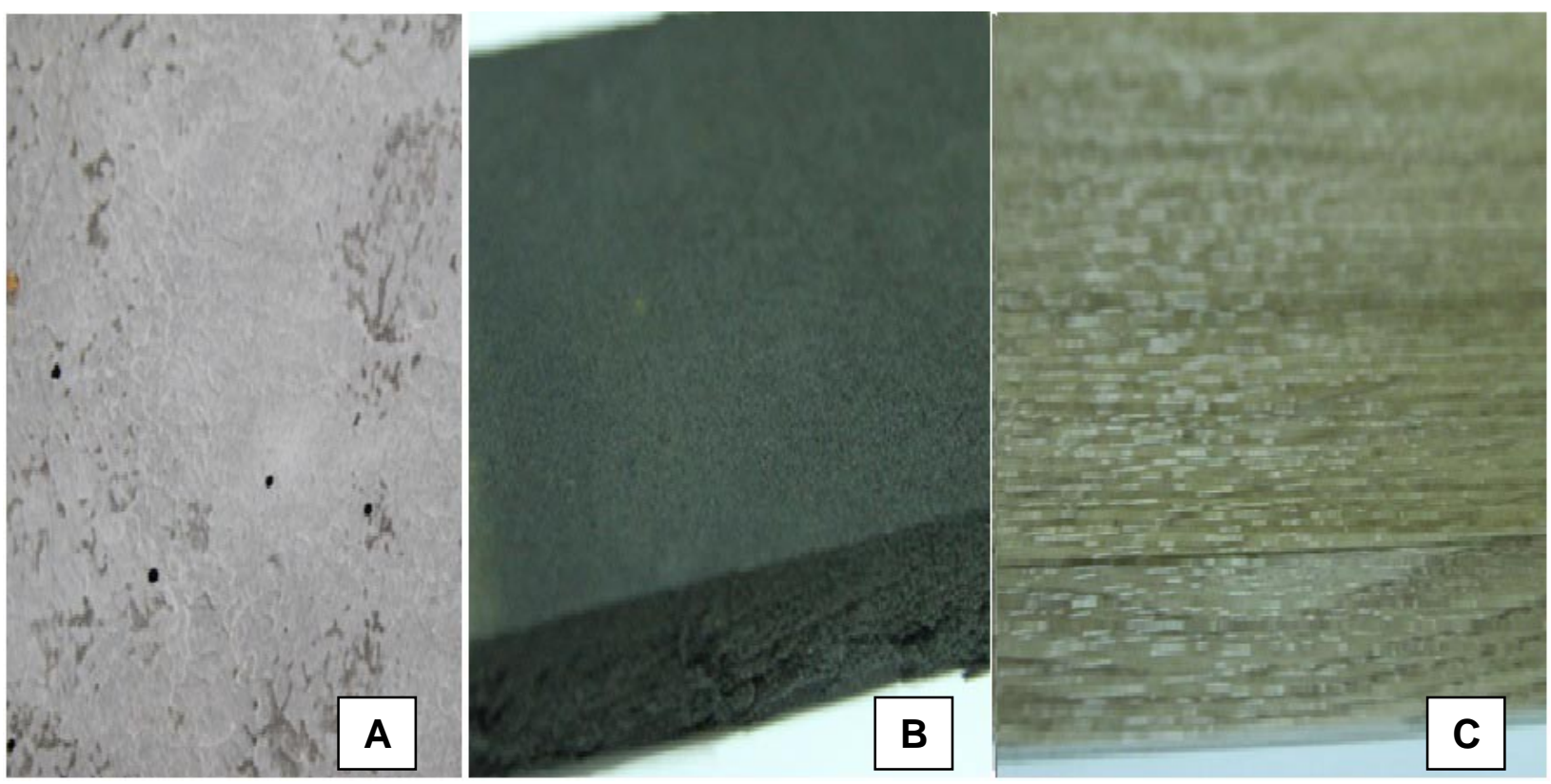

Figure 2-13 Detailed view of tunnel linings: (A) Concrete, (B) Neoprene, and (C) Vinyl 


\section{Chapter 3 -Slippage Testing}

\section{1 - Introduction}

The objective of the slippage testing was to evaluate the relationship between the plug and tunnel pressures (pressure differential) when the plug started to slip. These pressure differentials were then used to calculate the friction coefficient that exists between the plug and the different tunnel surfaces. These friction coefficients were also compared to other friction coefficient estimates obtained using different testing methods. By comparing these values, other factors influencing the friction coefficients can better be understood. It is hypothesized that the vinyl tunnel lining will have the lowest friction coefficient due to its very smooth, plastic like characteristics.

\section{2 - Friction Tests Using A Friction Testing Machine}

Previous friction tests were performed on the same Vectran fabric used in the experiments presented in this work. These tests were designed to simulate the conditions present in a plug and tunnel scenario. This friction machine is shown in Figure $3-1$. This machine works by placing a fabric sample between the sled and a stationary plane as shown in the figure. The fabric sample was attached to the sled with double-sided foam sticky tape. A normal force is applied by adding weight to the sled shaft. A total weight of $24.45 \mathrm{lbs}$ was added which provided a pressure of $11 \mathrm{psi}$ between the sled and plane. The hydraulic cylinder is then actuated and a load cell measures the force required to break contact between the sled and the plane. The linear variable differential transducer (LVDT) provided the displacement feedback which occurred with the moving plane. This applied force from the hydraulic cylinder along 
with the normal force is then used to calculate the friction coefficient between the sled (fabric) and the plane (tunnel surface). All of the tests from the friction testing machine were also performed while submerged in water so they more accurately replicated the slippage tests performed on the plug-tunnel setup. This water setup is shown in Figure 3-2.

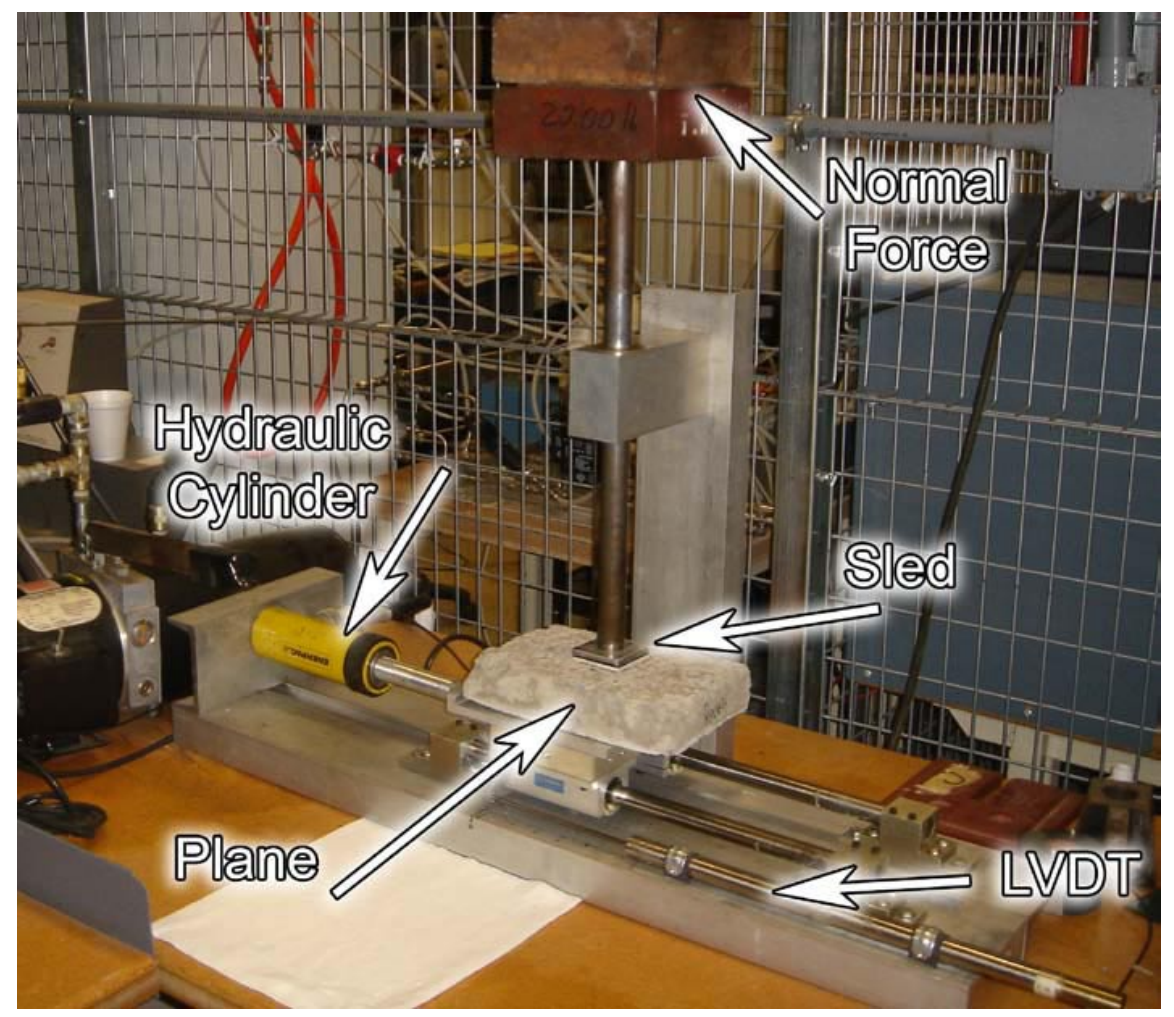

Figure 3-1 Friction testing machine used in previous friction testing (20) 


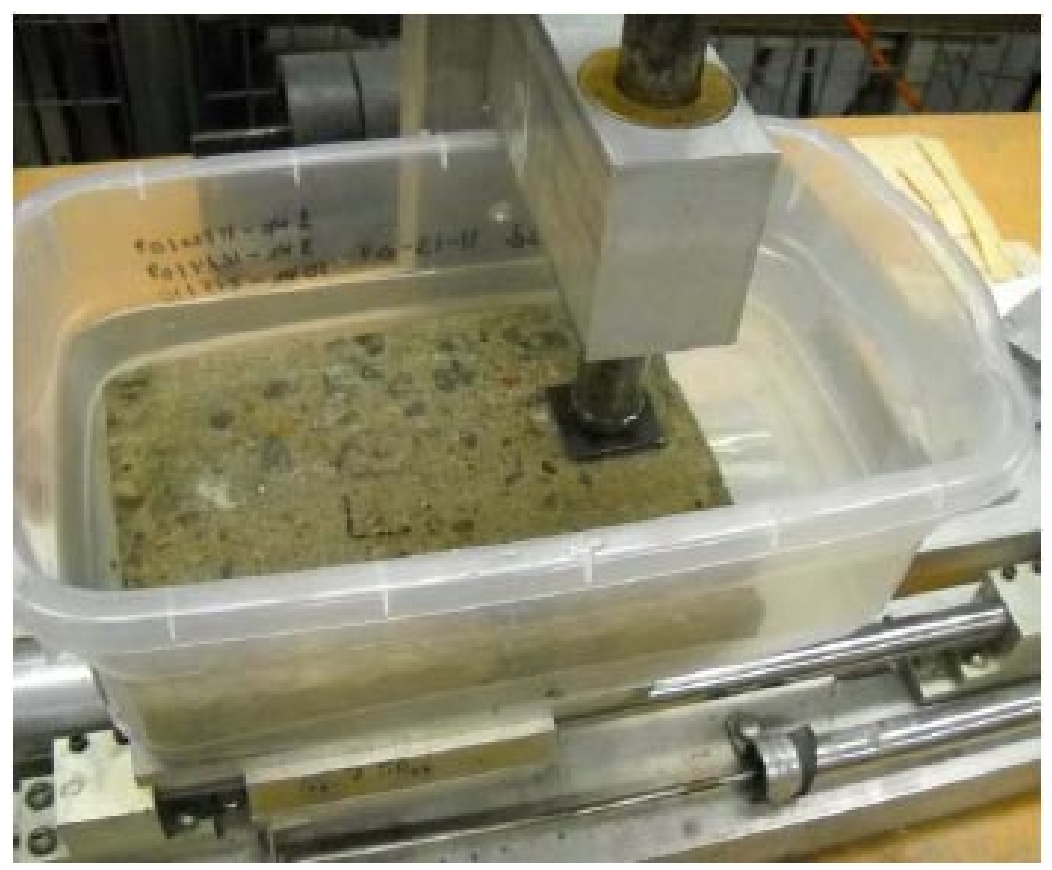

Figure 3-2 Wet friction machine test setup (20)

\section{3 - Procedure for Slippage Testing}

The plug was inserted into the tunnel and connected to the inflation system. The plug was then filled with water but not pressurized beyond 5 psi. After the plug was filled, the tunnel was then filled with water but not pressurized. Once testing was ready to begin, the tunnel pressure was raised to 2 psi less than the plug pressure. The data collection system was activated once the pressures were within this 2 psi differential.

Data was sampled at 1 second intervals collecting values for plug pressure, tunnel pressure, and plug displacement. The data was recorded for six plug pressures which were $5,10,15,20,25$, and 30 psi. Each of these pressures was tested for all three of the tunnel linings for a total of 18 slippage tests performed.

The goal of the testing was to find the point at which the plug would move due to the force acting on it by the tunnel pressure. Since all regulators and switches were 
manually operated, two people were required for testing. One person controlled the plug pressure while the other person controlled the tunnel pressure. Changing the tunnel pressure had a residual effect of the plug pressure. If the tunnel pressure would increase or decrease, it would increase or decrease the plug pressure respectively. The test was performed by keeping the plug pressure constant and raising the tunnel pressure towards the plug pressure until the plug slipped. A loud, audible thumping noise occurred when slippage took place which indicated that the test for that pressure could be stopped. The plug pressure was continuously adjusted to keep it as close as possible to the desired test pressure. If the plug pressure was not adjusted, it would continue to raise as the tunnel pressure was raised which would not produce the desired results.

The tests started at the lowest plug pressure and continued to the next highest pressure systematically. When testing for one pressure was completed, the data was recorded and then restarted for the next pressure. When all six plug pressures were recorded for a given tunnel lining, the plug and tunnel were deflated and a new liner was installed. The tests then continued with the same procedure for each additional liner.

\section{4 - Results/Discussion}

Because of the sensitivity of the plug pressure adjustment, it was difficult to reach and maintain the exact plug pressure desired for the tests. Table 3-1 shows the difference in the desired and actual plug pressures when slippage occurred. The errors varied from $0.49 \%$ for the 15 psi neoprene coating to $33.34 \%$ for the 5 psi vinyl coating. Since the friction coefficients could be calculated using the actual pressure, these errors 
did not play a significant role. These error values do indicate that the plug pressure did not deviate more than about $5 \%$ in 10 out of the 14 slippage tests.

Table 3-1 Desired and actual plug pressure error

\begin{tabular}{|c|c|c|}
\hline \multicolumn{3}{|c|}{ Concrete } \\
\hline $\begin{array}{c}\text { Desired Plug } \\
\text { Pressure (psi) }\end{array}$ & $\begin{array}{c}\text { Actual Plug } \\
\text { Pressure (psi) }\end{array}$ & $\begin{array}{c}\text { Percent } \\
\text { Difference }\end{array}$ \\
\hline 5 & 6.109 & $22.18 \%$ \\
\hline 10 & 10.535 & $5.35 \%$ \\
\hline 15 & 15.271 & $1.81 \%$ \\
\hline 20 & 19.536 & $-2.32 \%$ \\
\hline 25 & 24.136 & $-3.46 \%$ \\
\hline \multicolumn{3}{|c|}{ Neoprene } \\
\hline $\begin{array}{c}\text { Desired Plug } \\
\text { Pressure (psi) }\end{array}$ & $\begin{array}{c}\text { Actual Plug } \\
\text { Pressure (psi) }\end{array}$ & $\begin{array}{c}\text { Percent } \\
\text { Difference }\end{array}$ \\
\hline 5 & 4.584 & $-8.32 \%$ \\
\hline 10 & 9.518 & $-4.82 \%$ \\
\hline 15 & 15.073 & $0.49 \%$ \\
\hline 20 & 19.834 & $-0.83 \%$ \\
\hline 25 & 24.706 & $-1.18 \%$ \\
\hline \multicolumn{3}{|c|}{} \\
\hline $\begin{array}{c}\text { Vinyl } \\
\text { Presired Plug }\end{array}$ & $\begin{array}{c}\text { Actual Plug } \\
\text { Pressure (psi) }\end{array}$ & $\begin{array}{c}\text { Percent } \\
\text { Difference }\end{array}$ \\
\hline 5 & 6.667 & $33.34 \%$ \\
\hline 10 & 11.998 & $19.98 \%$ \\
\hline 15 & 15.147 & $0.98 \%$ \\
\hline 20 & 20.416 & $2.08 \%$ \\
\hline \multicolumn{2}{|c|}{}
\end{tabular}


A summary of the results for the slippage testing is shown in Table 3-2. This table displays the actual plug pressure and pressure differential between the plug and tunnel when slippage occurred.

Table 3-2 Slippage data for different tunnel linings

\begin{tabular}{|c|c|c|}
\hline \multicolumn{3}{|c|}{ Concrete } \\
\hline $\begin{array}{c}\text { Plug Pressure, } P_{\text {Plug }} \\
\text { (psi) }\end{array}$ & $\begin{array}{c}\text { Tunnel Pressure, } \boldsymbol{P}_{\text {Tunnel }} \\
(\mathrm{psi})\end{array}$ & $\begin{array}{c}\text { Pressure Differential, } \\
\left(\Delta P=P_{\text {Tunnel }}-P_{\text {Plug }}\right) \\
(\text { psi) }\end{array}$ \\
\hline 6.109 & 5.948 & 0.161 \\
\hline 10.535 & 10.461 & 0.074 \\
\hline 15.271 & 15.160 & 0.111 \\
\hline 19.536 & 18.755 & 0.781 \\
\hline 24.136 & 23.020 & 1.116 \\
\hline \multicolumn{3}{|c|}{ Neoprene } \\
\hline $\begin{array}{l}\text { Plug Pressure, } P_{\text {Plug }} \\
\text { (psi) }\end{array}$ & $\begin{array}{c}\text { Tunnel Pressure, } \boldsymbol{P}_{\text {Tunnel }} \\
\text { (psi) }\end{array}$ & $\begin{array}{c}\text { Pressure Differential, } \\
\left(\Delta \boldsymbol{P}=\boldsymbol{P}_{\text {Tunnel }}-\boldsymbol{P}_{\text {Plug }}\right) \\
(\text { psi) }\end{array}$ \\
\hline 4.584 & 4.473 & 0.111 \\
\hline 9.518 & 8.130 & 1.388 \\
\hline 15.073 & 12.060 & 3.013 \\
\hline 19.834 & 16.251 & 3.583 \\
\hline 24.706 & 20.763 & 3.943 \\
\hline \multicolumn{3}{|c|}{ Vinyl } \\
\hline $\begin{array}{c}\text { Plug Pressure, } P_{\text {Plug }} \\
\text { (psi) }\end{array}$ & $\begin{array}{c}\text { Tunnel Pressure, } \boldsymbol{P}_{\text {Tunnel }} \\
(\mathrm{psi})\end{array}$ & $\begin{array}{c}\text { Pressure Differential, } \\
\left(\Delta P=P_{\text {Tunnel }}-P_{\text {Plug }}\right) \\
(\text { psi) }\end{array}$ \\
\hline 6.667 & 6.630 & 0.037 \\
\hline 11.998 & 11.911 & 0.087 \\
\hline 15.147 & 15.023 & 0.124 \\
\hline 20.416 & 20.255 & 0.161 \\
\hline
\end{tabular}

As shown in the table, the concrete and neoprene liners have five sets of data and the vinyl liner has only four. Originally each liner was to be tested with six tests but was decreased for plug safety purposes. The plug not only had to perform tests for the purpose of this work but also other tests including deployment and endurance. Due to 
these factors, it was decided to keep the plug pressure below $70 \%$ of its design pressure. This decision did not allow any plug pressures to exceed 25 psi. By keeping the plug pressure lower, it minimized the risk of plug damage due to slippage. While performing the testing for the vinyl tunnel lining, one of the plug fittings became caught against the tunnel creating unsafe conditions thus causing the test to end prematurely without collecting data for the 25 psi plug pressure.

After reviewing the data from each slippage test, it was determined that the displacement sensor recording the movement of the plug did not collect valuable data. The slippage itself created very small displacements and that, combined with static interference and poor sensor resolution produced values for that were not able to be used to determine the point at which the plug slipped. Each set of data did, however, display unique trends in the plug and tunnel pressures that allowed the slippage point to be easily seen. When the plug slipped, it caused a sudden increase in tunnel volume. This volume increase caused a sudden decrease in the pressure in tunnel which also caused a decrease in plug pressure. An example of the data is shown in Figure 3-3. Only one set of data displayed an ideal case where the displacement sensor could be used to see the slippage point. This is shown in Figure 3-5. 


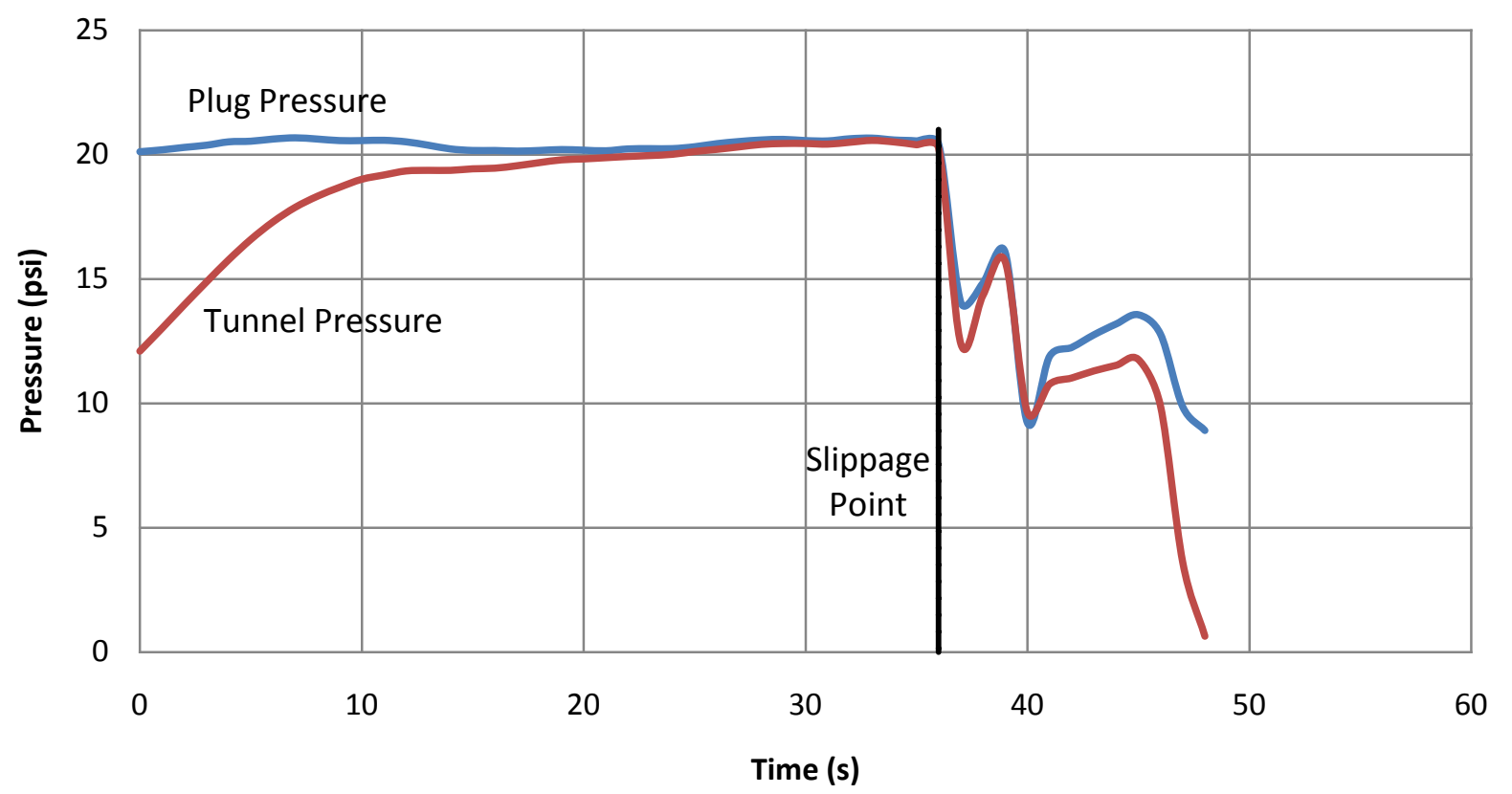

Figure 3-3 Example of slippage point for at 20 psi plug pressure

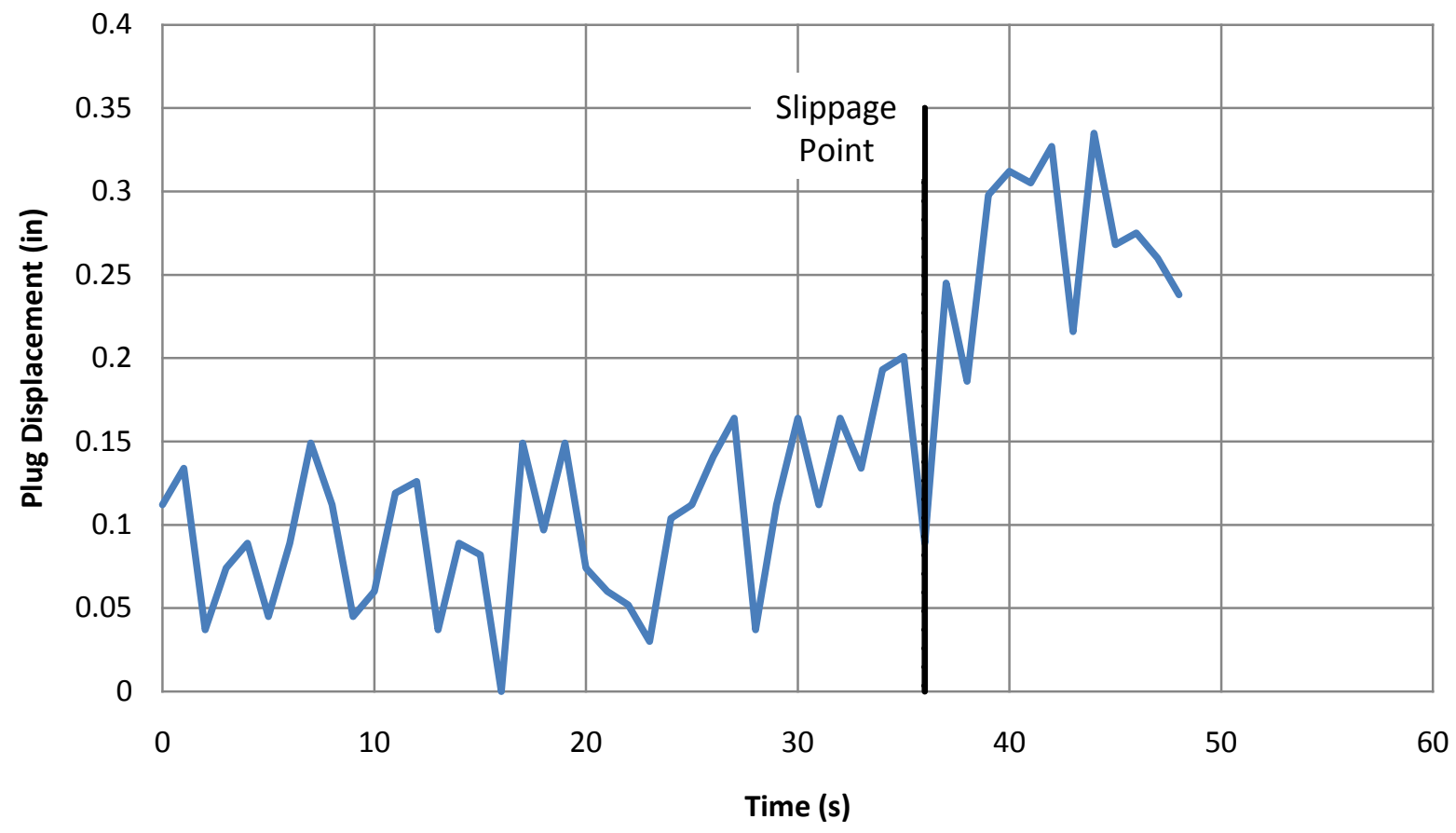

Figure 3-4 Example of slippage point location compared to the plug displacement 


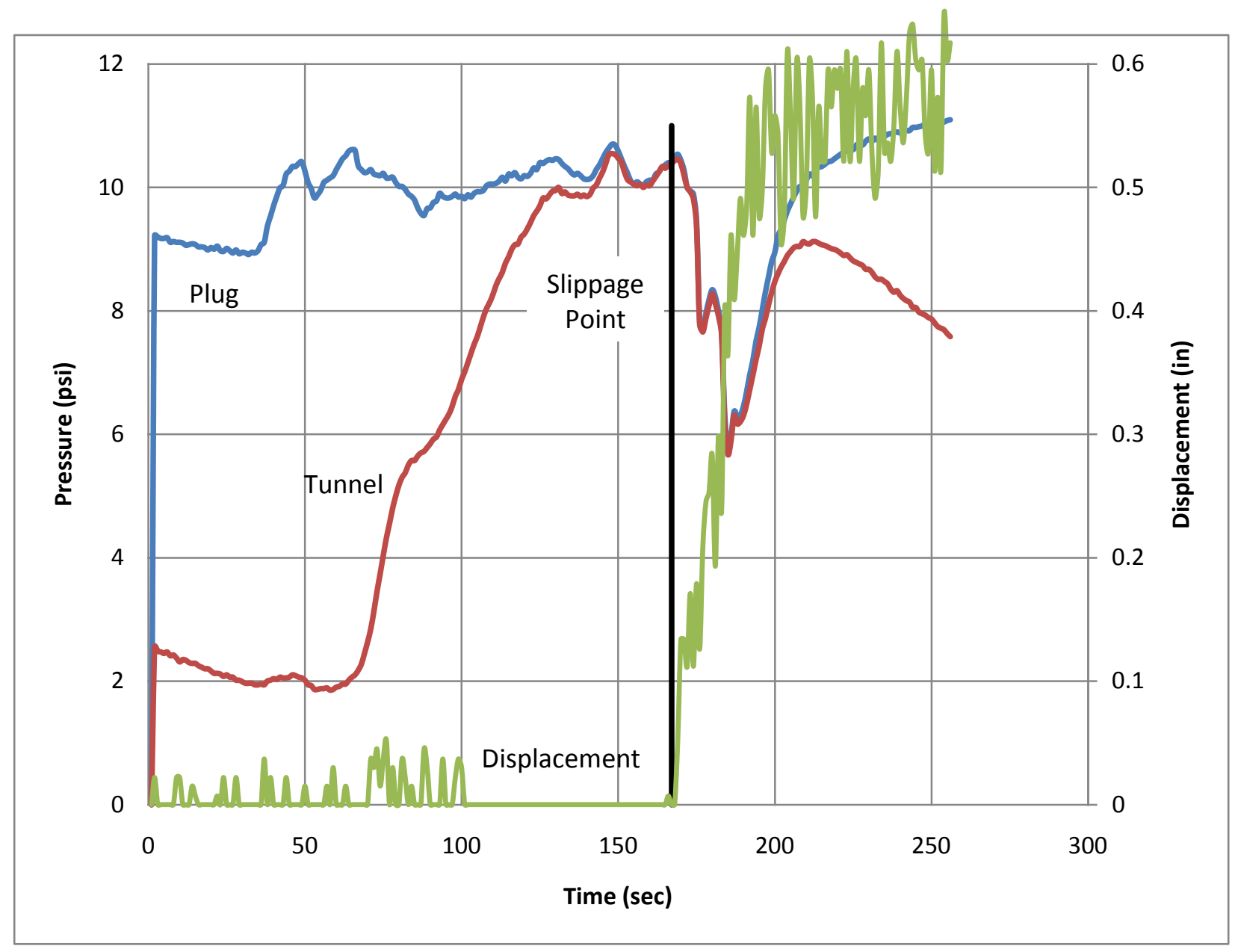

Figure 3-5 Slippage point for 10 psi plug pressure with concrete lining

Figure 3-3 starts by showing the plug pressure being maintained as close as possible to the testing pressure of $20 \mathrm{psi}$. The tunnel pressure was slowly raised to approach the plug pressure. When the tunnel pressure was raised to the slippage point (tunnel and plug pressure were nearly equal), both pressures dropped dramatically as seen at approximately 36 seconds indicated by the black line. It was at this point that the pressure differential was measured and the true slippage point was defined. The values collected from the displacement sensor at the same 20 psi plug pressure with the same slippage point are shown in Figure 3-4. It can be seen that there is no clearly 
defined point in the displacement at which the slippage occurs; therefore, the displacement data is omitted in the later graphs. The slippage data that was obtained and analyzed to find the slippage points is shown in Figure 3-6 through Figure 3-19. The exact slippage points in each graph are shown with the black vertical line. The original data which contains the pressure and displacement measurements are shown in Appendix E.

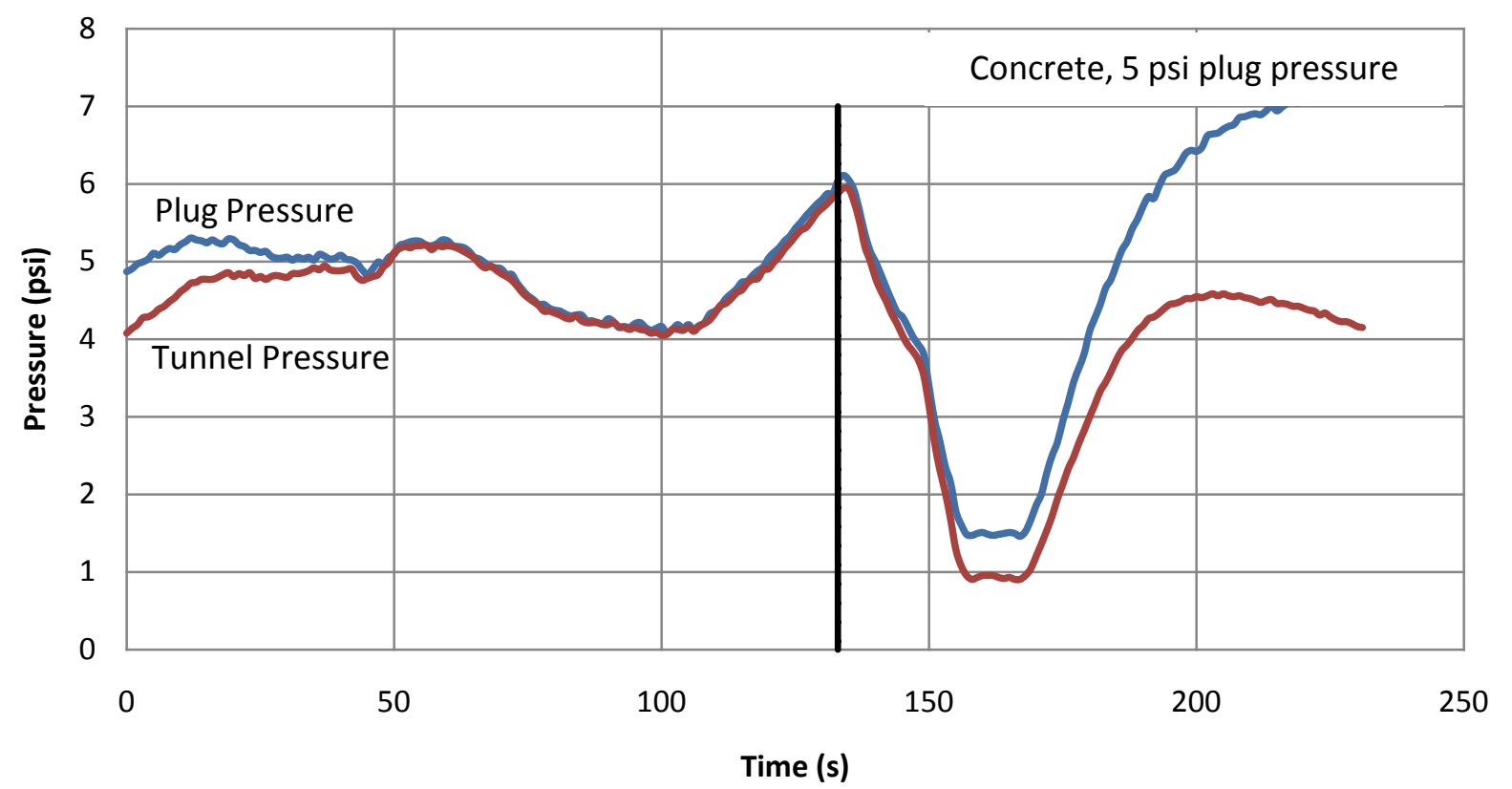

Figure 3-6 Concrete, 5 psi plug pressure 


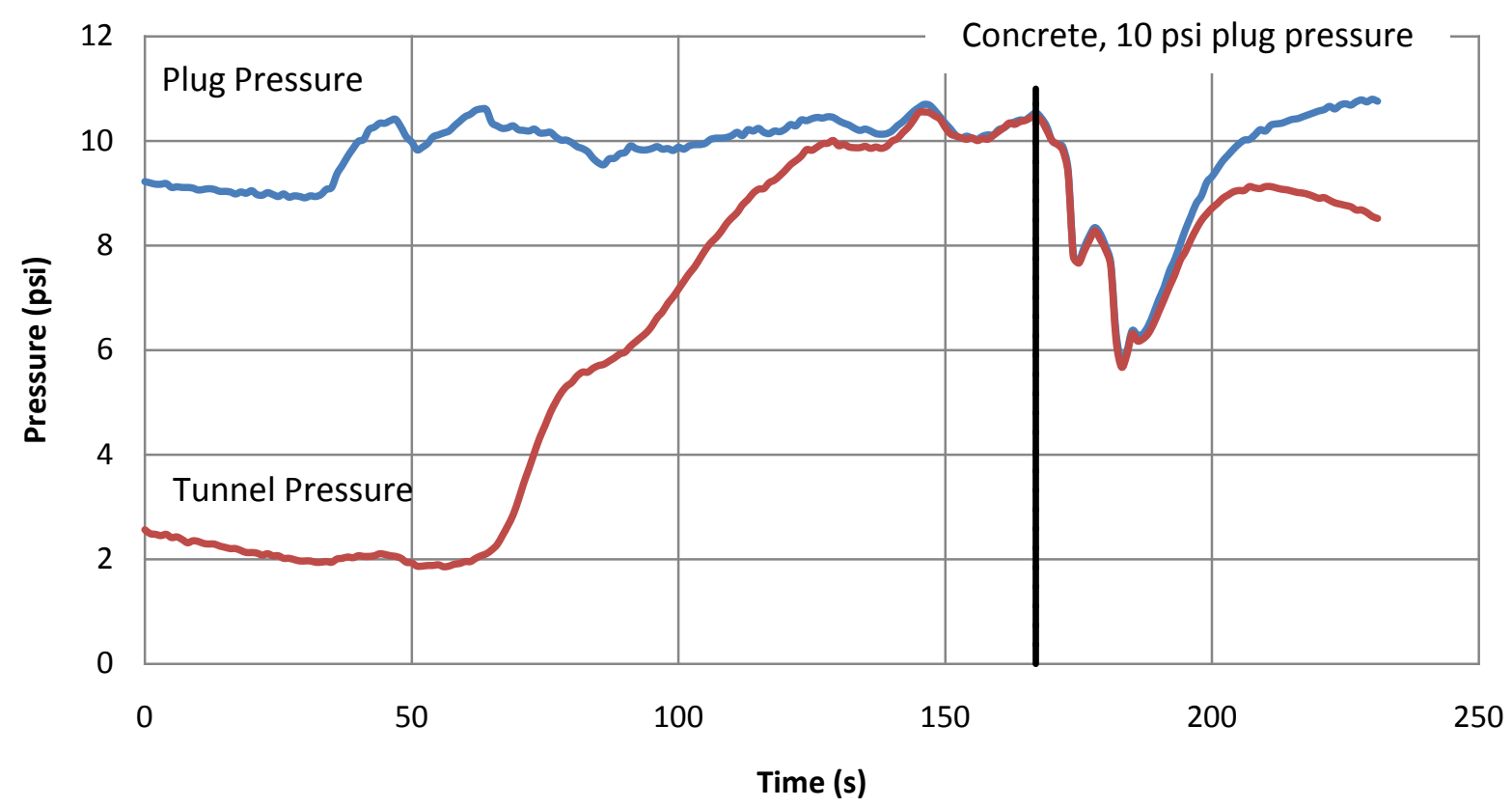

Figure 3-7 Concrete, 10 psi plug pressure

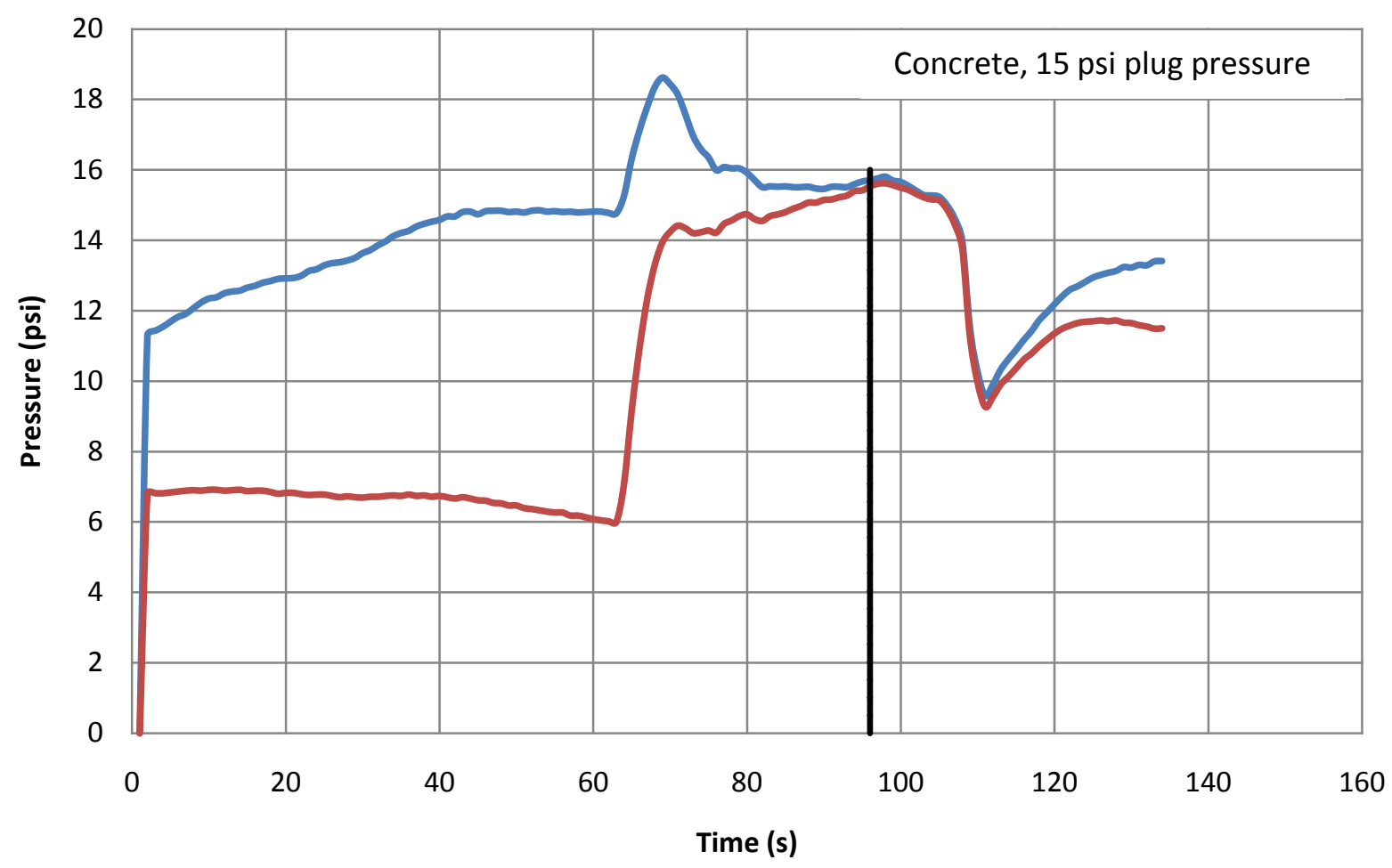

Figure 3-8 Concrete, 15 psi plug pressure 


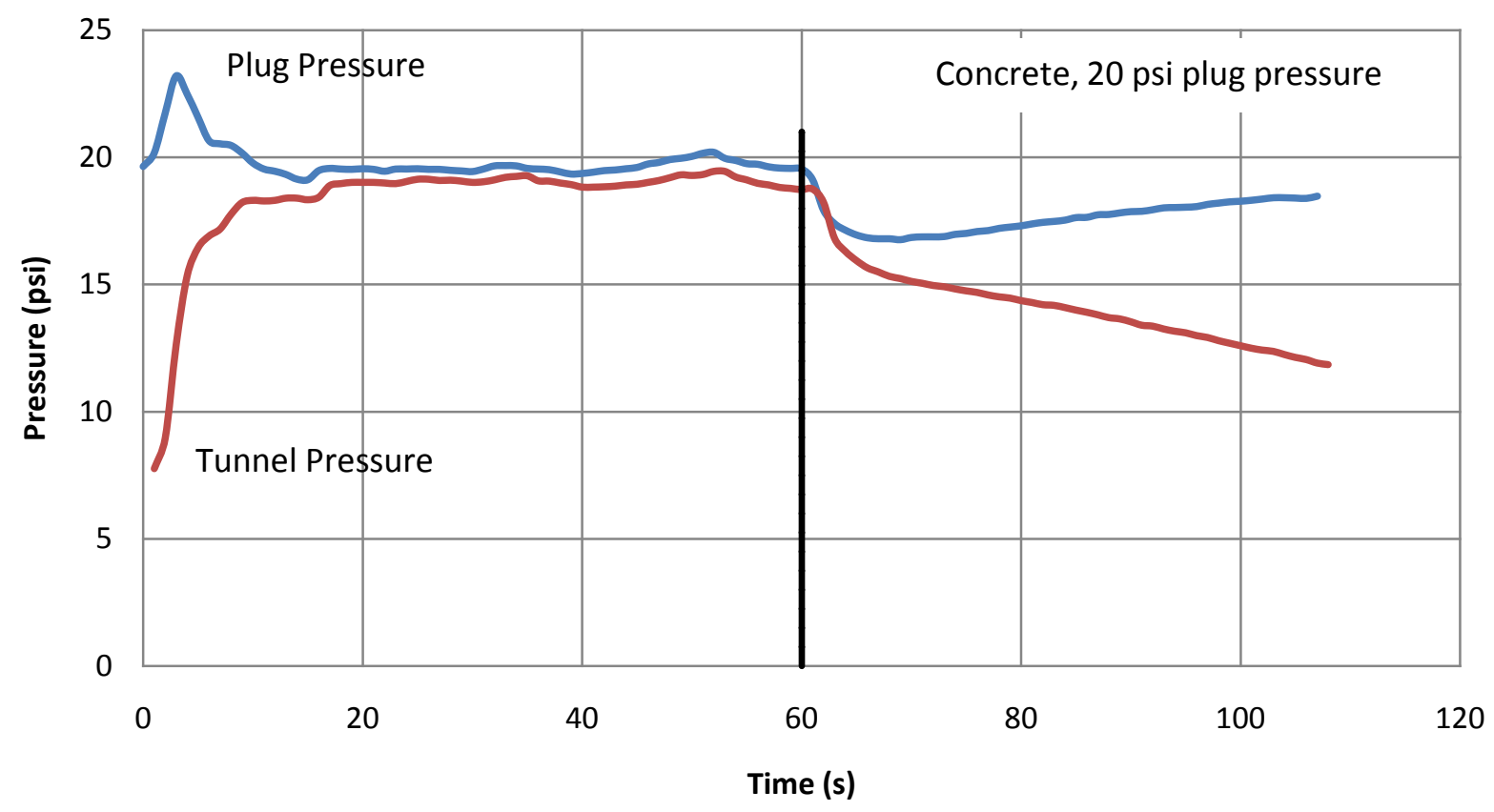

Figure 3-9 Concrete, 20 psi plug pressure

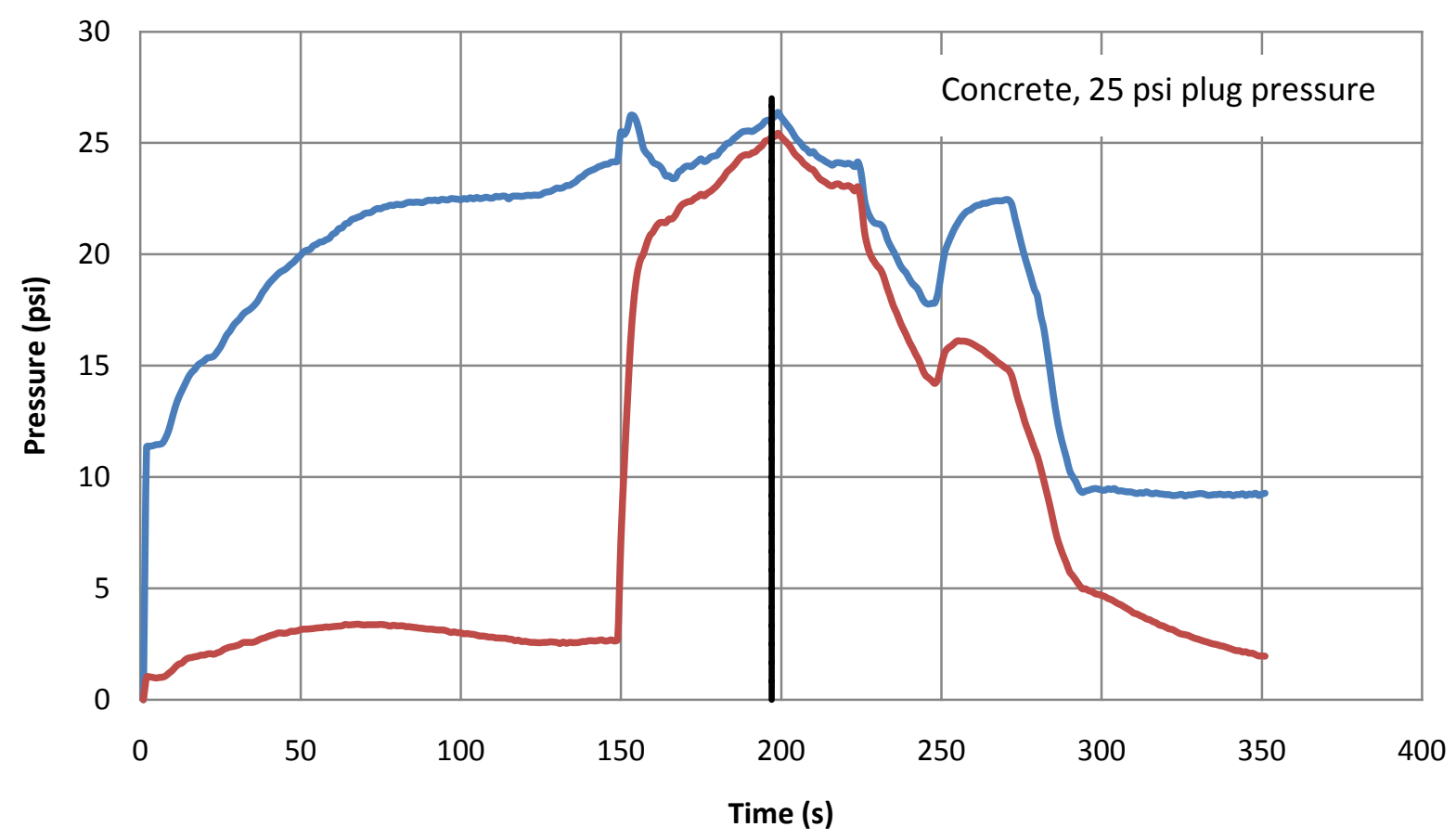

Figure 3-10 Concrete, 25 psi plug pressure 


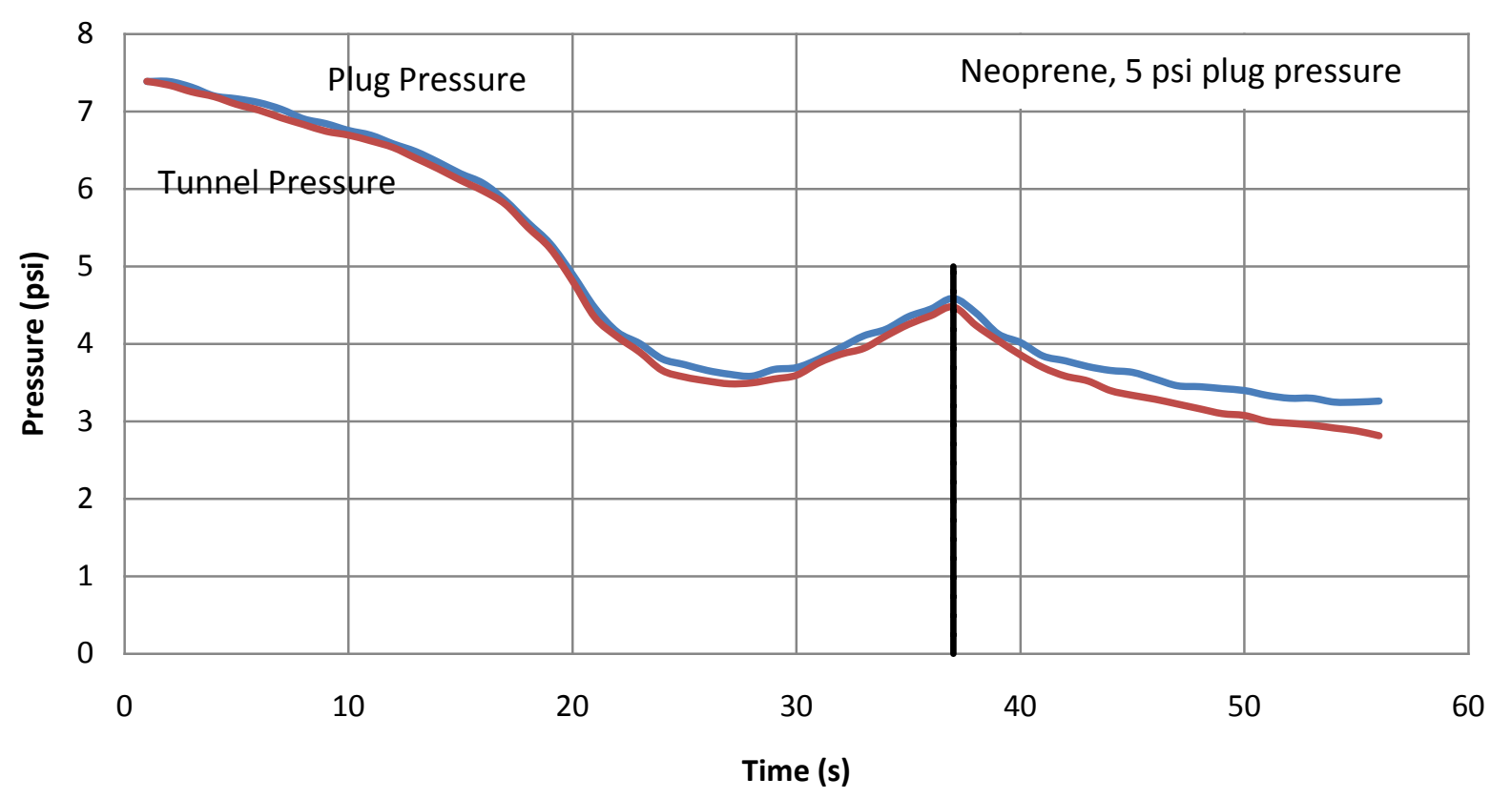

Figure 3-11 Neoprene, 5 psi plug pressure

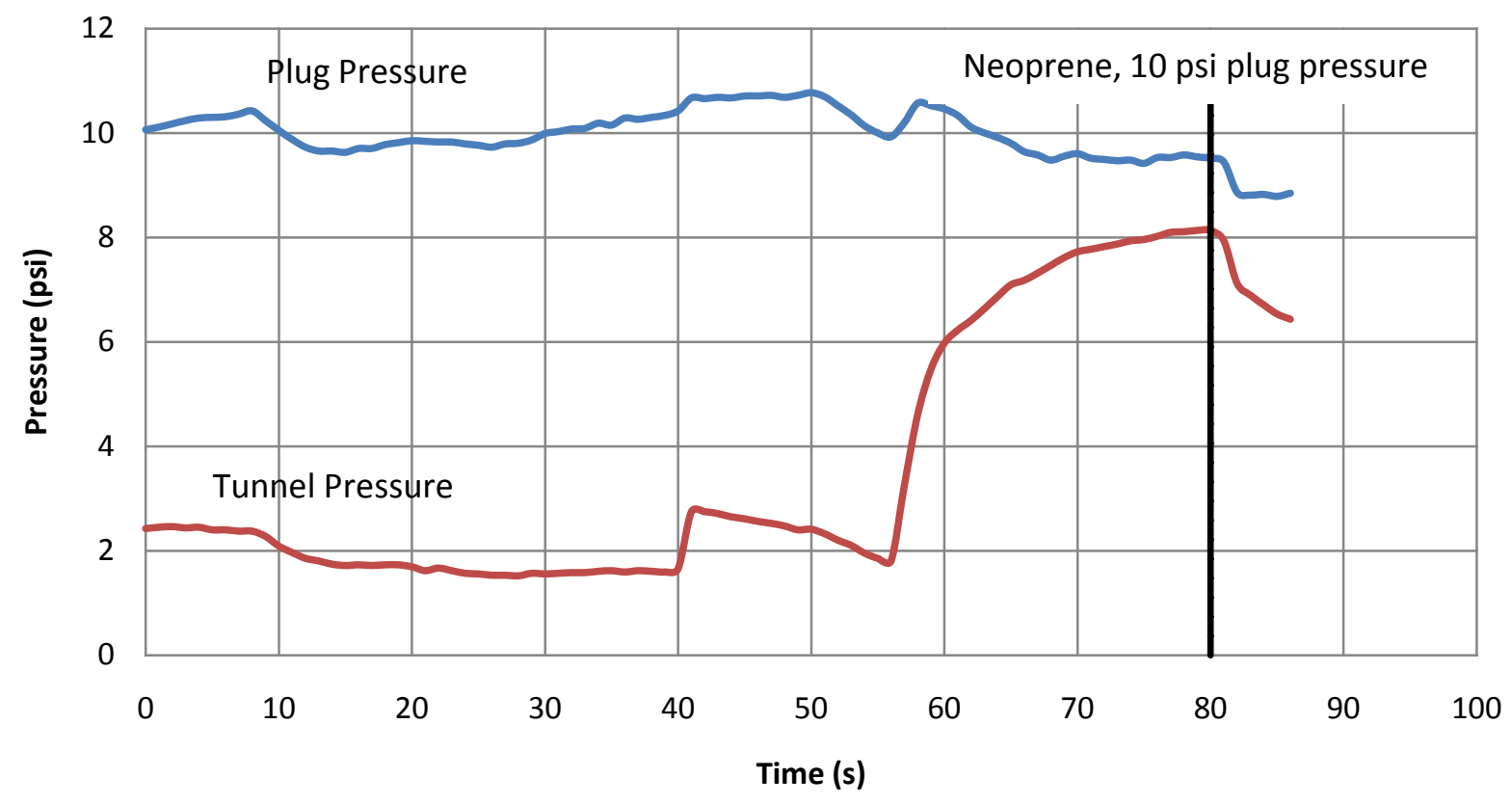

Figure 3-12 Neoprene, 10 psi plug pressure 


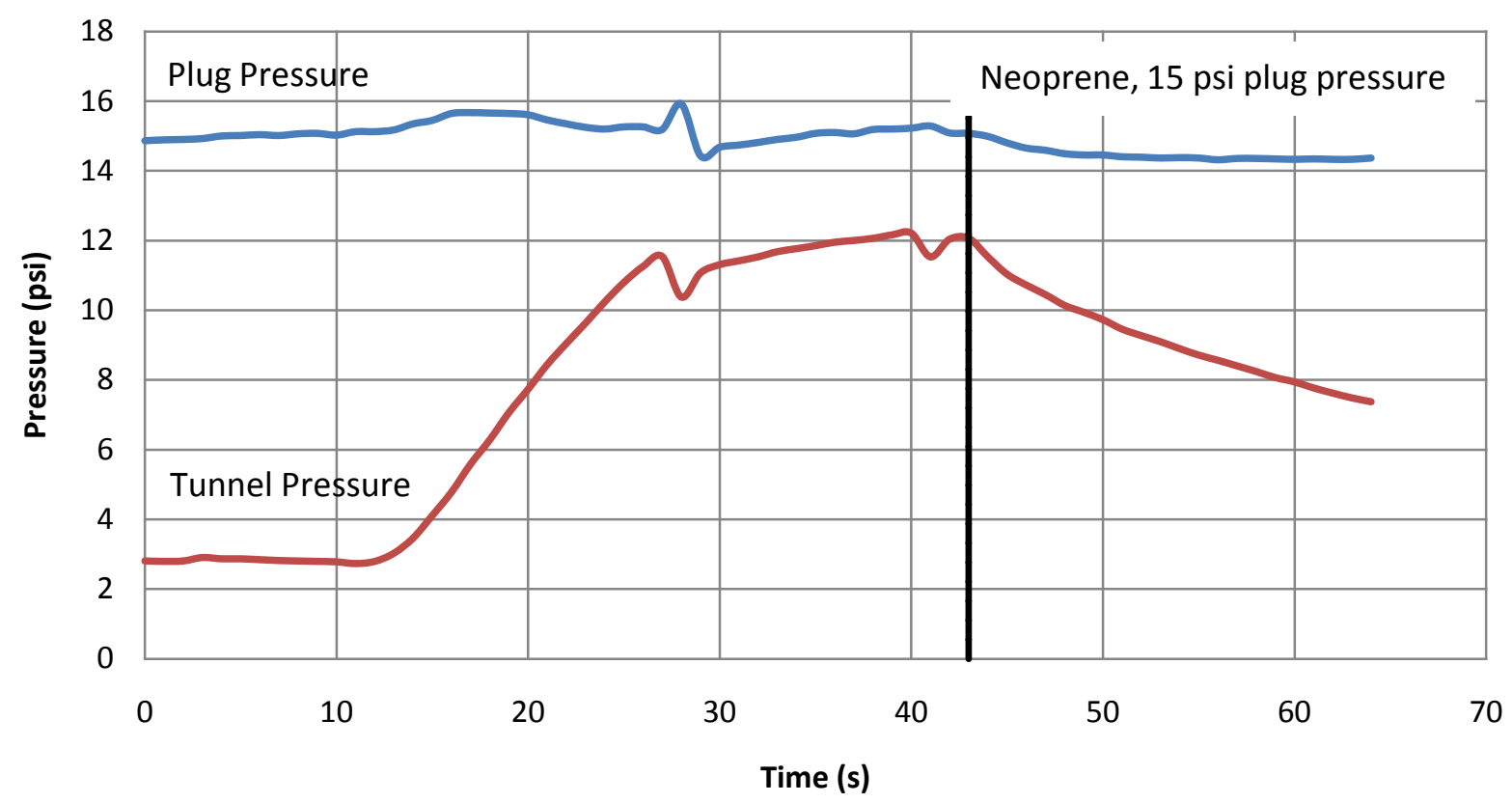

Figure 3-13 Neoprene, 15 psi plug pressure

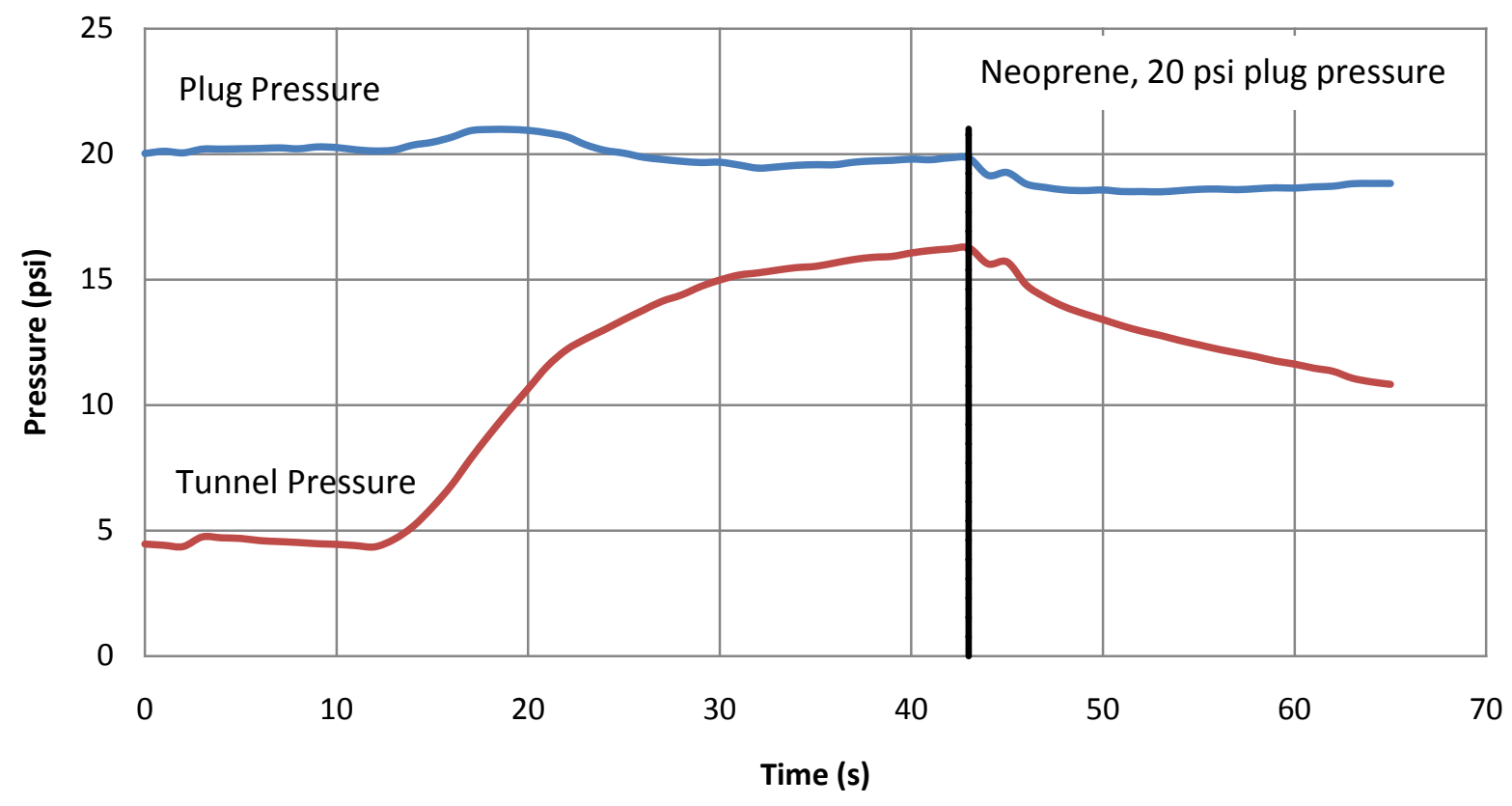

Figure 3-14 Neoprene, 20 psi plug pressure 


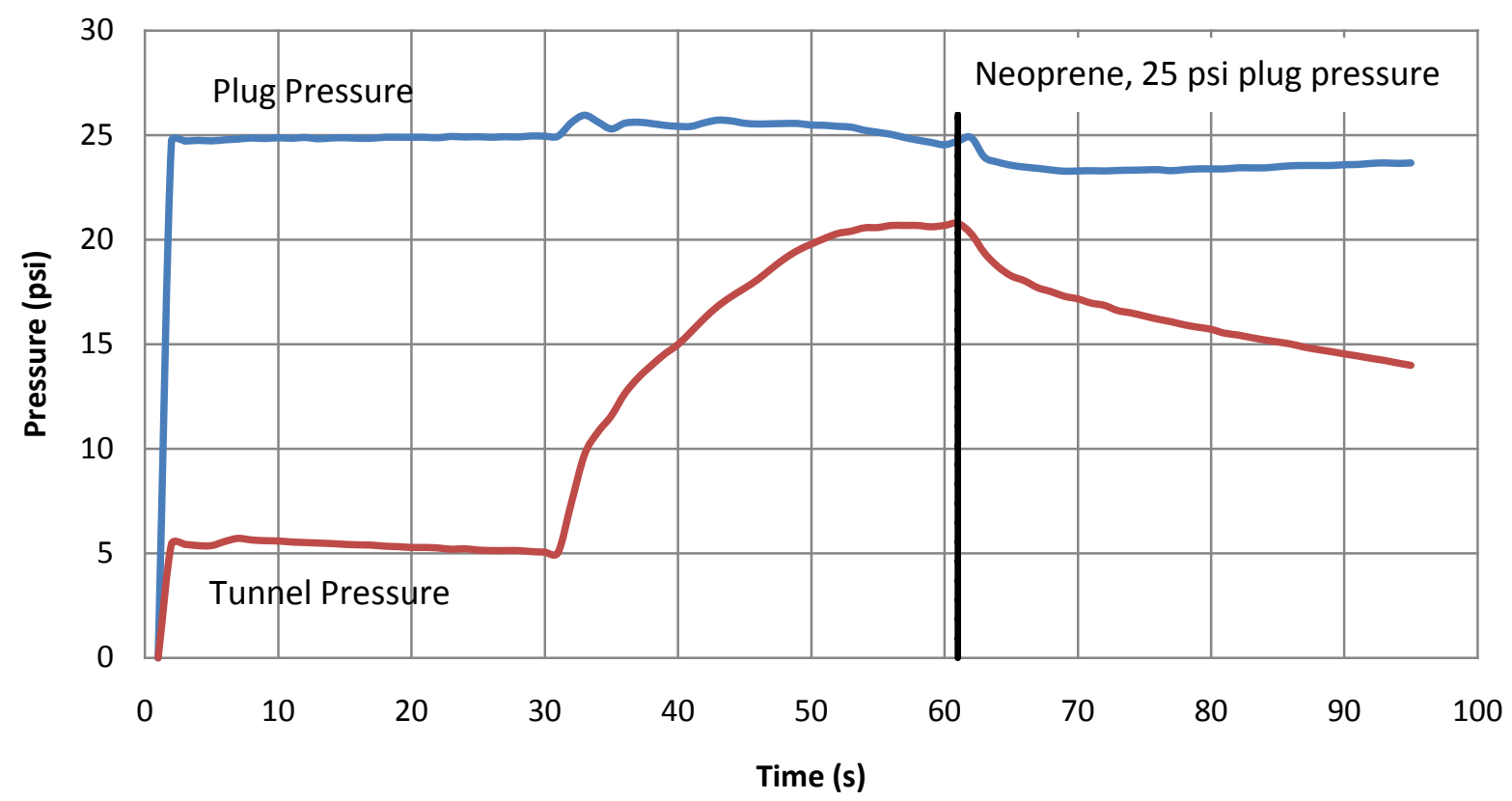

Figure 3-15 Neoprene, 25 psi plug pressure

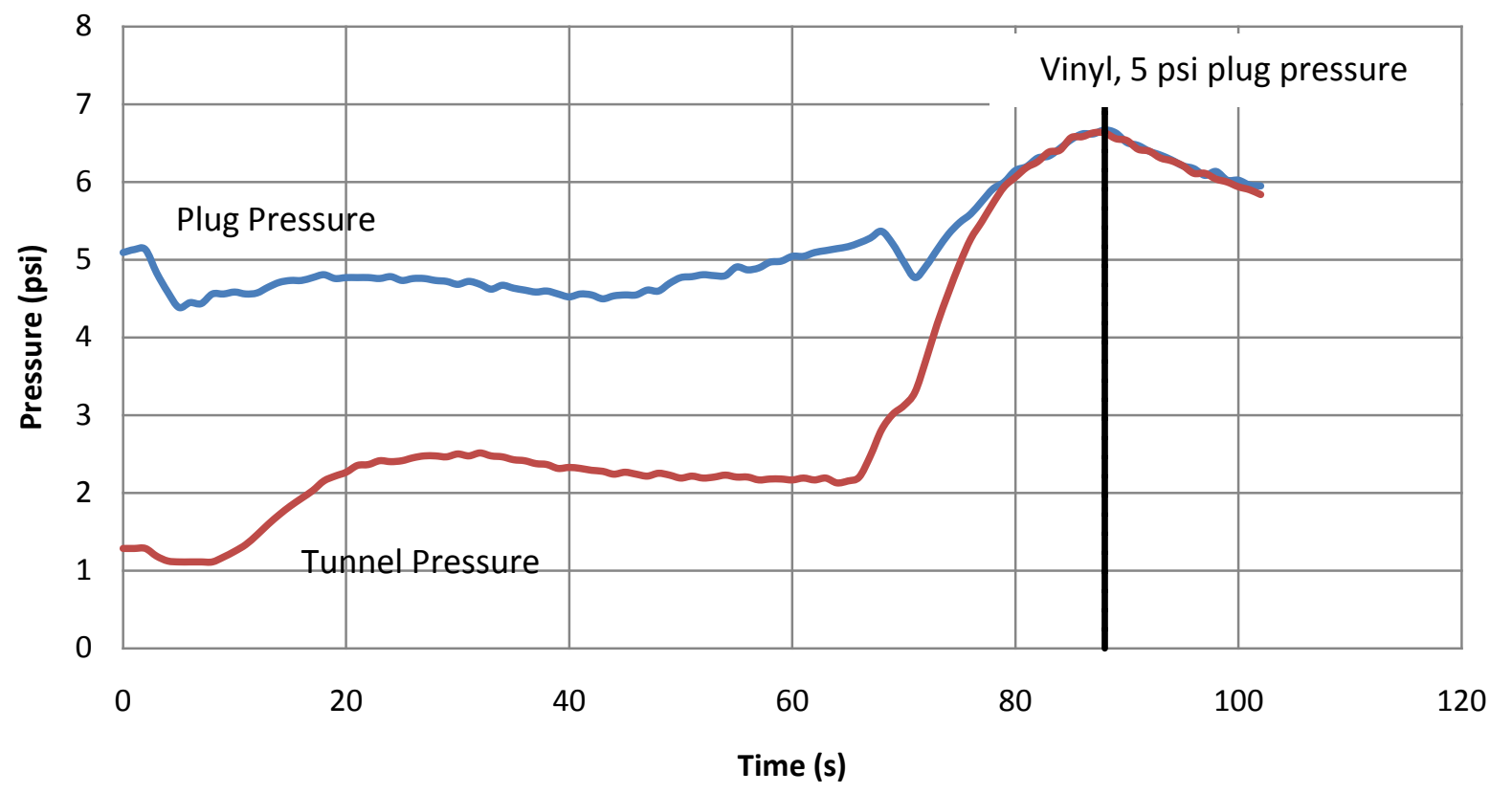

Figure 3-16 Vinyl, 5 psi plug pressure 


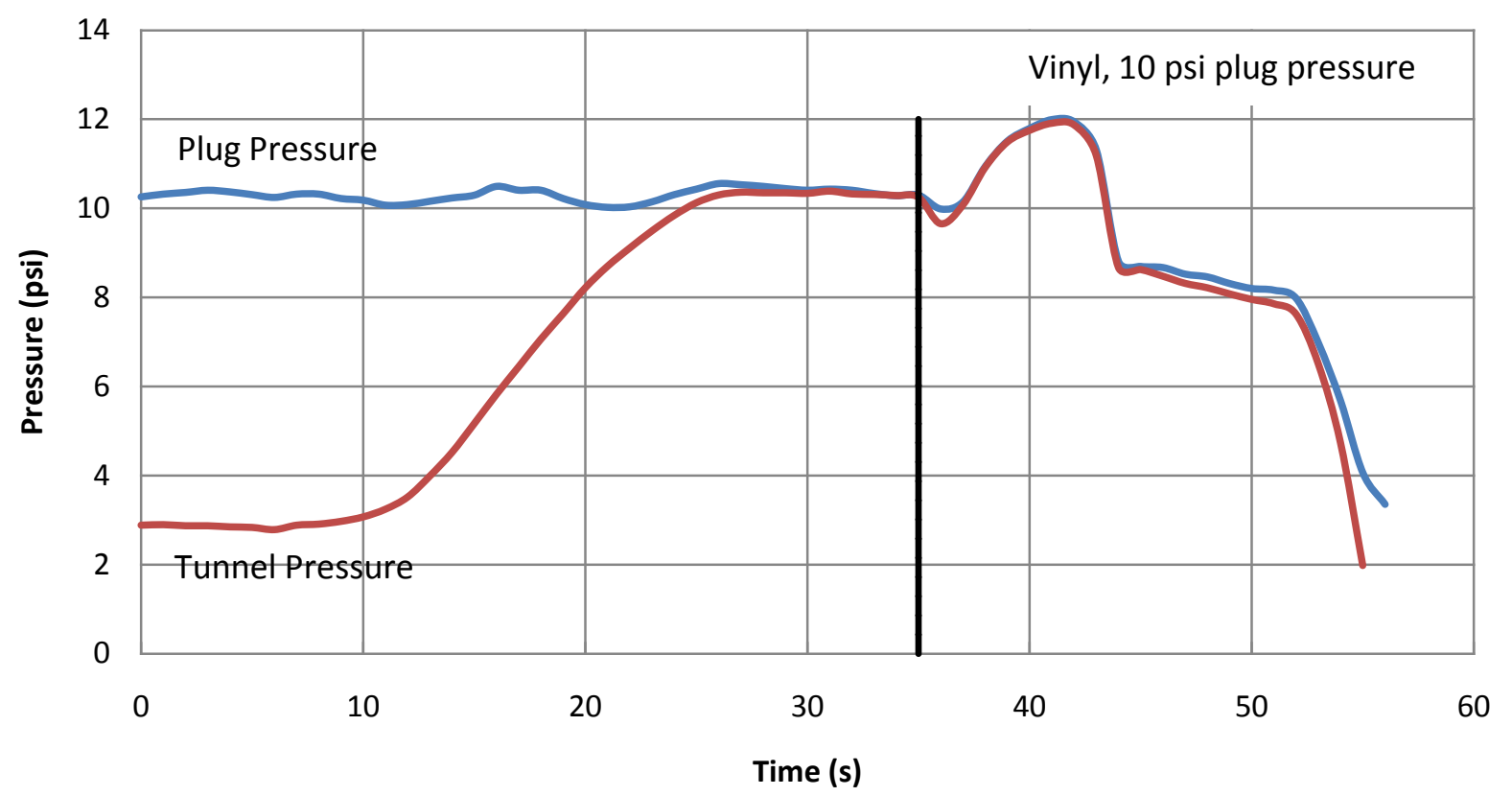

Figure 3-17 Vinyl, 10 psi plug pressure

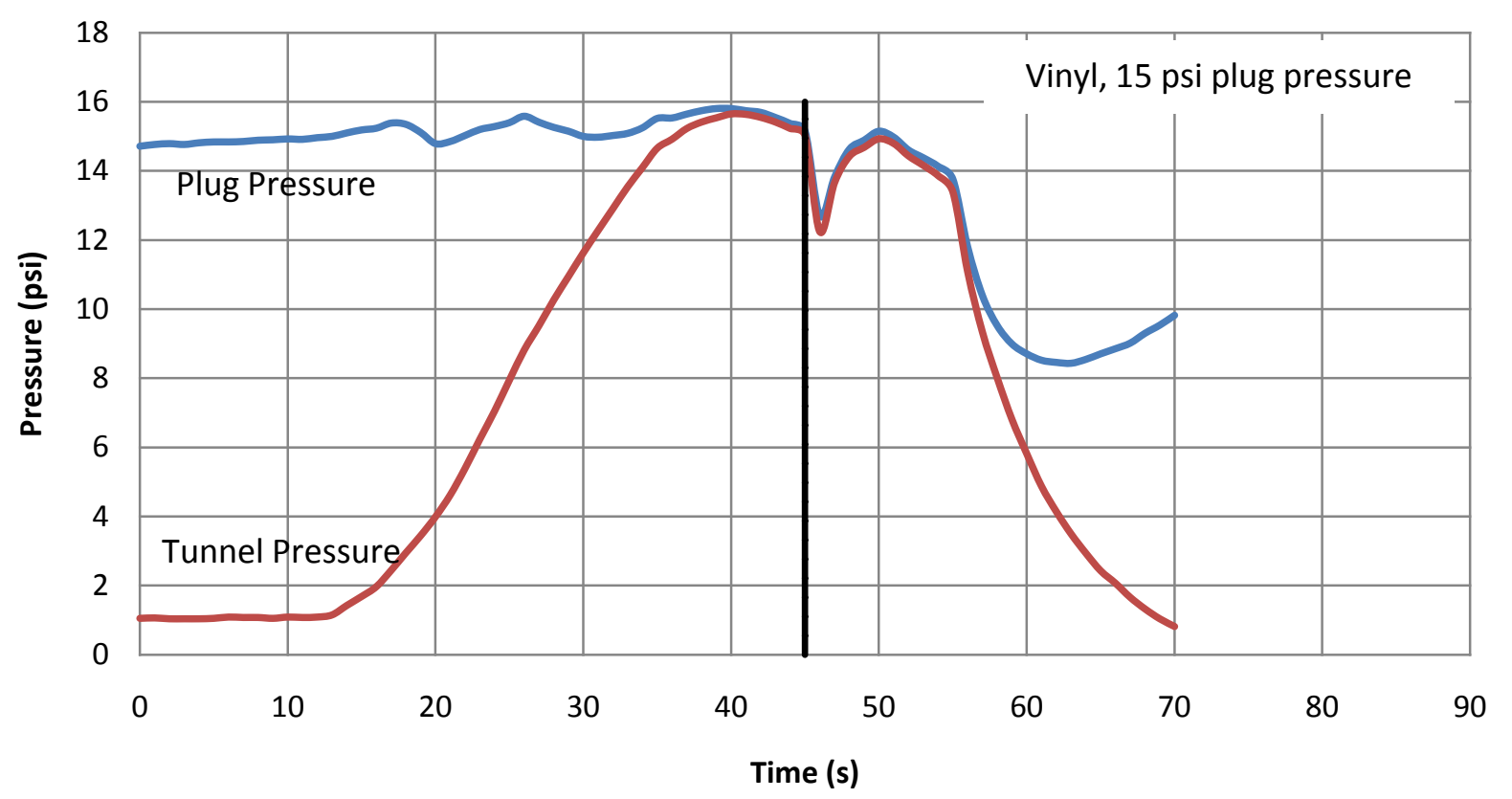

Figure 3-18 Vinyl, 15 psi plug pressure 


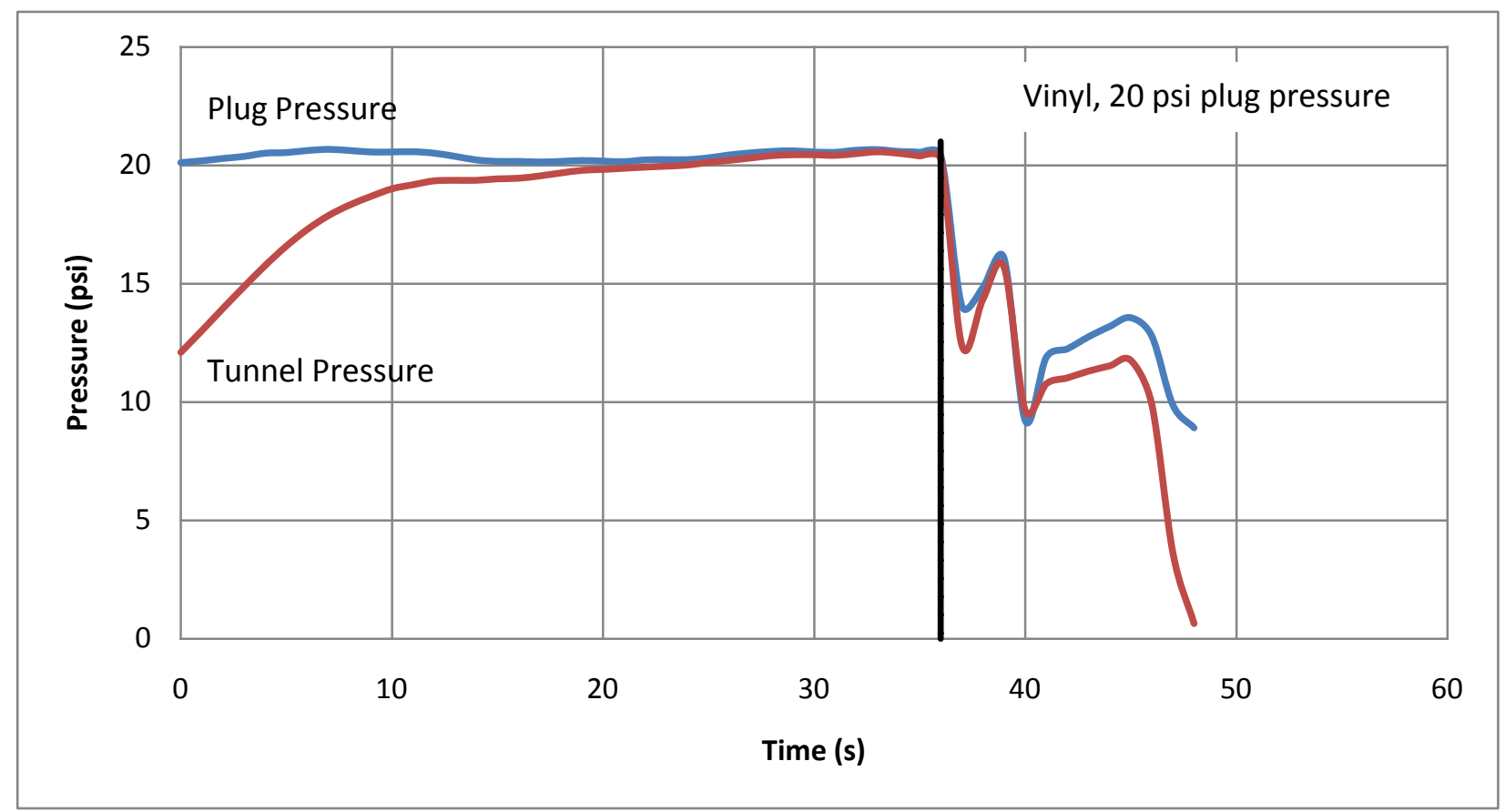

Figure 3-19 Vinyl, 20 psi plug pressure

The results summarized in Table 3-2 are shown plotted in Figure 3-20. This figure indicates that as plug pressure increases, the pressure differential at which the plug slips also increases. This is true for all three tunnel linings although there is a slight deviation at lower pressure with the concrete liner. 


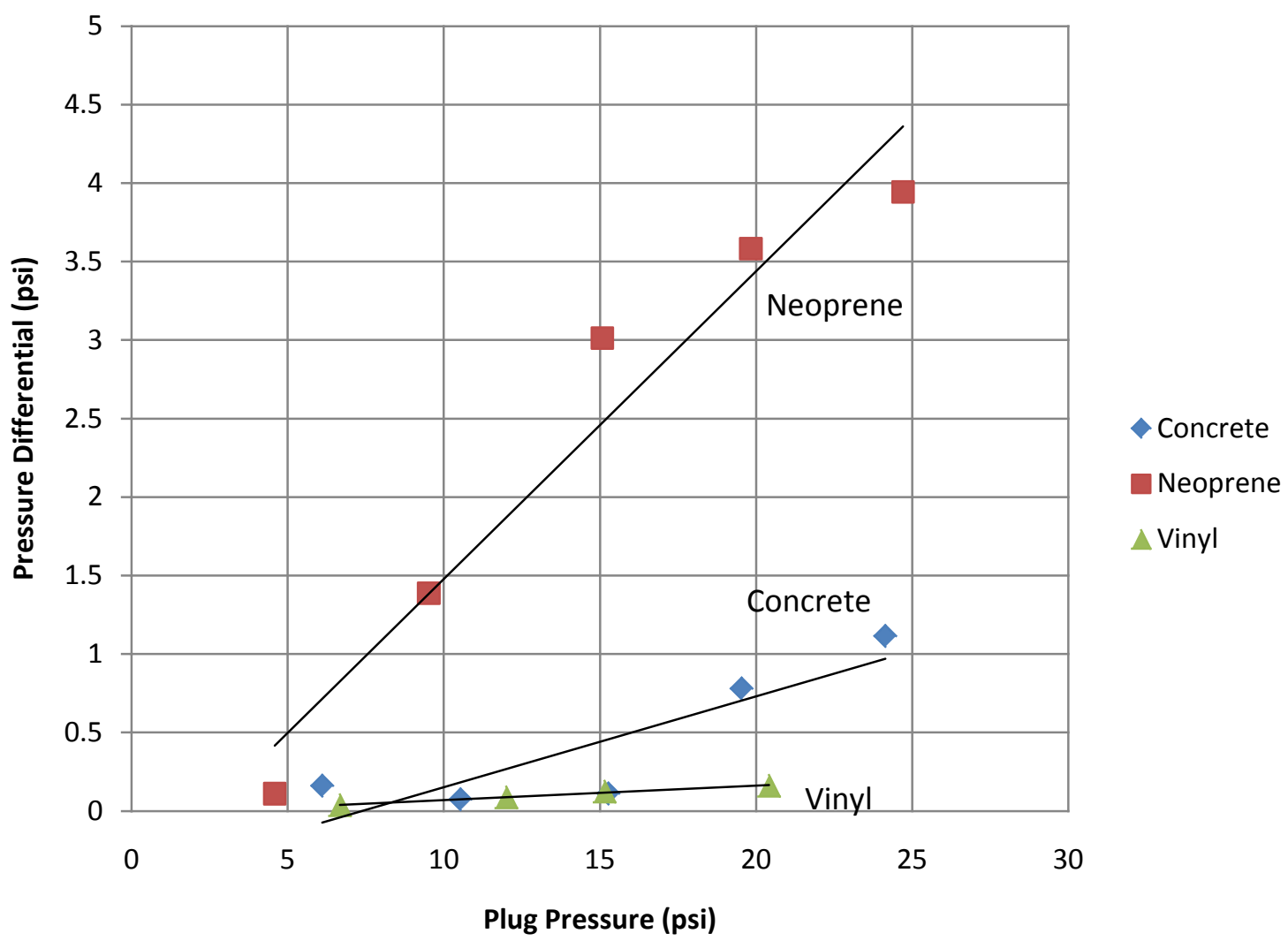

Figure 3-20 Plug pressure vs pressure differential

These pressure differentials were then used to calculate the friction coefficient for each tunnel lining. A static force balance was used to find the friction coefficient corresponding to the slippage instant in terms of the measured plug and tunnel pressures. The general static friction equation $F_{F}=f * N$ was used. Figure 3-21 shows a free body diagram of the acting forces applied to the tunnel and plug test bed along with their dimensions. 


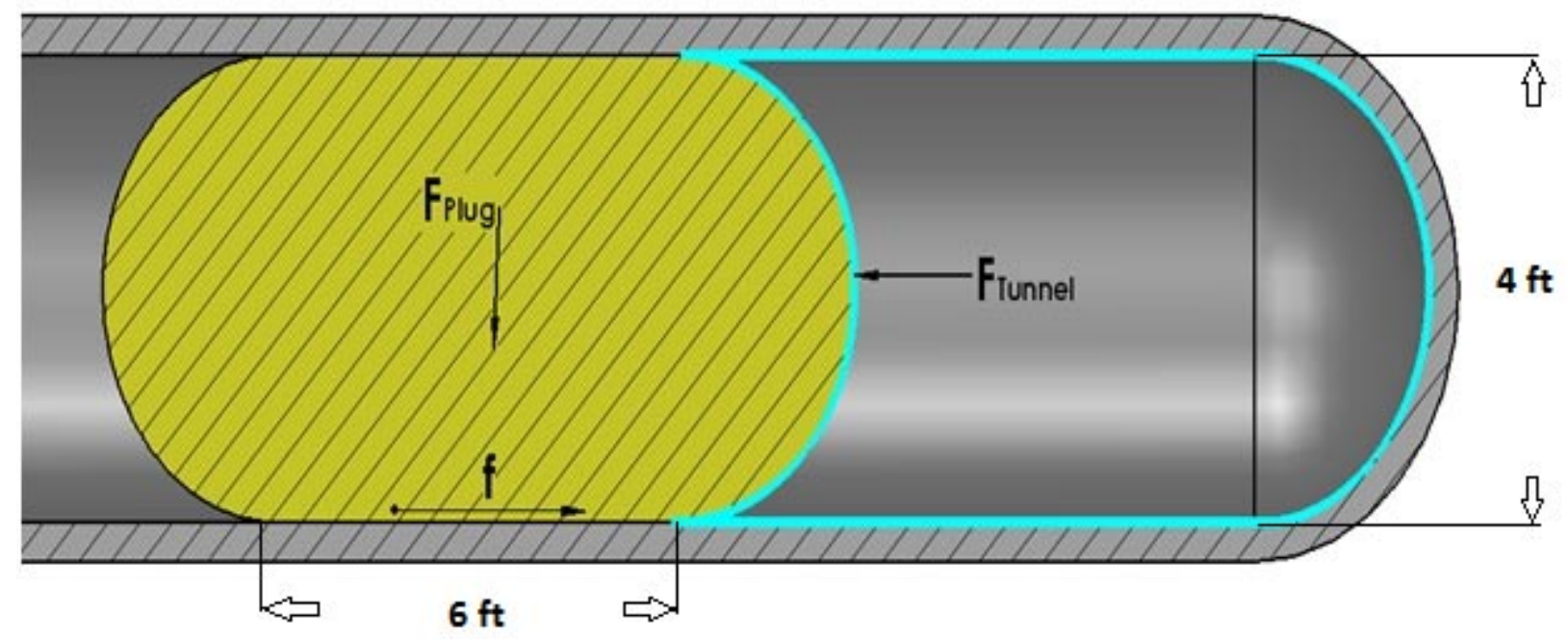

Figure 3-21 Force balance and dimensions of tunnel and plug

For slippage to occur, the equation $F_{\text {Tunnel }}>F_{\text {Plug }} * f$ had to be satisfied. Since both the forces acting on the plug and tunnel $\left(F_{\text {Tunnel }}\right.$ and $\left.F_{\text {Plug }}\right)$ can be determined from the measured pressures, the friction coefficient could be calculated. The pressures that were applied to the plug and tunnel at the time of slippage were used to find the forces. The general equation $F=P * A$ was used. The pressures had two components, the hydrostatic pressure of the water volume and the applied pressure from the pumps.

The force of the hydrostatic pressure of the water in the plug was first calculated. The hydrostatic pressure distribution is shown in Figure 3-22. 


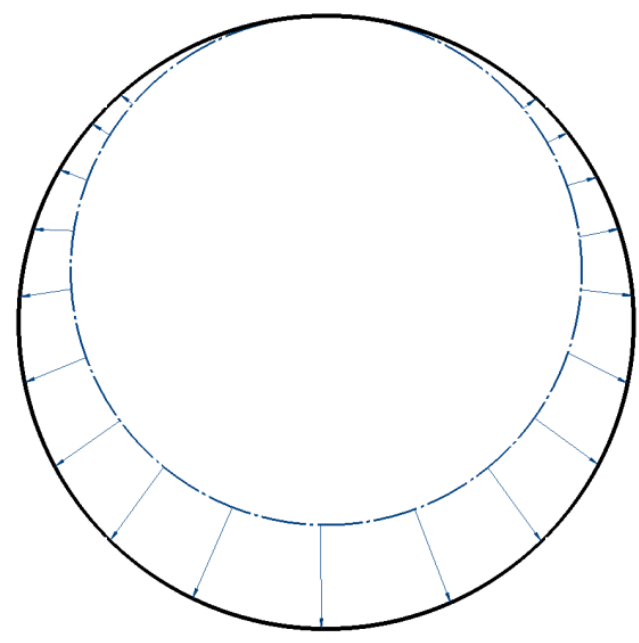

Figure 3-22 Hydrostatic pressure distribution on the plug

As seen from Figure 3-22, the pressure increases towards the bottom of the plug and decreases towards the top, therefore an integral was used to calculated the total force acting on the plug. The plug was simplified to a cylinder because the end caps were not in contact with the tunnel.

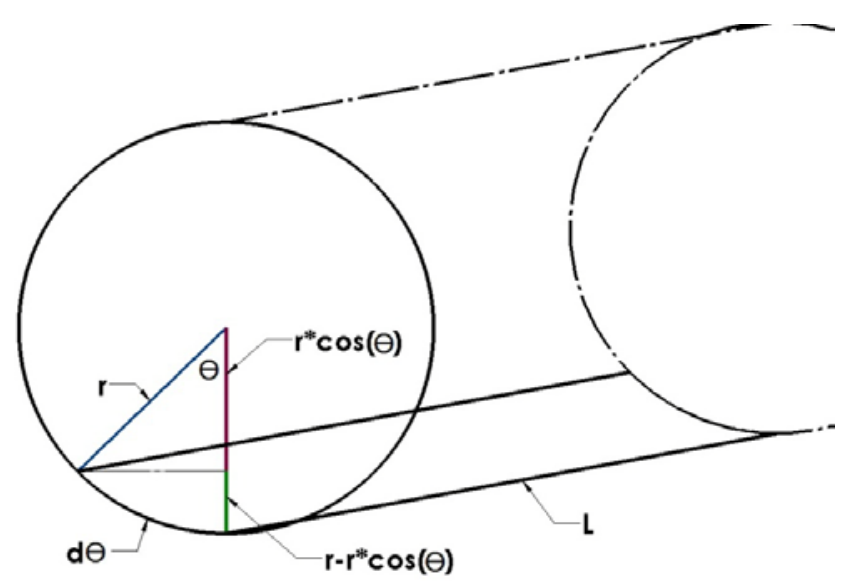

The total force is given by:

$$
\mathrm{F}=\mathrm{P} * \mathrm{~A}
$$


where the hydrostatic pressure is given by:

$$
\mathrm{P}=\gamma * \mathrm{~h}
$$

Working in cylindrical coordinates: the elevation, $h$, can be expressed in terms of the radius $r$ :

$$
\mathrm{P}(\mathrm{r})=\gamma * \mathrm{~h}(\mathrm{r})
$$

Then the total hydrostatic force in the plug, $\mathrm{F}_{\mathrm{PH}}$, is given by the integral of the pressure distribution along the contact area of the plug:

$$
\mathrm{F}_{\mathrm{PH}}=\int \mathrm{P}(\mathrm{r}) * \mathrm{dA}
$$

where:

$$
\mathrm{dA}=\mathrm{L} * \mathrm{~d} \theta
$$

Plugging Equation [3-3] and Equation [3-5] into Equation [3-4] we obtain:

$$
\mathrm{F}_{\mathrm{PH}}=\int \gamma * \mathrm{~h}(\mathrm{r}) * \mathrm{~L} * \mathrm{~d} \theta=\gamma \mathrm{L} \int \mathrm{h}(\mathrm{r}) \mathrm{d} \theta
$$

The elevation, $h$, in polar coordinates is:

$$
\begin{aligned}
& \mathrm{h}\left\{\begin{array}{c}
\pi / 2 \\
0
\end{array}=\mathrm{r}-\mathrm{r} * \cos (\theta)\right. \\
& \mathrm{h}\left\{\begin{array}{c}
\pi \\
\pi / 2
\end{array}=\mathrm{r}+\mathrm{r} * \cos (\theta)\right.
\end{aligned}
$$

Plugging Equation [3-7] into Equation [3-6], we obtain:

$F_{P H}=\gamma L \int_{0}^{\frac{\pi}{2}}[r-r * \cos (\theta)] d \theta+\gamma L \int_{\frac{\pi}{2}}^{\pi}[r-r * \cos (\theta)] d \theta$ for half of the plug force 
Then the total hydrostatic force in the plug is:

$$
\begin{gathered}
\mathrm{F}_{\mathrm{PH}}=2 * \gamma * \mathrm{~L} * \mathrm{r} *(\pi-2) \\
\mathrm{F}_{\mathrm{PH}}=2 * 62.4 \frac{\mathrm{lbs}}{\mathrm{ft}^{3}} * 6 \mathrm{ft} * 2 \mathrm{ft} *(\pi-2) \mathrm{ft} \\
\mathrm{F}_{\mathrm{PH}}=1709.65 \mathrm{lbs}
\end{gathered}
$$

The hydrostatic force of the water in the tunnel volume was then calculated as follows:

$$
\mathrm{F}_{\mathrm{TH}}=\gamma * \mathrm{~h}_{\mathrm{c}} * \mathrm{~A}_{\mathrm{T}}
$$

Where:

$$
\mathrm{h}_{\mathrm{c}}=\frac{\mathrm{D}_{\mathrm{T}}}{2}
$$

Then, combining Equations [3-10] and [3-11]:

$$
\begin{gathered}
\mathrm{F}_{\mathrm{TH}}=62.4 \frac{\mathrm{lbs}}{\mathrm{ft}^{3}} * 2 f t * \pi *(2 f t)^{2} \\
\mathrm{~F}_{\mathrm{TH}}=1568.3 \mathrm{lbs}
\end{gathered}
$$

The values resulting from Equations [3-9] and [3-12] were then added to their respective pressures that were applied by the pumps. Equation [3-13] shows the friction coefficient calculation:

$$
\frac{\mathrm{F}_{\mathrm{TH}}+\mathrm{F}_{\mathrm{ATP}}}{\mathrm{F}_{\mathrm{PH}}+\mathrm{F}_{\mathrm{APP}}}=\mathrm{f}
$$

where $\mathrm{F}_{\mathrm{TH}}$ is the hydrostatic tunnel force, $\mathrm{F}_{\mathrm{ATP}}$ is the force from the applied tunnel pressure, $\mathrm{F}_{\mathrm{PH}}$ is the hydrostatic plug force, and $\mathrm{F}_{\mathrm{APP}}$ is the force from the applied plug pressure. 
For the tunnel:

$$
\mathrm{F}_{\mathrm{ATP}}=\mathrm{P}_{\mathrm{ATP}} * \mathrm{~A}_{\mathrm{T}}=\mathrm{P}_{\mathrm{ATP}} * 144 \frac{\mathrm{in}^{2}}{\mathrm{ft}^{2}} * \pi *(2 \mathrm{ft})^{2}
$$

For the plug:

$$
\mathrm{F}_{\mathrm{APP}}=\mathrm{P}_{\mathrm{APP}} * \pi * \mathrm{D} * \mathrm{~L}=\mathrm{P}_{\mathrm{APP}} * 144 \frac{\mathrm{in}^{2}}{\mathrm{ft}^{2}} * \pi * 4 f t * 6 f t
$$

Then combining Equations [3-13], [3-14], and [3-15] yield:

$$
\frac{1568.3 \mathrm{lbs}+\mathrm{P}_{\mathrm{ATP}} * 1808.64 \mathrm{in}^{2}}{1709.65 \mathrm{lbs}+\mathrm{P}_{\mathrm{APP}} * 10857.34 \mathrm{in}^{2}}=\mathrm{f}
$$

Equation [3-16] was then used in combination with the slippage data to produce the friction coefficients for the different tunnel linings shown in Table 3-3. In these calculations it was assumed that the tunnel force acting on the end of the plug was acting on a flat circular face. The true shape of the end cap of the plug is hemispherical but due to the uncertainty of deformation caused by the acting tunnel force, this hemispherical shape was not accounted for. The assumption of a flat circular plate yields the worst case condition that could occur, therefore, was used for the friction coefficient calculations.

If a hemispherical face was used it would result in a slightly higher friction coefficient due to the larger surface area on which the tunnel pressure acts. This can 
be seen by calculating $1 / 4$ of the plug force on the hemisphere using a double integral. The force is:

$$
\frac{\mathrm{F}}{4}=\iint_{0}^{\frac{\pi}{2}} \mathrm{P} * \mathrm{dA}
$$

where $\mathrm{dA}=\operatorname{rd} \theta * \operatorname{rd} \varnothing$ and $\mathrm{d} \theta$ represents the distance in the longitudinal direction and $\mathrm{d} \emptyset$ represents the distance in the lateral direction. Only the horizontal component of the pressure is used in both the lateral and longitudinal direction to yield:

$$
\frac{\mathrm{F}}{4}=\iint_{0}^{\frac{\pi}{2}} \mathrm{P} * \cos \emptyset * \cos \theta * \mathrm{rd} \theta * \mathrm{rd} \emptyset=\mathrm{P} * \mathrm{r}^{2} \iint_{0}^{\frac{\pi}{2}} \cos \emptyset * \cos \theta \mathrm{d} \emptyset \mathrm{d} \theta
$$

Integrating Equation [3-18] yields:

$$
\frac{\mathrm{F}}{4}=\mathrm{P} * \mathrm{r}^{2}
$$

where the area for the hemispherical end, $A_{\text {hemisphere }}$, is $4 * \mathrm{r}^{2}$. For the flat plate used for the friction coefficient calculations, the tunnel area, $A_{T}$, is $3.14 * \mathrm{r}^{2}$. The hemispherical end cap area is approximately $21 \%$ larger than the assumed flat plate area which would result in an approximate $21 \%$ larger friction coefficient. As previously stated, the smaller area value was used for the worst case scenario. 
Table 3-3 Friction coefficients for different tunnel linings

\begin{tabular}{|c|c|c|c|}
\hline \multicolumn{4}{|c|}{ Concrete } \\
\hline $\begin{array}{c}\text { Plug } \\
\text { Pressure } \\
\text { (psi) }\end{array}$ & $\begin{array}{l}\text { Tunnel } \\
\text { Pressure } \\
\text { (psi) }\end{array}$ & $\begin{array}{c}\text { Pressure } \\
\text { Differential (psi) }\end{array}$ & $\begin{array}{c}\text { Friction } \\
\text { Coefficient, } f \\
\text { Eq. [3-16] }\end{array}$ \\
\hline 6.109 & 5.948 & 0.161 & 0.181 \\
\hline 10.535 & 10.461 & 0.074 & 0.177 \\
\hline 15.271 & 15.16 & 0.111 & 0.173 \\
\hline 19.536 & 18.755 & 0.781 & 0.166 \\
\hline 24.136 & 23.02 & 1.116 & 0.164 \\
\hline & & $\begin{array}{c}\text { Average Friction } \\
\text { Coefficient }\end{array}$ & 0.172 \\
\hline \multicolumn{4}{|c|}{ Neoprene } \\
\hline $\begin{array}{c}\text { Plug } \\
\text { Pressure } \\
\text { (psi) } \\
\end{array}$ & $\begin{array}{c}\text { Tunnel } \\
\text { Pressure } \\
\text { (psi) }\end{array}$ & $\begin{array}{c}\text { Pressure } \\
\text { Differential (psi) }\end{array}$ & $\begin{array}{c}\text { Friction } \\
\text { Coefficient, } f \\
\text { Eq. [3-16] } \\
\end{array}$ \\
\hline 4.584 & 4.473 & 0.111 & 0.188 \\
\hline 9.518 & 8.13 & 1.388 & 0.155 \\
\hline 15.073 & 12.06 & 3.013 & 0.141 \\
\hline 19.834 & 16.251 & 3.583 & 0.143 \\
\hline \multirow[t]{2}{*}{24.706} & 20.763 & 3.943 & 0.145 \\
\hline & & $\begin{array}{c}\text { Average Friction } \\
\text { Coefficient }\end{array}$ & 0.154 \\
\hline \multicolumn{4}{|c|}{ Vinyl } \\
\hline $\begin{array}{c}\text { Plug } \\
\text { Pressure } \\
\text { (psi) }\end{array}$ & $\begin{array}{l}\text { Tunnel } \\
\text { Pressure } \\
\text { (psi) }\end{array}$ & $\begin{array}{c}\text { Pressure } \\
\text { Differential (psi) }\end{array}$ & $\begin{array}{c}\text { Friction } \\
\text { Coefficient, } f \\
\text { Eq. [3-16] }\end{array}$ \\
\hline 6.667 & 6.63 & 0.037 & 0.183 \\
\hline 11.998 & 11.911 & 0.087 & 0.175 \\
\hline 15.147 & 15.023 & 0.124 & 0.173 \\
\hline \multirow[t]{2}{*}{20.416} & 20.255 & 0.161 & 0.171 \\
\hline & & $\begin{array}{c}\text { Average Friction } \\
\text { Coefficient }\end{array}$ & 0.176 \\
\hline
\end{tabular}




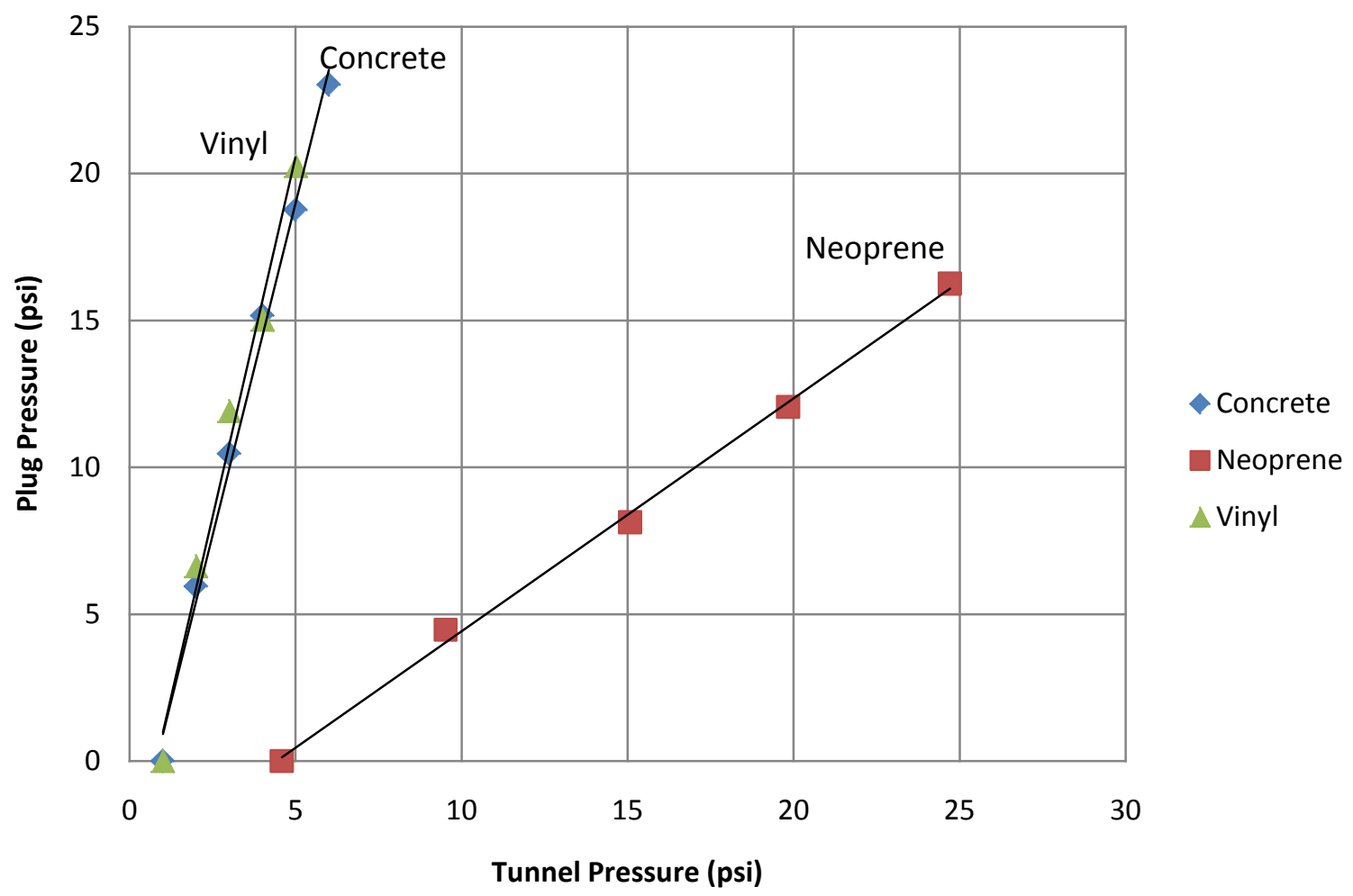

Figure 3-23 Plug pressure vs. tunnel pressure for each tunnel lining

It can be observed in Table 3-3 that the neoprene tunnel lining had the lowest average friction coefficient of 0.154 while the vinyl lining had the highest value of 0.176 . The concrete was very close to the vinyl with a value of 0.172 . The results contradict the original hypothesis which suggested that the vinyl covering would have the lowest friction coefficient. It is thought that the urethane coating on the plug fabric sticks well to the plastic like surface of the vinyl lining, creating this higher friction coefficient. Figure 3-23 shows the plug pressure verses the tunnel pressure for the different tunnel linings. The increased slopes of vinyl and concrete indicate a higher friction coefficient than that of neoprene. 
These friction values were also compared to other values obtained from the friction machine testing of the material. A comparison of these values is shown in Table 3-4.

Table 3-4 Comparison of friction values for different testing methods

\begin{tabular}{|c|c|c|}
\hline & \multicolumn{2}{|c|}{ Average Friction Coefficient } \\
\hline & $\begin{array}{c}\text { Plug-Tunnel } \\
\text { Test }\end{array}$ & $\begin{array}{c}\text { Friction Machine } \\
\text { Test }\end{array}$ \\
\hline Concrete & 0.172 & 0.620 \\
\hline Neoprene & 0.154 & 0.610 \\
\hline Vinyl & 0.176 & 0.710 \\
\hline
\end{tabular}

From the results summarized in Table $3-4$, it can be easily noticed that the friction values for the plug and tunnel slippage tests are significantly lower than the values from the friction sled tests. This information tells us not that values are incorrect but that there are other factors influencing the friction characteristics in the tunnel tests that were not present in the sled tests. Note also that the sled tests do follow the same trend as the plug and tunnel tests in that the neoprene has the lowest friction coefficient and the vinyl having the highest value.

Leakage rate (presented in Chapter 4) appears to be one factor that influences the friction factor. This relationship is shown in Table 3-5. 
Table 3-5 Relationship between friction coefficient and leakage rate

\begin{tabular}{|c|c|c|}
\hline & $\begin{array}{c}\text { Average } \\
\text { Friction } \\
\text { Coefficient } \\
\text { (f) }\end{array}$ & $\begin{array}{c}\text { Average } \\
\text { Leakage } \\
\text { Rate } \\
\text { (gpm) }\end{array}$ \\
\hline Neoprene & 0.154 & 1.09 \\
\hline Concrete & 0.172 & 0.90 \\
\hline Vinyl & 0.176 & 0.61 \\
\hline
\end{tabular}

When comparing the average friction coefficient to the average leakage rate of different tunnel linings, it can be observed that there is an inverse relationship. As the leakage rate increases, the friction coefficient decreases. This relationship is shown in Figure 3-24.

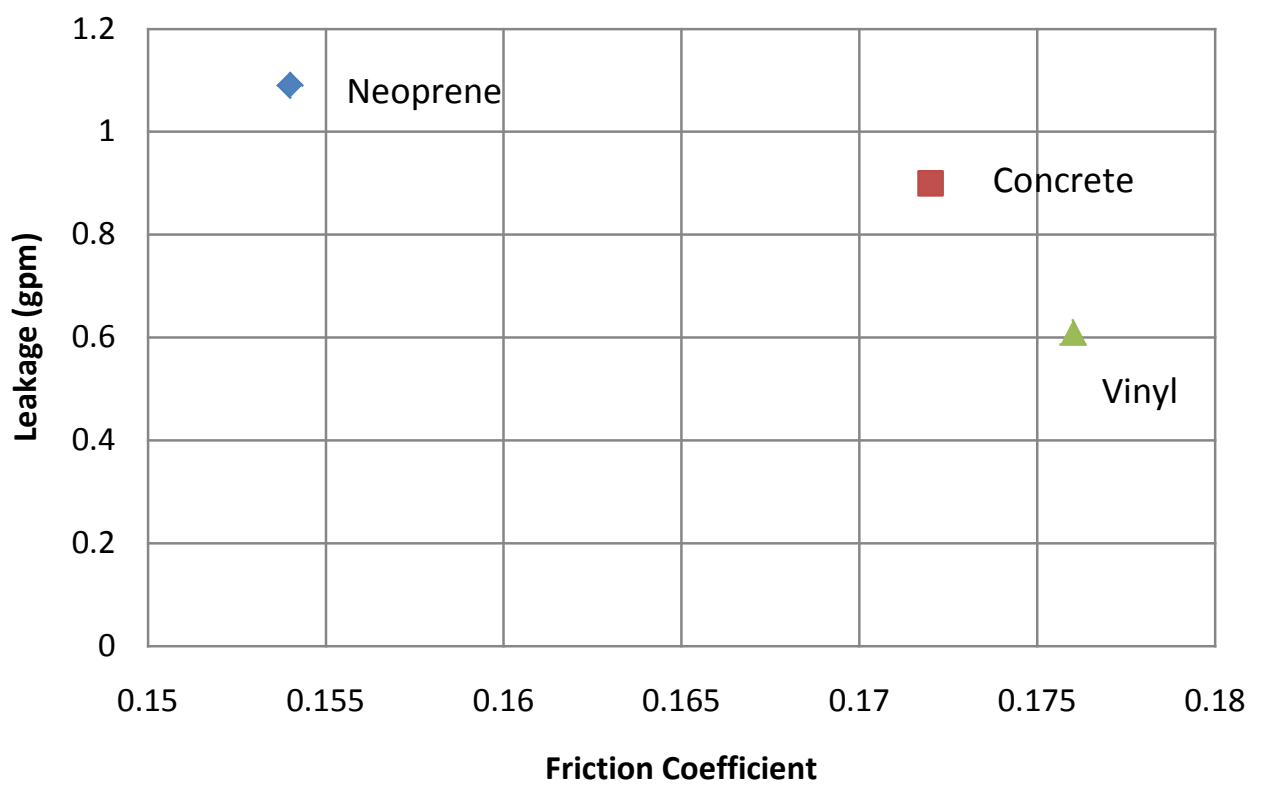

Figure 3-24 Leakage rate vs. friction coefficient 
One of the possible explanations for this relationship is that the increase in flow rate creates larger spaces or crevices in which the water moves around the plug. This water flow could be causing hydrodynamic effects like a thin layer of water between the plug and tunnel surface causing a decrease in the friction coefficient.

The pressure sensitivity of the plug to the tunnel pressure that was previously discussed in Section 3.3 can be seen in Figure 3-25 and shows what happens when the plug pressure is not adjusted when the tunnel is being pressurized.

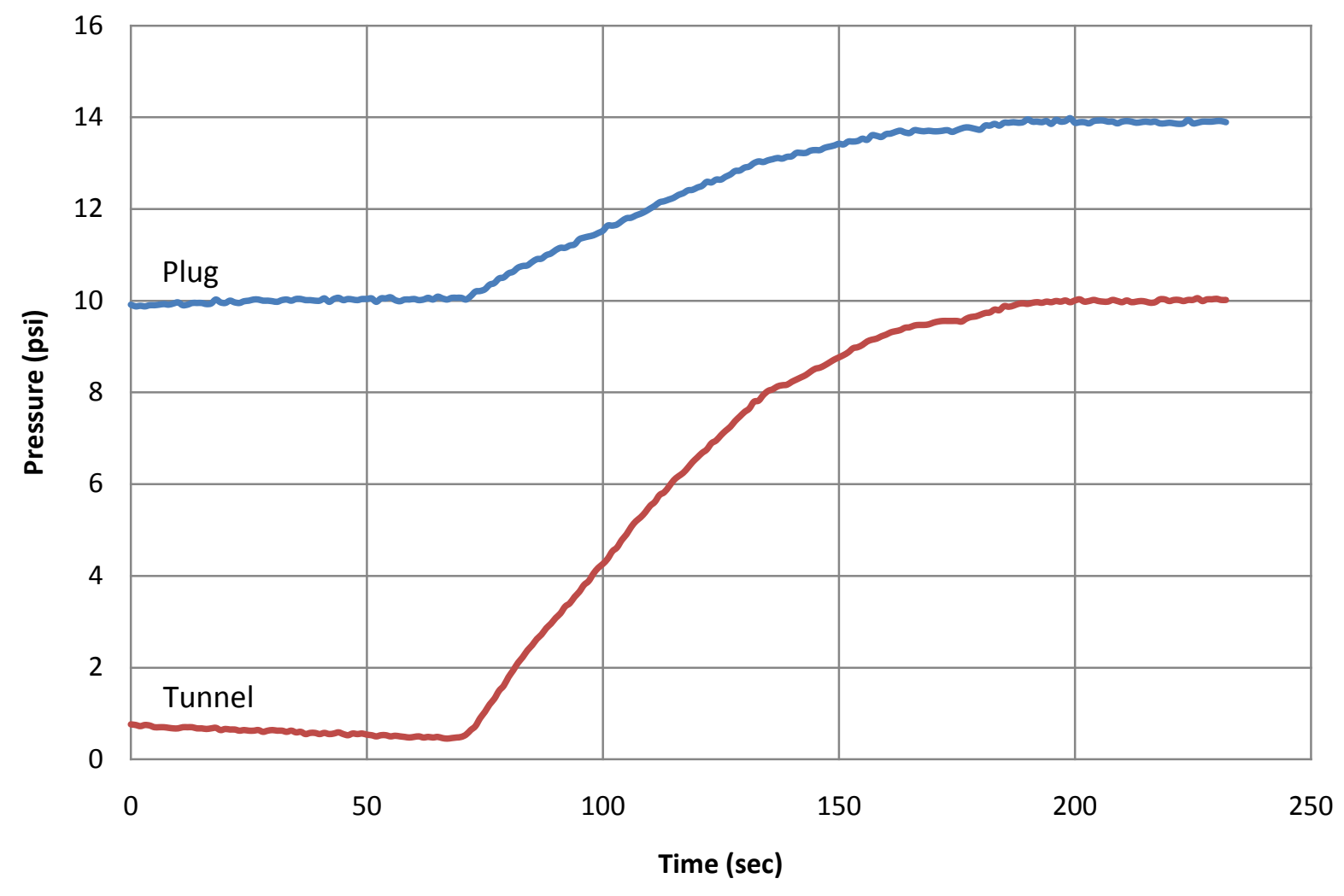

Figure 3-25 Plug pressure sensitivity

The plug pressure is set to $10 \mathrm{psi}$ and the pressure is not adjusted and the tunnel pressure is raised from $1 \mathrm{psi}$ to $10 \mathrm{psi}$. The plug pressure increases approximately $4 \mathrm{psi}$ 
due to this tunnel pressure increase. This shows that if the plug pressure was not adjusted while performing the tests, the maximum design pressure of the plug could be exceeded, causing the plug material to fail.

By releasing water from the plug to adjust the pressure, the volume of water is decreased allowing the pressure to decrease. This relationship can be seen by:

$$
\text { Pressure }=(\text { Bulk modulus }) * \frac{\text { Volume }_{\text {change }}}{\text { Volume }_{\text {initial }}}
$$

The bulk modulus of water is high at $2.2 \times 10^{9} \mathrm{~Pa}$ which means very small volume changes have a significant effect on pressure. Using Equation [3-17], a volume change of 0.01 gallons with an initial plug volume of 800 gallons changes the pressure 4 psi. 


\section{Chapter 4 - Leakage Testing}

\section{1 - Introduction}

The leakage testing provided data showing how changes in the plug and tunnel pressure affected leakage flow rates. Several different plug pressures were evaluated with different pressure differentials between them and the tunnel. These leakage rates were performed for three different tunnel linings.

\section{2 - Procedure}

The plug was inserted into the tunnel and connected to the inflation system. The plug was then filled with water but not pressurized beyond 5 psi. After the plug was filled, the tunnel was then filled with water but not pressurized. Both pressures were then adjusted to the desired positions, making sure the tunnel pressure always stayed at least 1 psi below the plug pressure to avoid the chance of plug slippage. One person was located at each the plug pressure regulator and the tunnel pressure regulator. By using two people, the pressures could be adjusted simultaneously to reach the desired test point. The pressures had to be carefully observed because the change in one pressure affected the pressure in the other.

Leakage rates were recorded for seven different plug pressures ranging from 5 psi to the maximum allowable pressure of $35 \mathrm{psi}$. The tunnel pressure was set to a certain percentage of the plug pressure. These percentages were $20 \%, 40 \%, 60 \%$, and $80 \%$. Percentages of the plug pressure were used to keep the data consistent across the various plug pressures. For each plug pressure, three leakage rates were recorded for each of the tunnel pressures (percentage of plug pressure). This equaled a total of 
12 leakage rates for each plug pressure. An average leakage for each plug and tunnel pressure combination could then be found. A total of 84 leakage tests were performed for each of the three linings which equaled final total of 252 tests. Table 4-1 shows an example of the blank sheet that was used to collect data for a 20 psi plug pressure. Data collection did not start until one minute after the desired plug and tunnel pressures were reached. This allowed enough time to be sure that no further pressure fluctuations occurred and to be sure the leakage rate had become constant.

Table 4-1 Example leakage collection sheet

\begin{tabular}{|c|c|c|c|c|}
\hline $\begin{array}{c}\text { Plug Pressure (psi) } \\
\begin{array}{c}\text { Tunnel Pressure } \\
\text { (\% of Plug } \\
\text { Pressure) }\end{array}\end{array}$ & $\begin{array}{c}\text { Tunnel Pressure } \\
\text { (psi) }\end{array}$ & Time (s) & Weight (lb) & $\begin{array}{c}\text { Leakage } \\
\text { (GPM) }\end{array}$ \\
\hline $20 \%$ & 4 & & & \\
\hline $20 \%$ & 4 & & & \\
\hline $20 \%$ & 4 & & & \\
\hline $40 \%$ & 8 & & & \\
\hline $40 \%$ & 8 & & & \\
\hline $40 \%$ & 8 & & & \\
\hline $60 \%$ & 12 & & & \\
\hline $60 \%$ & 12 & & & \\
\hline $60 \%$ & 12 & & & \\
\hline $80 \%$ & 16 & & & \\
\hline $80 \%$ & 16 & & & \\
\hline $80 \%$ & 16 & & & \\
\hline & & & & \\
\hline
\end{tabular}

As shown in the table, a leakage rate in gallons per minute was the desired final outcome. Because of the way the water leaked from the tunnel, a flow meter would not have been a practical method of data collection. Leakage (or flow) rate can be defined 
as the volume of water per unit of time as seen in Equation [4-1]. Using this definition, a container was used to collect a volume of water during a specific time. This volume and the time in which it was collected equaled the leakage rate. The equations used for the calculations are shown below:

$$
\begin{gathered}
\text { Leakage Rate }=\frac{\text { Volume }}{\text { Time }} \\
\text { Volume }=\frac{\text { Weight }}{\gamma}
\end{gathered}
$$

Then, combining Equations [4-1] and [4-2]:

$$
\text { Leakage Rate }=\frac{\left[\frac{\text { Weight }}{\gamma}\right]}{\text { Time }\left(\frac{1 \mathrm{~min}}{60 \mathrm{sec}}\right)}
$$

Where water is:

$$
\gamma=\left(62.4 \frac{l b s}{f t^{3}}\right)\left(\frac{1 f t^{3}}{7.48 g a l}\right)=8.34 \frac{l b s}{g a l}
$$

Therefore:

$$
\text { Leakage Rate }=\frac{\left[\frac{\text { Weight }}{8.34 \frac{\text { lbs }}{\text { gal }}}\right]}{\text { Time }\left(\frac{1 \mathrm{~min}}{60 \mathrm{sec}}\right)}
$$

As shown in Equation [4-2], the weight was divided by the specific gravity of water to obtain the volume. This volume was then divided by the time it took to collect the water which gave the leakage rate in gallons per minutes (gpm) shown in Equation [4-4]. The weight of the water was measured by pouring it into another container positioned on a 
scale. The data was collected and assembled in a spreadsheet to obtain the final values for the leakage rate so they could be compared.

\section{3 - Results/Discussion}

The results for the leakage rates are shown in Table 4-2. This table summarizes the results of these tests in the following ways. Each plug pressure has a total of four different leakage rates, one for each respective tunnel pressure obtained from Table 4-1. These leakage rates are the result of an average of three separate leakage readings for each tunnel pressure. The pressure differential was calculated by taking the difference between the plug and tunnel pressures. The leakage results for each tunnel lining were graphed and displayed in Figure 4-1, Figure 4-2, and Figure 4-3. The scales on each graph are kept the same for comparison purposes.

It can be observed in each graph that the leakage rate decreases when the pressure differential between the plug and tunnel increases. This is an expected result. A larger pressure differential means that the plug and tunnel pressures are further from each other. When this differential increases, the plug is able to exert more force on the tunnel walls which seals the contact surface better and therefore the water in the tunnel is not able to flow around the plug. This trend is observed across all tunnel linings indicating that it is independent of the tunnel lining material. 
Table 4-2 Leakage rate test results

\begin{tabular}{|c|c|c|c|c|c|c|}
\hline & & & & Concrete & Neoprene & Vinyl \\
\hline $\begin{array}{c}\text { Plug } \\
\text { Pressure } \\
\text { (psi) } \\
\end{array}$ & $\begin{array}{c}\text { Tunnel } \\
\text { Pressure (\% of } \\
\text { Plug Pressure) } \\
\end{array}$ & $\begin{array}{c}\text { Tunnel } \\
\text { Pressure } \\
\text { (psi) }\end{array}$ & $\begin{array}{c}\text { Pressure } \\
\text { Differential } \\
\text { (psi) }\end{array}$ & $\begin{array}{c}\text { Leakage } \\
\text { Rate (gpm) }\end{array}$ & $\begin{array}{c}\text { Leakage } \\
\text { Rate (gpm) }\end{array}$ & $\begin{array}{c}\text { Leakage } \\
\text { Rate (gpm) }\end{array}$ \\
\hline 5 & $20 \%$ & 1 & 4 & 0.21 & 0.11 & 0.08 \\
\hline 5 & $40 \%$ & 2 & 3 & 0.31 & 0.40 & 0.23 \\
\hline 5 & $60 \%$ & 3 & 2 & 0.41 & 0.75 & 0.36 \\
\hline 5 & $80 \%$ & 4 & 1 & 0.54 & 0.94 & 0.49 \\
\hline 10 & $20 \%$ & 2 & 8 & 0.25 & 0.27 & 0.17 \\
\hline 10 & $40 \%$ & 4 & 6 & 0.39 & 0.57 & 0.32 \\
\hline 10 & $60 \%$ & 6 & 4 & 0.28 & 0.81 & 0.42 \\
\hline 10 & $80 \%$ & 8 & 2 & 0.68 & 1.09 & 0.54 \\
\hline 15 & $20 \%$ & 3 & 12 & 0.23 & 0.29 & 0.21 \\
\hline 15 & $40 \%$ & 6 & 9 & 0.48 & 0.53 & 0.34 \\
\hline 15 & $60 \%$ & 9 & 6 & 0.65 & 0.76 & 0.47 \\
\hline 15 & $80 \%$ & 12 & 3 & 0.84 & 1.04 & 0.61 \\
\hline 20 & $20 \%$ & 4 & 16 & 0.33 & 0.29 & 0.19 \\
\hline 20 & $40 \%$ & 8 & 12 & 0.52 & 0.53 & 0.32 \\
\hline 20 & $60 \%$ & 12 & 8 & 0.73 & 0.76 & 0.44 \\
\hline 20 & $80 \%$ & 16 & 4 & 0.94 & 1.04 & 0.60 \\
\hline 25 & $20 \%$ & 5 & 20 & 0.35 & 0.30 & 0.20 \\
\hline 25 & $40 \%$ & 10 & 15 & 0.58 & 0.53 & 0.33 \\
\hline 25 & $60 \%$ & 15 & 10 & 0.79 & 0.77 & 0.46 \\
\hline 25 & $80 \%$ & 20 & 5 & 1.04 & 1.06 & 0.62 \\
\hline 30 & $20 \%$ & 6 & 24 & 0.37 & 0.31 & 0.23 \\
\hline 30 & $40 \%$ & 12 & 18 & 0.61 & 0.53 & 0.36 \\
\hline 30 & $60 \%$ & 18 & 12 & 0.84 & 0.79 & 0.49 \\
\hline 30 & $80 \%$ & 24 & 6 & 1.10 & 1.15 & 0.65 \\
\hline 35 & $20 \%$ & 7 & 28 & 0.39 & 0.31 & 0.31 \\
\hline 35 & $40 \%$ & 14 & 21 & 0.63 & 0.54 & 0.44 \\
\hline 35 & $60 \%$ & 21 & 14 & 0.87 & 0.83 & 0.58 \\
\hline \multirow[t]{2}{*}{35} & $80 \%$ & 28 & 7 & 1.16 & 1.31 & 0.76 \\
\hline & & & $\begin{array}{c}\text { Average } \\
\text { Leakage at } \\
80 \% \text { of Plug } \\
\text { Pressure }\end{array}$ & 0.90 & 1.09 & 0.61 \\
\hline
\end{tabular}




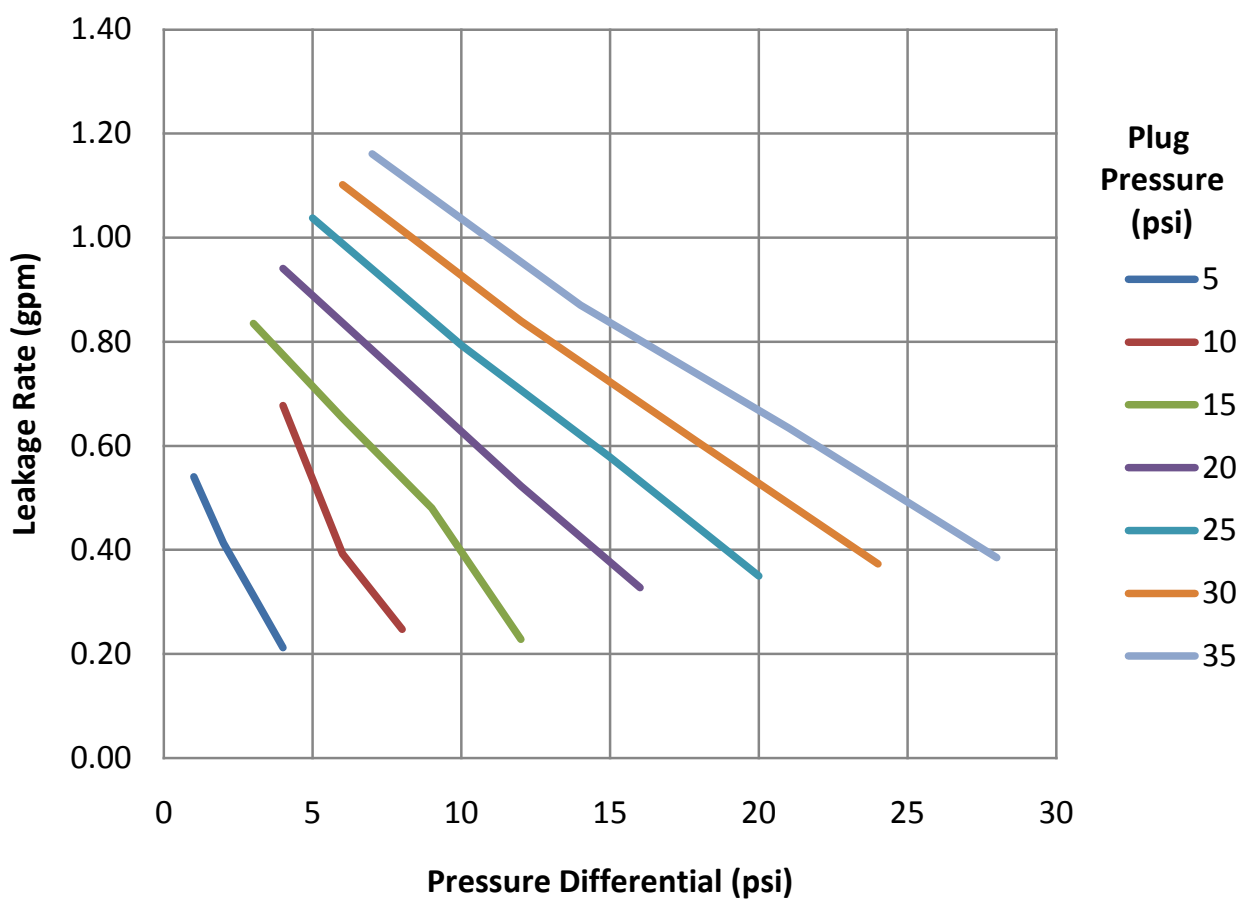

Figure 4-1 Pressure differential vs. leakage rate for concrete

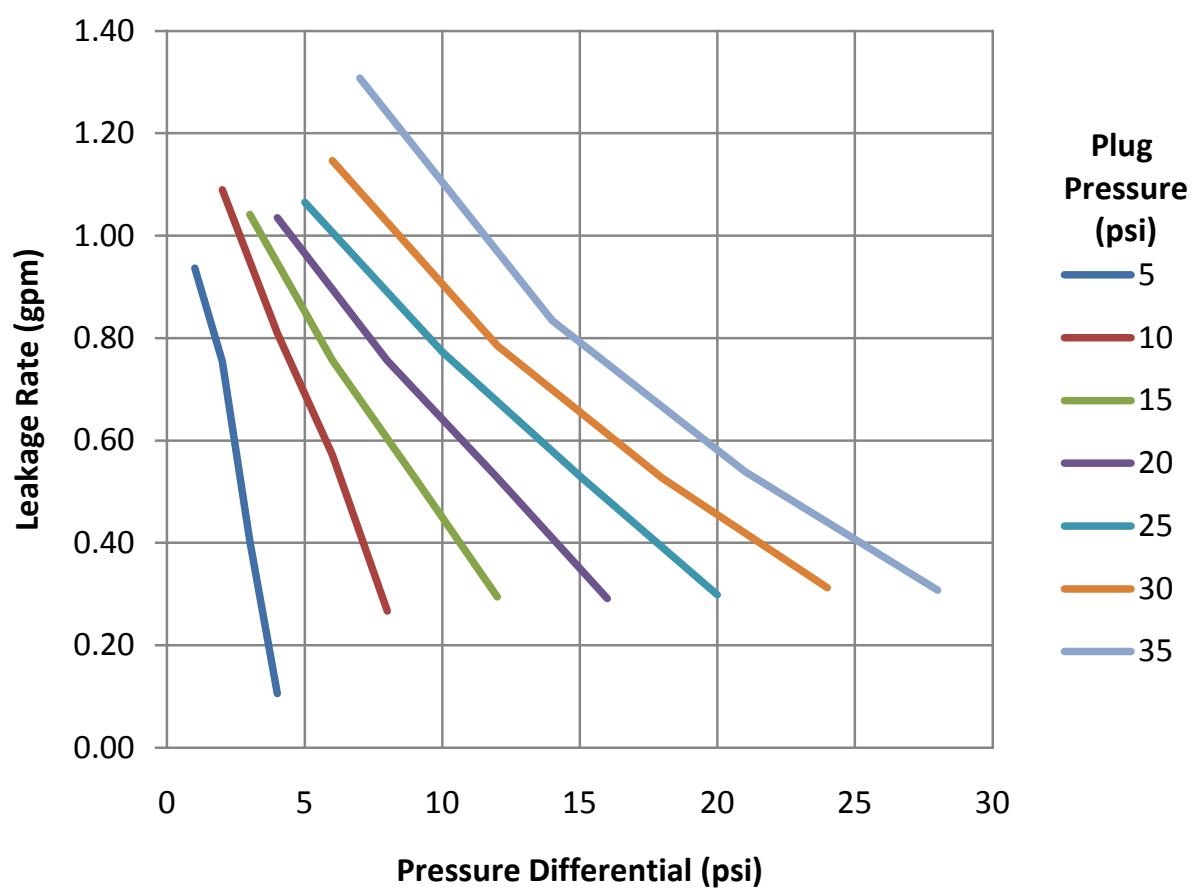

Figure 4-2 Pressure differential vs. leakage rate for neoprene 


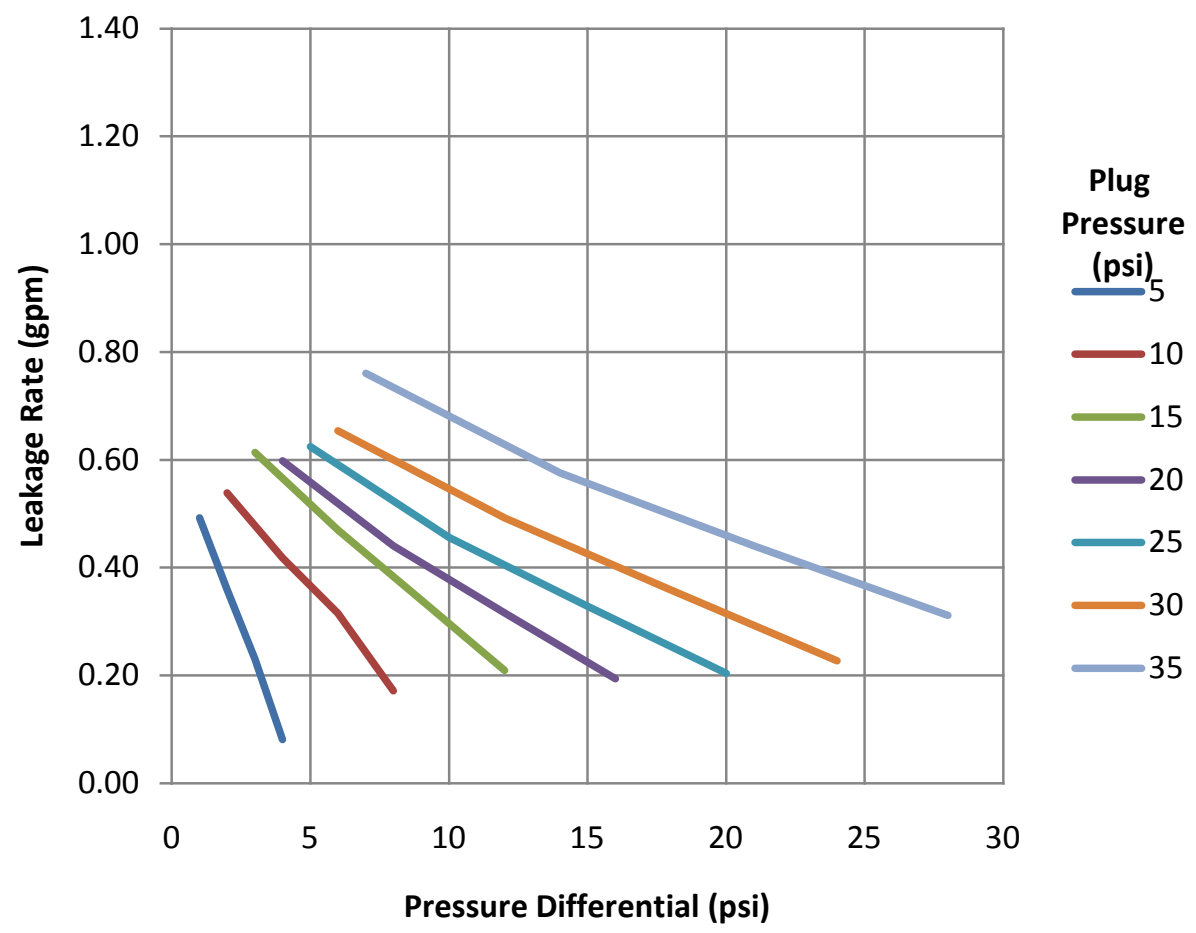

Figure 4-3 Pressure differential vs. leakage rate for vinyl

Pressure differential is not the only factor that influences the leakage rate. When observing the aforementioned figures, it is noticed that for a given pressure differential, the leakage rate increases as the plug pressure increases. This is indicative of higher plug pressures causing more leakage, despite having the same pressure differentials. Figure 4-4 shows an example of this trend with concrete lining. Since the plug pressure must always be more than the tunnel pressure to avoid unwanted plug slippage, plotting the tunnel pressure with respect to leakage rates was used to represent how the leakage rate increases with increased pressures in both the tunnel and plug. As shown, the largest tunnel pressure (consequently having the largest plug pressure) has the largest leakage rate. All linings follow this general trend. 


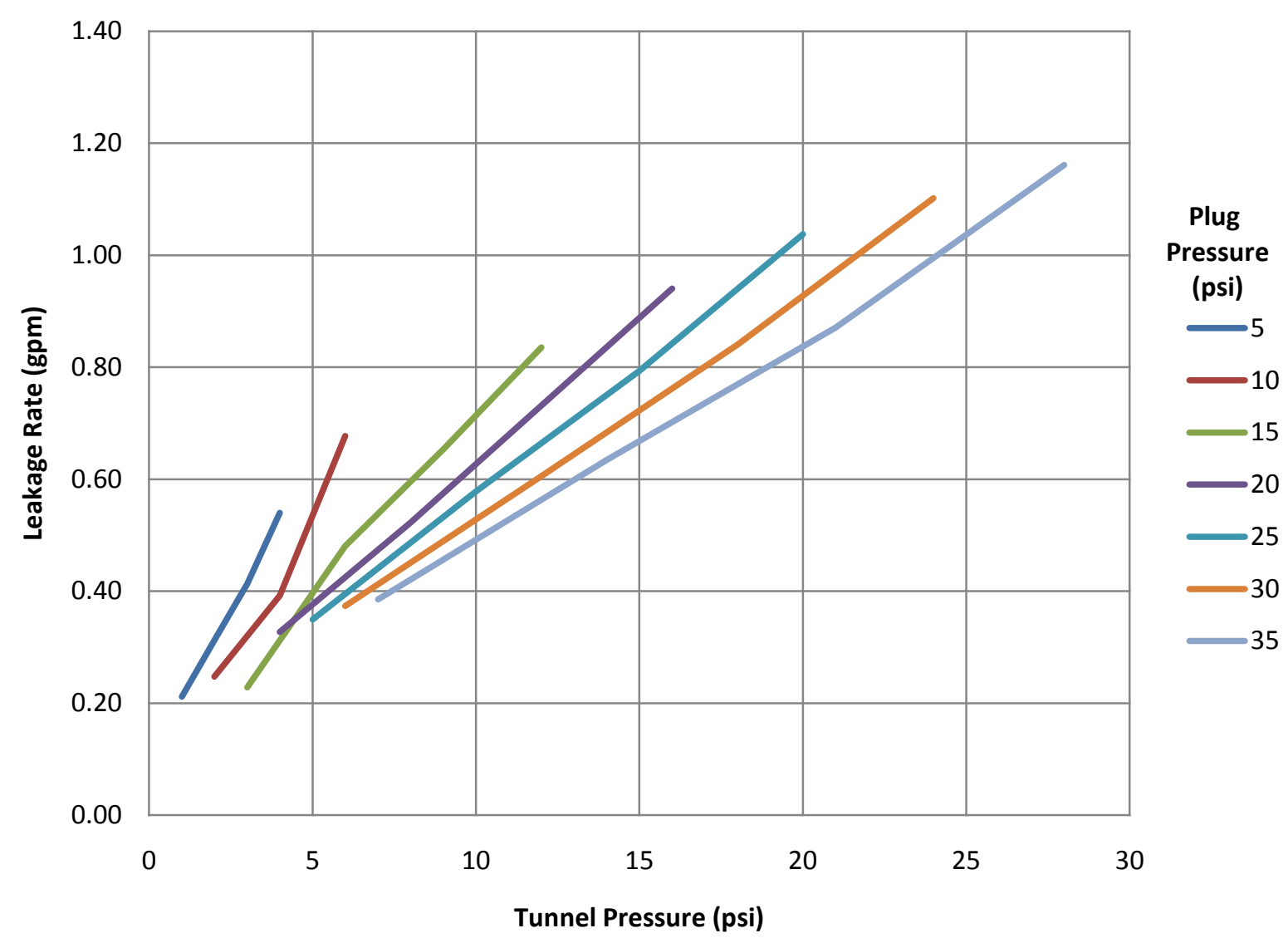

Figure 4-4 Tunnel pressure vs. leakage rate for concrete lining

To gain a better understanding of how the different tunnel linings performed against each other, a common tunnel pressure was compared. The leakage rates for $80 \%$ of the plug pressure were averaged which is shown in Table 4-2 and the results were unexpected. It was originally hypothesized that by adding a compressible material that could fill any voids between the plug and tunnel would decrease leakage. The compressible neoprene lining which was thought to be the best for this test actually performed the worst with a leakage rate of $1.09 \mathrm{gpm}$. The vinyl lining actually performed the best with the least leakage rate of $0.61 \mathrm{gpm}$. The plain concrete lining fell between the other two with a rate of $0.90 \mathrm{gpm}$. The maximum leakage rate was 
$1.31 \mathrm{gpm}$ which occurred with the neoprene lining at 35 psi plug pressure and $28 \mathrm{psi}$ tunnel pressure. The minimum leakage rate was $0.08 \mathrm{gpm}$ which occurred with the vinyl lining at 5 psi plug pressure and 1 psi tunnel pressure.

The results from these tests were also used to calculate approximate leakages that could be expected in a larger tunnel (16 foot diameter). This diameter was chosen since it is the size of the tunnel that will be tested in future RTP experiments.

In order to calculate the leakage rate for the 16 foot tunnel, several assumptions had to be made. It was assumed that the velocity of leakage did not change from the original 4 foot test to the larger scaled 16 foot test. The Bernoulli equation:

$$
p_{1}+\frac{1}{2} \rho V_{1}^{2}+\gamma z_{1}=p_{2}+\frac{1}{2} \rho V_{2}^{2}+\gamma z_{2}
$$

was used to calculate the velocity of the flow from the original data. It was assumed in the Bernoulli equation that the heights of the flow, $z_{1}$ and $z_{2}$ were equal, therefore cancelled. It was assumed that the velocity on the pressurized side of the tunnel, $V_{1}$, was 0 and the pressure on the open side of the tunnel, $p_{2}$, was 0 . These assumptions reduced the equation to $p_{1}=\frac{1}{2} \rho V_{2}{ }^{2}$ which was rearranged to form $V_{2}=\sqrt{\frac{2 p_{1} * 144}{\rho}}$ with 144 being used to convert the tunnel pressure, $p_{1}$ in psi, to psf. This equation was then used to calculate the velocity for each leakage rate. The equation for flow rate $Q=V A$ was then used to find the leakage area, $A$, for each leakage rate. A scaling factor was calculated from the ratio of the 4 foot tunnel cross sectional area to the 16 foot tunnel cross sectional area. This resulted in $\frac{\pi r_{16 f t \text { tunel }}{ }^{2}}{\pi r_{4 f t \text { tunnel }}{ }^{2}}=16$. This scaling 
factor was then multiplied by the leakage areas for each leakage rate to obtain a scaled leakage rate for a 16 foot tunnel. The results are shown in Table 4-3.

As shown, the leakage rates were only calculated for the concrete tunnel lining. A plot of the 16 foot tunnel leakage rates and the small scale leakage rates for a plug pressure of 20 psi are shown in Figure 4-5. It should be noted that these estimated leakage rates are for a tunnel that has no other features such as steps, pipes, and rails that could drastically affect leakage rates. The validity of the assumptions and the accuracy of the proposed model can be verified with tests on the 16 foot plug not covered in this work.

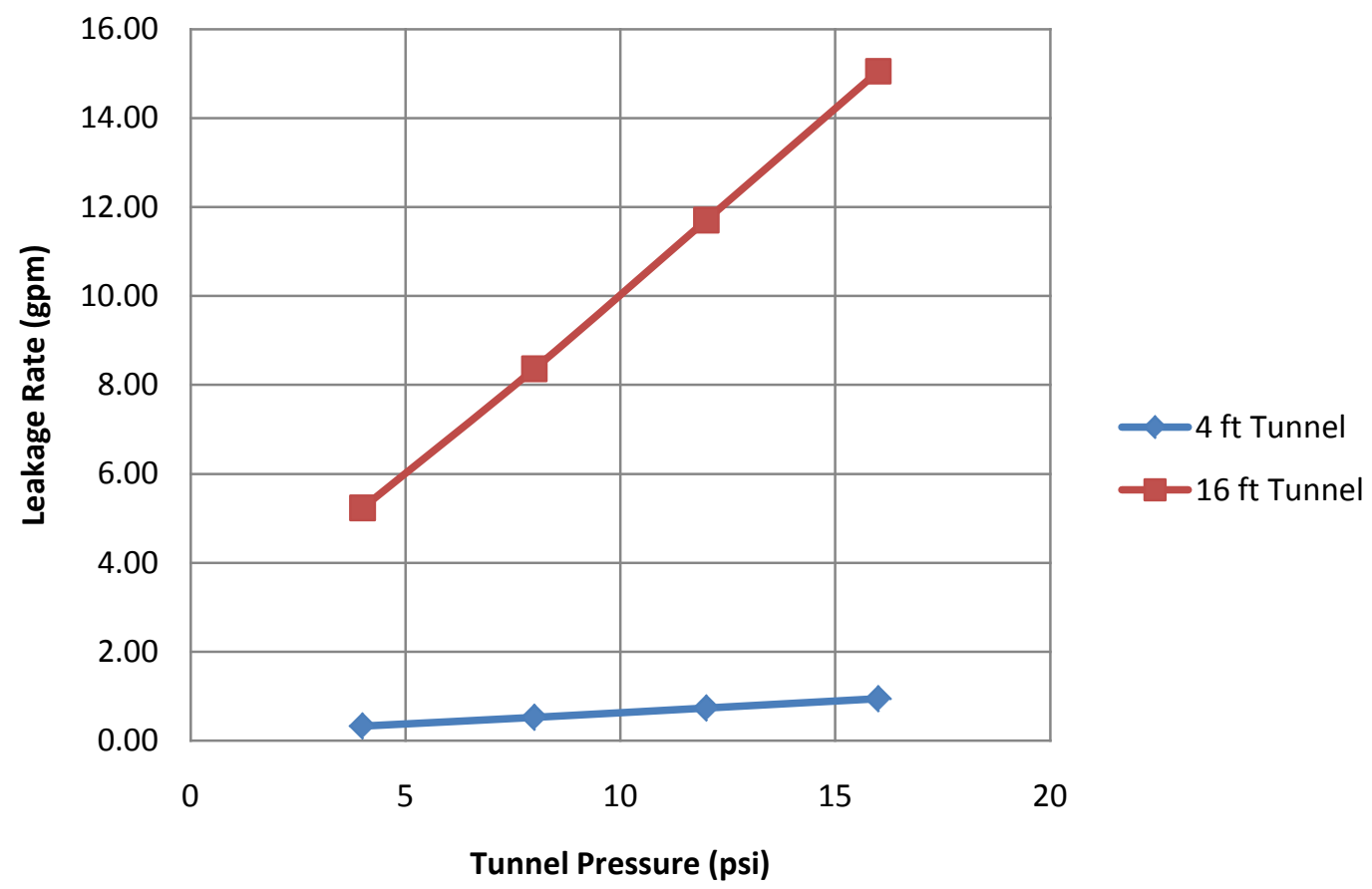

Figure 4-5 Leakage rates from $4 \mathrm{ft}$ and $16 \mathrm{ft}$ tunnels at a plug pressure of $20 \mathrm{psi}$ 
Table 4-3 Estimated leakage rates for a $16 \mathrm{ft}$ diameter tunnel

\begin{tabular}{|c|c|c|c|c|c|c|c|c|}
\hline \multicolumn{9}{|c|}{ Concrete } \\
\hline $\begin{array}{c}\text { Plug } \\
\text { Pressure } \\
\text { (psi) }\end{array}$ & $\begin{array}{c}\text { Tunnel } \\
\text { Pressure } \\
\text { (\% of Plug } \\
\text { Pressure) }\end{array}$ & $\begin{array}{c}\text { Tunnel } \\
\text { Pressure } \\
\text { (psi) }\end{array}$ & $\begin{array}{c}\text { Pressure } \\
\text { Differential } \\
\text { (psi) }\end{array}$ & $\begin{array}{c}\text { Tested } \\
4 \mathrm{ft} \\
\text { Leakage } \\
\text { Rate } \\
\text { (gpm) } \\
\end{array}$ & $\begin{array}{c}\text { Velocity } \\
\text { (ft/s) }\end{array}$ & $\begin{array}{c}\text { Area } \\
\left(\mathrm{ft}^{\wedge} 2\right)\end{array}$ & $\begin{array}{c}16 \mathrm{ft} \\
\text { Scaled } \\
\text { Leakage } \\
\text { Area } \\
\left(\mathrm{ft}^{\wedge} 2\right)\end{array}$ & $\begin{array}{c}16 \mathrm{ft} \\
\text { Leakage } \\
\text { Rate (gpm) }\end{array}$ \\
\hline 5 & 20 & 1 & 4 & 0.21 & 12.18 & $3.87 \mathrm{E}-05$ & $6.20 \mathrm{E}-04$ & 3.39 \\
\hline 5 & 40 & 2 & 3 & 0.31 & 17.23 & 4.04E-05 & $6.47 \mathrm{E}-04$ & 5.00 \\
\hline 5 & 60 & 3 & 2 & 0.41 & 21.10 & 4.36E-05 & $6.98 \mathrm{E}-04$ & 6.61 \\
\hline 5 & 80 & 4 & 1 & 0.54 & 24.37 & 4.94E-05 & 7.90E-04 & 8.64 \\
\hline 10 & 20 & 2 & 8 & 0.25 & 17.23 & $3.20 \mathrm{E}-05$ & $5.12 \mathrm{E}-04$ & 3.96 \\
\hline 10 & 40 & 4 & 6 & 0.39 & 24.37 & 3.59E-05 & $5.74 \mathrm{E}-04$ & 6.27 \\
\hline 10 & 60 & 6 & 4 & 0.28 & 29.84 & $2.09 \mathrm{E}-05$ & $3.34 \mathrm{E}-04$ & 4.48 \\
\hline 10 & 80 & 8 & 2 & 0.68 & 34.46 & $4.38 \mathrm{E}-05$ & $7.00 \mathrm{E}-04$ & 10.83 \\
\hline 15 & 20 & 3 & 12 & 0.23 & 21.10 & $2.41 \mathrm{E}-05$ & $3.86 \mathrm{E}-04$ & 3.65 \\
\hline 15 & 40 & 6 & 9 & 0.48 & 29.84 & $3.59 \mathrm{E}-05$ & $5.74 \mathrm{E}-04$ & 7.69 \\
\hline 15 & 60 & 9 & 6 & 0.65 & 36.55 & $3.98 \mathrm{E}-05$ & $6.37 \mathrm{E}-04$ & 10.46 \\
\hline 15 & 80 & 12 & 3 & 0.84 & 42.21 & $4.41 \mathrm{E}-05$ & $7.05 \mathrm{E}-04$ & 13.36 \\
\hline 20 & 20 & 4 & 16 & 0.33 & 24.37 & $2.99 \mathrm{E}-05$ & 4.79E-04 & 5.23 \\
\hline 20 & 40 & 8 & 12 & 0.52 & 34.46 & $3.38 \mathrm{E}-05$ & $5.41 \mathrm{E}-04$ & 8.36 \\
\hline 20 & 60 & 12 & 8 & 0.73 & 42.21 & $3.86 \mathrm{E}-05$ & $6.18 \mathrm{E}-04$ & 11.71 \\
\hline 20 & 80 & 16 & 4 & 0.94 & 48.74 & 4.30E-05 & $6.88 \mathrm{E}-04$ & 15.05 \\
\hline 25 & 20 & 5 & 20 & 0.35 & 27.24 & $2.86 \mathrm{E}-05$ & $4.58 \mathrm{E}-04$ & 5.60 \\
\hline 25 & 40 & 10 & 15 & 0.58 & 38.53 & 3.34E-05 & $5.35 \mathrm{E}-04$ & 9.25 \\
\hline 25 & 60 & 15 & 10 & 0.79 & 47.19 & $3.75 \mathrm{E}-05$ & $5.99 \mathrm{E}-04$ & 12.69 \\
\hline 25 & 80 & 20 & 5 & 1.04 & 54.49 & $4.24 \mathrm{E}-05$ & $6.79 \mathrm{E}-04$ & 16.60 \\
\hline 30 & 20 & 6 & 24 & 0.37 & 29.84 & $2.79 \mathrm{E}-05$ & $4.46 \mathrm{E}-04$ & 5.97 \\
\hline 30 & 40 & 12 & 18 & 0.61 & 42.21 & $3.20 \mathrm{E}-05$ & $5.11 \mathrm{E}-04$ & 9.69 \\
\hline 30 & 60 & 18 & 12 & 0.84 & 51.69 & 3.62E-05 & $5.79 \mathrm{E}-04$ & 13.44 \\
\hline 30 & 80 & 24 & 6 & 1.10 & 59.69 & 4.11E-05 & $6.58 \mathrm{E}-04$ & 17.62 \\
\hline 35 & 20 & 7 & 28 & 0.39 & 32.24 & $2.66 \mathrm{E}-05$ & $4.26 \mathrm{E}-04$ & 6.17 \\
\hline 35 & 40 & 14 & 21 & 0.63 & 45.59 & $3.10 \mathrm{E}-05$ & 4.96E-04 & 10.15 \\
\hline 35 & 60 & 21 & 14 & 0.87 & 55.83 & $3.47 \mathrm{E}-05$ & $5.56 \mathrm{E}-04$ & 13.92 \\
\hline 35 & 80 & 28 & 7 & 1.16 & 64.47 & 4.01E-05 & $6.42 \mathrm{E}-04$ & 18.58 \\
\hline
\end{tabular}




\section{Chapter 5 - Error Analysis}

\section{1 - Introduction}

Error analysis is defined as the study and evaluation of uncertainly in measurements (25). All measurements made in experiments come with a degree of uncertainty. This analysis estimates the error that could be present within the tests that were performed. There are several types of error calculations that can be used. The technique used in this section is called the propagation of uncertainties method. The general formula used for this method is shown as:

$$
\Delta X=\sqrt{\left(\frac{\partial X}{\partial Y} \Delta Y\right)^{2}+\left(\frac{\partial X}{\partial Z} \Delta Z\right)^{2}+\cdots}
$$

where $\Delta X$ is error of the original function and $\Delta Y$ and $\Delta Z$ are the errors of the respective measured values used to calculated the function (23).

\section{2 - Leakage Error}

To calculate the leakage error, the general equation:

$$
Q=\frac{W}{T}
$$

where $W$ is weight and $T$ is time, was used since this is basic equation used calculate the leakage rate presented in Chapter 4. Then, putting Equation [5-2] in terms of Equation [5-1]:

$$
\Delta Q=\sqrt{\left(\frac{\partial Q}{\partial W} \Delta W\right)^{2}+\left(\frac{\partial Q}{\partial T} \Delta T\right)^{2}}
$$


where $\Delta W$ is the specified scale error of $\pm 0.1 \mathrm{lbs}$ which is given by the manufacturer and $\Delta T$ is an error of 0.3 seconds, which accounts for human reaction time (26). The error in estimating the leakage is:

$$
\Delta Q=\sqrt{\left(\frac{\partial Q}{\partial W} \Delta W\right)^{2}+\left(\frac{\partial Q}{\partial T} \Delta T\right)^{2}}=\sqrt{\left(\frac{1}{T} \Delta W\right)^{2}+\left(\frac{-W}{T^{2}} \Delta T\right)^{2}}
$$

This formula was then combined with the data from each leakage reading. An average error was calculated for each plug and tunnel pressure. The errors for the tunnel pressure at $80 \%$ of the plug pressure were averaged to gain a value of error for each of the three tunnel linings. These errors are shown in conjunction with the $80 \%$ plug pressure leakage values in Table 5-1.

Table 5-1 Leakage errors for each tunnel lining

\begin{tabular}{|c|c|c|c|}
\hline Tunnel Lining & Concrete & Neoprene & Vinyl \\
\hline $\begin{array}{c}\text { Average Leakage at } \\
\mathbf{8 0 \%} \text { of Plug } \\
\text { Pressure }\end{array}$ & 0.90 & 1.09 & 0.61 \\
\hline $\begin{array}{c}\text { Average Error at } \\
\mathbf{8 0 \%} \text { of Plug } \\
\text { Pressure } \\
\text { (+/-gpm) }\end{array}$ & $1.13 \mathrm{E}-03$ & $1.42 \mathrm{E}-03$ & $1.30 \mathrm{E}-03$ \\
\hline $\begin{array}{c}\text { Error Percentage } \\
\text { (+/- \%) }\end{array}$ & $0.13 \%$ & $0.13 \%$ & $0.21 \%$ \\
\hline
\end{tabular}

The tunnel pressure values that were $80 \%$ of the plug pressure provided the highest leakage rates and the largest error values. The vinyl had the largest error at $+/-0.21 \%$.

\section{3 - Slippage Error}

To calculate the slippage error, Equation [3-16] from Chapter 3 was used. This equation was simplified to: 


$$
f=\frac{P_{A T P} A_{T}}{P_{A P P} A_{P}}
$$

which is the ratio between the applied force from the tunnel and the applied force of the plug as explained in Chapter 3. Then, the error for the friction can be expressed in terms of Equation [5-1] as:

$$
\Delta f=\sqrt{\left(\frac{\partial f}{\partial P_{A T P}} \Delta P_{A T P}\right)^{2}+\left(\frac{\partial f}{\partial A_{T}} \Delta A_{T}\right)^{2}+\left(\frac{\partial f}{\partial P_{A P P}} \Delta P_{A P P}\right)^{2}+\left(\frac{\partial f}{\partial A_{P}} \Delta A_{P}\right)^{2}}
$$

where $\Delta P_{A T P}$ and $\Delta P_{A P P}$ are the errors of the pressure transducers which are accurate to $\pm 0.25 \%$ of $0-50$ psi. This gives and error of $\pm 0.125 \mathrm{psi}$ for each pressure transducer. Both $\Delta A_{T}$ and $\Delta A_{P}$ were limited by the resolution of the measuring device resulting in a value of \pm 0.0625 inches. Since $A_{T}$ and $A_{P}$ are equal because of the constraints of the tunnel, the error is then written as:

$$
\Delta f=\sqrt{\left(\frac{1}{P_{A P P}} \Delta P_{A T P}\right)^{2}+\left(\frac{P_{A T P}}{P_{A P P} A_{P}} \Delta A_{T}\right)^{2}+\left(\frac{-P_{A T P}}{P_{A P P}^{2}} \Delta P_{A P P}\right)^{2}+\left(\frac{-P_{A T P}}{P_{A P P} A_{P}} \Delta A_{P}\right)^{2}}
$$

Equation [5-7] was then used to calculate an error for each of the friction coefficients. An average was then found for each tunnel lining. The results are shown in Table 5-2.

Table 5-2 Friction coefficient error for each tunnel lining

\begin{tabular}{|c|c|c|c|}
\hline Tunnel Lining & Concrete & Neoprene & Vinyl \\
\hline $\begin{array}{c}\text { Average Friction } \\
\text { Coefficient }\end{array}$ & 0.172 & 0.154 & 0.176 \\
\hline $\begin{array}{c}\text { Average Error } \\
\text { (+/-f) }\end{array}$ & 0.016 & 0.018 & 0.017 \\
\hline $\begin{array}{c}\text { Error Percentage } \\
\text { (+/- f) }\end{array}$ & $9.30 \%$ & $11.69 \%$ & $9.66 \%$ \\
\hline
\end{tabular}


Both the concrete and vinyl errors are less than $+/-10 \%$. Only the neoprene showed a larger error at $+/-11.69 \%$. 


\section{Chapter 6 - Conclusions and Future Work}

\section{1 - Leakage Testing Conclusions}

The leakage testing was performed by inflating a plug within a small scale tunnel with a specified pressure of water. A volume of water was then pressurized behind the plug and the flow rate coming around the plug was then measured. The testing was performed for seven different plug pressures on three different tunnel linings with the tunnel pressures varying by a percentage of the plug pressure. These tests showed that a compressible material like neoprene was not ideal in preventing leakage as it allowed the largest average flow rate of $1.09 \mathrm{gpm}$ while the concrete and vinyl had values of $0.90 \mathrm{gpm}$ and $0.61 \mathrm{gpm}$ respectively at a tunnel pressure of $80 \%$ of the plug pressure.

Several trends were also noted in the leakage results. The most important trends show that as the pressure differential between the plug and tunnel increased, the leakage rate decreased; it was also shown that the higher plug pressures (which in turn had higher tunnel pressures) also produced higher leakage rates.

\section{2 - Slippage Testing Conclusions}

Friction coefficients were calculated by the slippage testing performed with the plug and tunnel pressure differentials. The plug was inflated to as close to possible to several predefined pressures. The tunnel pressure was then brought as close as possible to the plug pressure until slippage occurred. The difference in the tunnel and plug pressures were then used to find the friction coefficient for three different tunnel linings that were tested. 
The vinyl tunnel lining produced the largest average friction value of 0.176 . The lowest average value was the neoprene lining with 0.154 . The concrete was very close to the vinyl with an average value of 0.172 . It was also found that as the plug pressure increased, the pressure differential at which slippage occurred also increased. The friction coefficient was also found to have an inverse relationship with the leakage rate. As the leakage rate increased, the friction coefficient decreased, meaning that slippage occurred easier when the leakage rate was higher. This was most likely due to the increased flow of water around the plug creating less surface area for the plug to contact the tunnel walls.

\section{3 - Future Work}

One of the most important areas for future work is to expand the number of tunnel linings for both the leakage and slippage testing. These different surfaces would give a wider variety of friction coefficients and leakage trends that could be associated for any tunnel. Various concrete surfaces with a different roughness would be especially valuable as that is the material used in most tunnels.

Most tunnel sections always contain some features such as side steps, pipes, track rails, or other miscellaneous items. Additional testing for both leakage and slippage with these features present in the tunnel would be very helpful. By performing these small scale tests using scaled features, a much more accurate measurement of leakage rate could be obtained since the plug is not capable of completely sealing around these items. The friction coefficient calculated from the slippage data would also provide more accurate results due to the decreased surface area that may not be touching the tunnel walls. 
It was observed in the leakage tests that the plug did not always inflate the exact same way within the tunnel. This was due to the plug being slightly oversized to make sure it was always in contact with the tunnel. Some tests had to be stopped and restarted from initial inflation so that the orientation could be adjusted. These stoppages indicated that there was a possibility that the plug might have larger wrinkles allowing more leakage around the plug. More trials from initial inflation would help to see if this was indeed a problem. A larger number of trials would give a more accurate representation of the average leakage across the pressure ranges.

Another method of measuring the leakage rate would also be preferred for future testing. The method used in these tests was slow and time consuming requiring post processing and other calculations. A flow meter able to be connected to the tunnel would make the data collection process quicker and easier so a larger number of trials could be performed.

A more accurate way of measuring when the plug moves during the slippage tests is also an item of future work. This could be accomplished by using laser sensors to measure displacement to gain a better understanding of how the plug slides within the tunnel. Due to the efforts to minimize plug damage, the trials for the friction data had to be very limited. For future design evaluations, more data for this area is certainly needed to confirm plug length depending on the friction surface of the tunnel. 


\section{References}

1. L'Garde. Inflatable Space Structures. Cited: March 23, 2011.

http://www.lgarde.com/index.htm.

2. Cadogan, D., Sandy, C. and Grahne, M. Development and Evaluation of the Mars Pathffinder Inflatable Airbag Landing System. 49th International Astronautical Congress. 1998.

3. Cadogan, David, et al. Intelligent Flexible Materials for Deployable Space Structures (InFlex). ILC Dover LP. 2006.

4. Hanlon, Mike. Inflatable composite structures enable lightweight transportable buildings. 2005, http://www.gizmag.com/go/4017/.

5. Mills, Warwick. Inflatable Systems Military and Defense Applications. Cited Online: March 23, 2011. http://www.warwickmills.com/Inflatables/Inflatable-Systems.aspx.

6. Dover, ILC. Lighter Than Air Structures. Cited Online: March 23, 2011. http://www.ilcdover.com/Lighter-Than-Air-Structures/.

7. Humphrey, Hubert H. About the Metrodome. Cited Online: March 23, 2011. http://www.msfc.com/about.cfm.

8. Syracuse University Athletics. History of the Carrier Dome. Cited Online: March 23, 2011. http://suathletics.syr.edu/sports/2009/2/3/GEN_0203090820.aspx.

9. Inflatable Plug Bag for Testing Plumbing. Patent. 1949. 
10. Petersen. Peterson Companies. Cited Online: March 23, 2011.

http://www.pipeplug.com/aboutus.html.

11. Inouye, Randall R. The Great Chicago Flood of 1992. 1992, Civil EngineeringASCE, Vol. 62, pp. 52-55.

12. Inflatable Apparatus for Sealing a Pipeline. Patent. 1999.

13. Petersen. Miscellaneous Line Stop Case Studies. Cited Online: March 23, 2011. http://www.pipeplug.com/misc_line_stop_case_studies.html.

14. Firetactics. KINGS CROSS FIRE - LONDON 2007 from the LONDON FIRE JOURNAL. Cited Online: March 23, 2011.

http://www.firetactics.com/KINGSCROSS.htm.

15. Lindstrand. Inflatable Tunnel Plugs. Cited Online: March 23, 2011.

http://www.lindstrandtech.com/innovation_centre.html.

16. Petersen. An Inflatable Tunnel Seal Stops Flooding of World's Largest Undeveloped Uranium Mine. Cited Online: March 23, 2011.

http://www.pipeplug.com/case_study_camecos_cigar_lake_flooding_remediation.html.

17. Parker, Doug J. Transit Cooperative Research Program Synthesis 80 Transit Security Update. 2008.

18. TSA. TSA Collaborates on Resilient Tunnel Project. [Online] [Cited: March 23, 2011.] http://www.tsa.gov/weekly/062909.shtm. 
19. Going Underground: Homeland Security Works on Tool to Prevent Tunnel Disasters. Fox News. [Online] September 5, 2008. [Cited: March 23, 2011.] http://www.foxnews.com/story/0,2933,417461,00.html.

20. Weadon, Timothy L. Master's Thesis. Long Term Loading and Additional Material Properties of Vectran Fabric for Inflatable Structure Applications. West Virginia University. 2010.

21. International, ASTM. Standard Test Method for Static and Kinetic Coefficients of Friction of Plastic Film and Sheeting. ASTM D1894.

22. Molina, Juan C. Master's Thesis. Mechanical Characterization of Fabrics for Inflatable Structures. West Virginia University. 2008.

23. ICRI (International Concrete Repair Institute). Guideline for Selecting and Specifying Concrete Surface Preparation for Sealers, Coatings, and Polymer Overlays. 1997.

24. Young, Donald F., et al. A Brief Introduction to Fluid Mechanics. [ed.] Lea Radick. 4th. s.I. : John Wiley \& Sons, Inc., 2007.

25. Taylor, John R. An Introduction to Error Analysis: The Study of Uncertainties in Physical Measurements. [ed.] 2nd. s.I. : University Science Books, 1997.

26. Kosinski, Robert J. A Literature Review on Reaction Time. [Online] September 2010. [Cited: April 8, 2011.] http://biae.clemson.edu/bpc/bp/Lab/110/reaction.htm\#Type\%20of\%20Stimulus. 


\section{Appendix A - Pressure Transducer Documentation}

\section{ALL STAINLESS STEEL TRANSDUCER MULTIMEDIA COMPATIBILITY HIGH-PERFORMANCE SLILCON TECHNOLOGY}

\section{PX309 Series \\ Gage/Absolute Pressure \\ O to 5 Vdc Output \\ $0-1$ to $0-10,000 \mathrm{psi}$ \\ $0-70$ mbar to 0-690 bar}

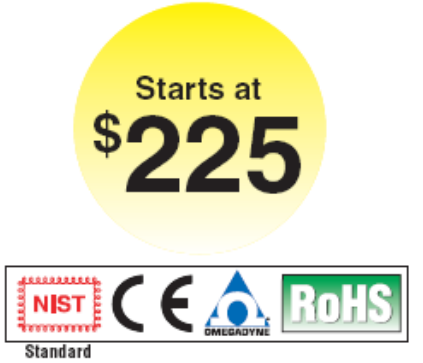

1, 2, and 5 psi Low Pressure Ranges

$\checkmark$ Rugged, Solid State Design

$\checkmark$ All Stainless Steel

High Stability, Low Drift

$0.25 \%$ Accuracy

$\checkmark$ RoHS Compliant

$\checkmark$ IP65 Protection Class

\section{SPECIFICATIONS}

Excitation: 9 to $30 \mathrm{Vdc}(<10 \mathrm{~mA})$ (reverse polarity and overvoltage protected)

Output: 0 to $5 \mathrm{Vdc}$

Accuracy: $\pm 0.25 \%$ FS BSL at $25^{\circ} \mathrm{C}$

includes linearity, hysteresis and

repeatability

Zero Offset: $\pm 2 \%$ FSO

$\pm 4 \%$ for 1 and 2 psi ranges

Span Setting: $\pm 2 \%$ FSO;

$\pm 4 \%$ for 1 and 2 psi ranges

Total Error Band: $\pm 2 \% \mathrm{FSO}$, includes

linearity, hysteresis, repeatability,

thermal hysteresis and

thermal errors (except $1 \mathrm{psi}= \pm 4.5 \%$

and $2 \mathrm{psi}= \pm 3 \%$ )

Long-Term Stablilty (1 Year):

$\pm 0.25 \%$ typical

Typical Life: 10 million cycles

Operating Temperature: -40 to $85^{\circ} \mathrm{C}$

$\left(-40\right.$ to $\left.185^{\circ} \mathrm{F}\right)$

Compensated Temperature

$>5$ psI Range: -20 to $85^{\circ} \mathrm{C}$ ( -4 to $\left.185^{\circ} \mathrm{F}\right)$

$\leq 5$ psl Range: 0 to $50^{\circ} \mathrm{C}\left(32\right.$ to $\left.122^{\circ} \mathrm{F}\right)$

Proof Pressure:

psla and $\leq 50$ psig: $3 x$ capacity

or 20 psi, whichever is greater

$\geq 100$ psi: $2 x$ capacity

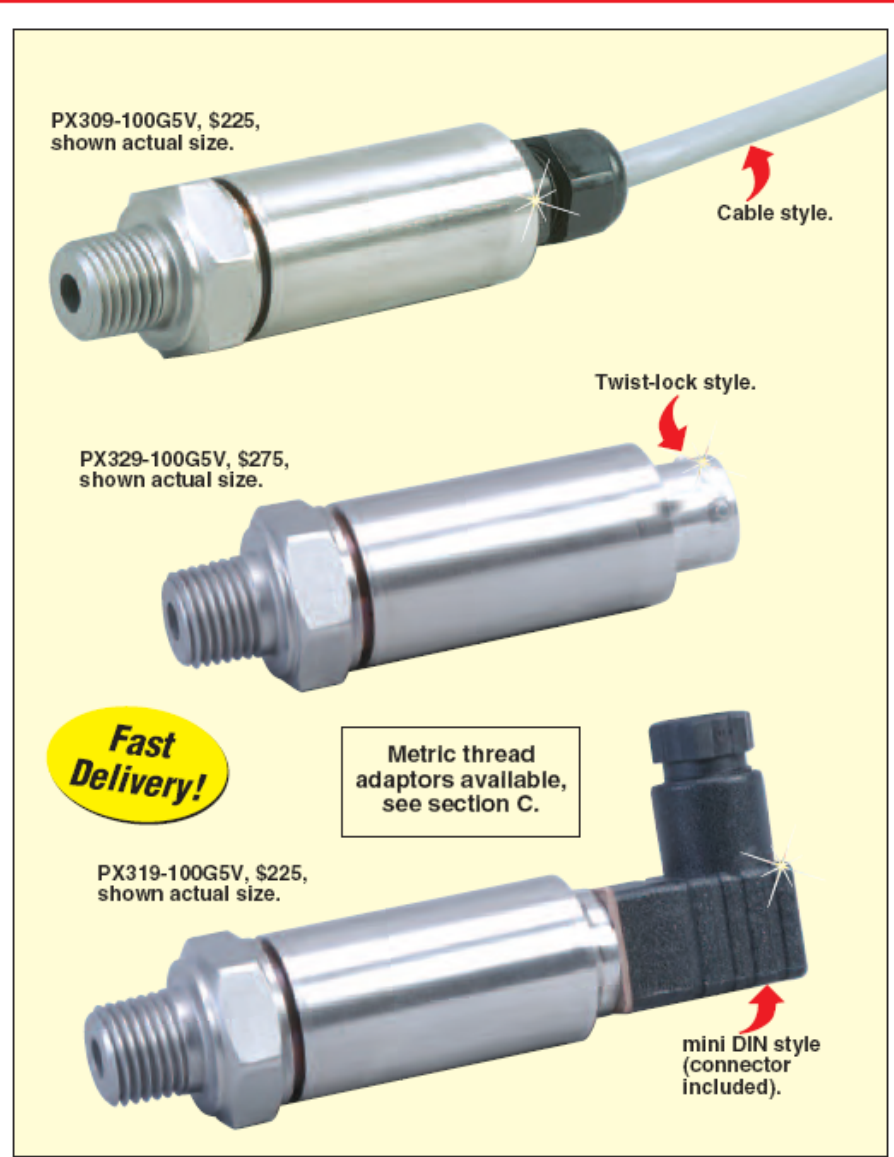

Burst Pressure: $5 x$ capacity or $25 \mathrm{psi}$, whichever is greater

Response Time: $<1 \mathrm{~ms}$

Shock: $50 \mathrm{~g}, 11$ ms half-sine shock

Vlbration: $\pm 20 \mathrm{~g}$

Wetted Parts: 316 SS for all psia

ranges and 1 to 50 psig; $17-4 \mathrm{PH}$ SS for

ranges 100 to $10,000 \mathrm{psig}$

Pressure Port: $1 / 4-18$ MNPT

Electrical Connections:

PX309: 1.5 m (5') 3-conductor cable

PX319: mini DIN connector with

mating connector included

PX329: Twist-lock connector,

mating connector sold separately

(PT06V-10-6S)

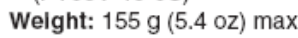

B-96
Note: Units 100 psig and above may be subjected to vacuum on the pressure

For alternative performance specifications contact Engineering.

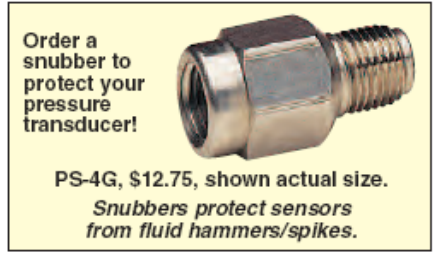
port without damage

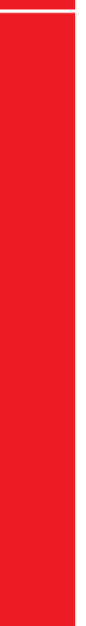




\section{Appendix B - Scale Documentation}

DEFENDER ${ }^{\text {TM }} 3000$

The best selling modular scale for basic industrial needs

Defender 3000 Series Bench Scales are easy to use, reliable and affordable scales that are ideal for general weighing and simple counting applications in production, packaging, and shipping and receiving areas

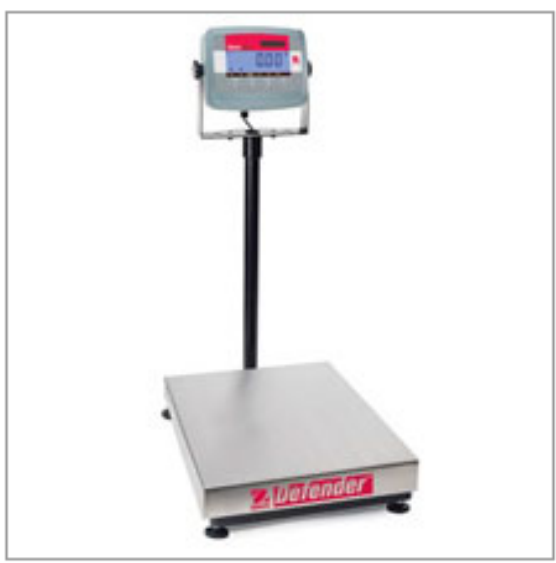

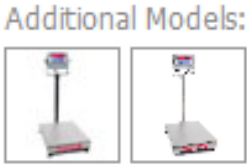

- Sturdy tubular platform design with high quality 304 stainless steel top plate

- Approved models

- Internal rechargeable battery

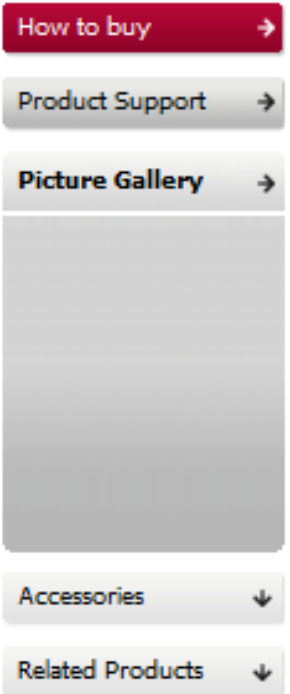

Related Products

\section{APPLICATION MODES

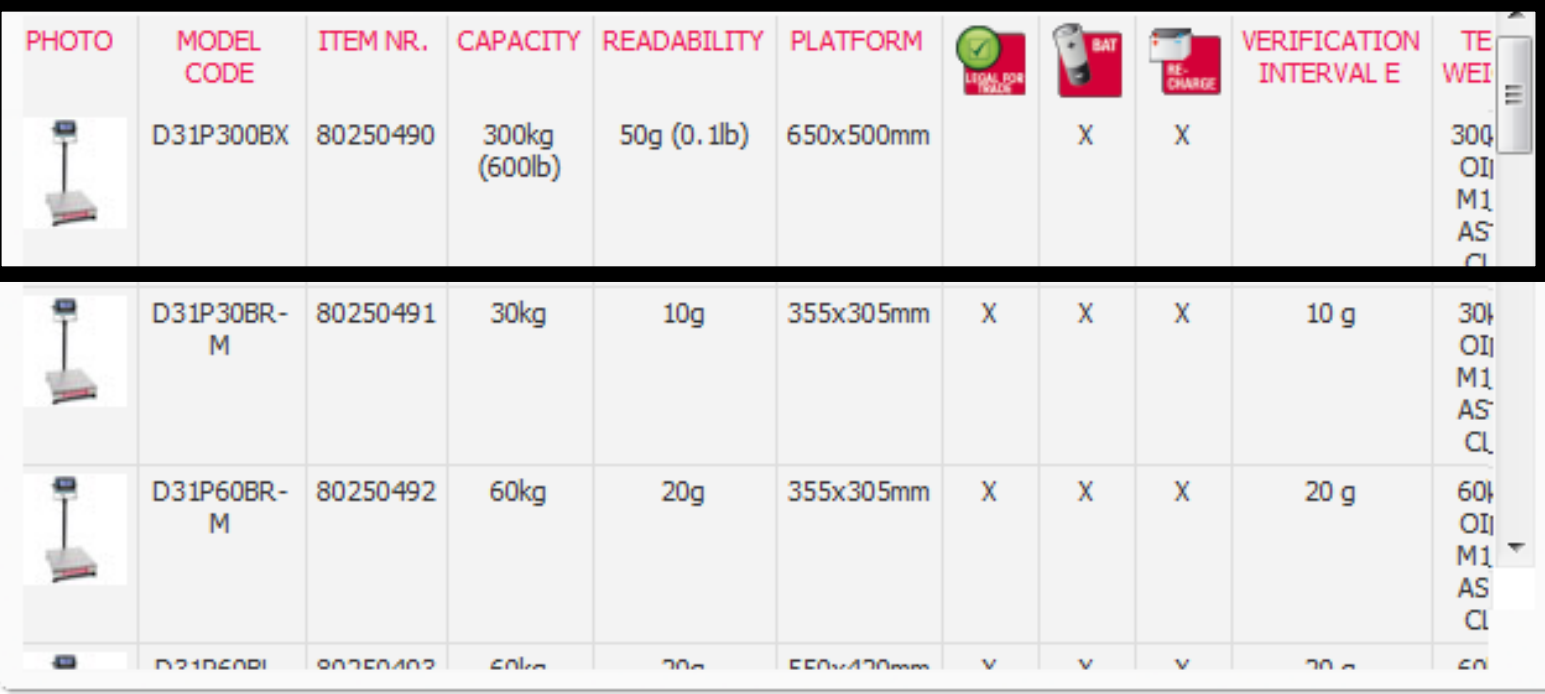




\section{Appendix C - Pump Curve Documentation}

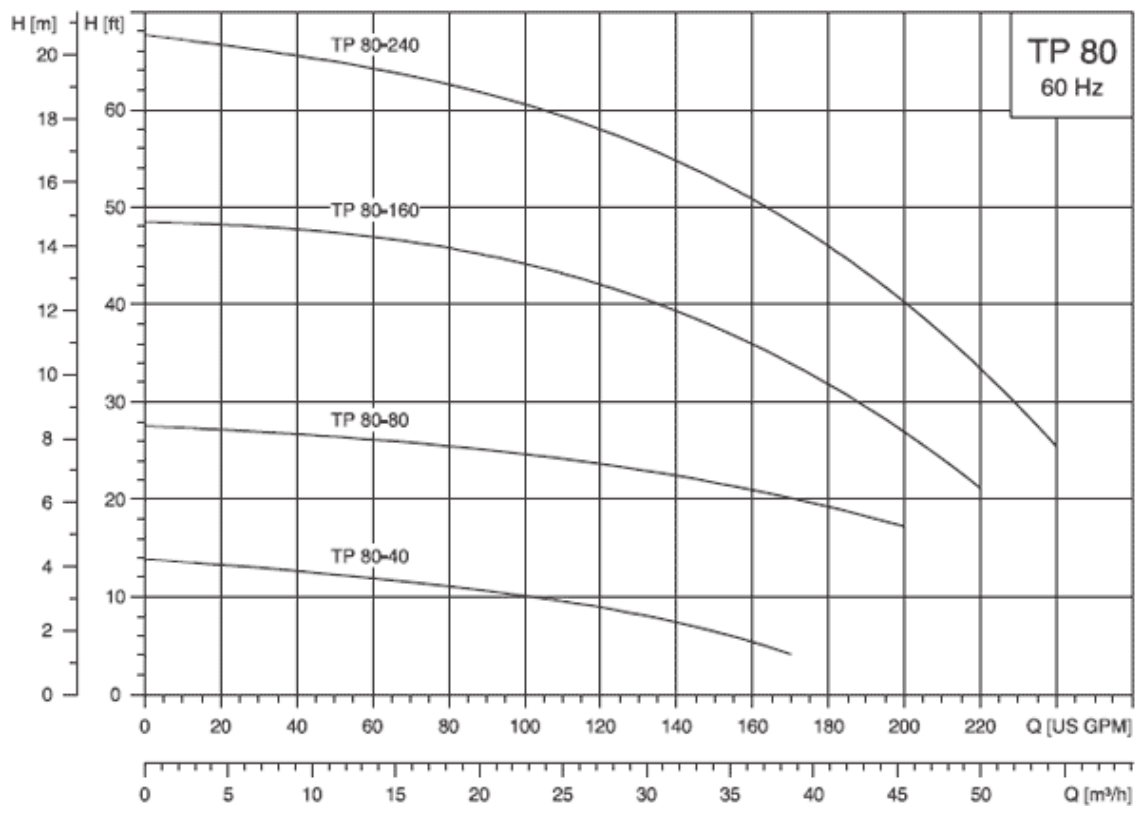

High flow, low pressure pump curve

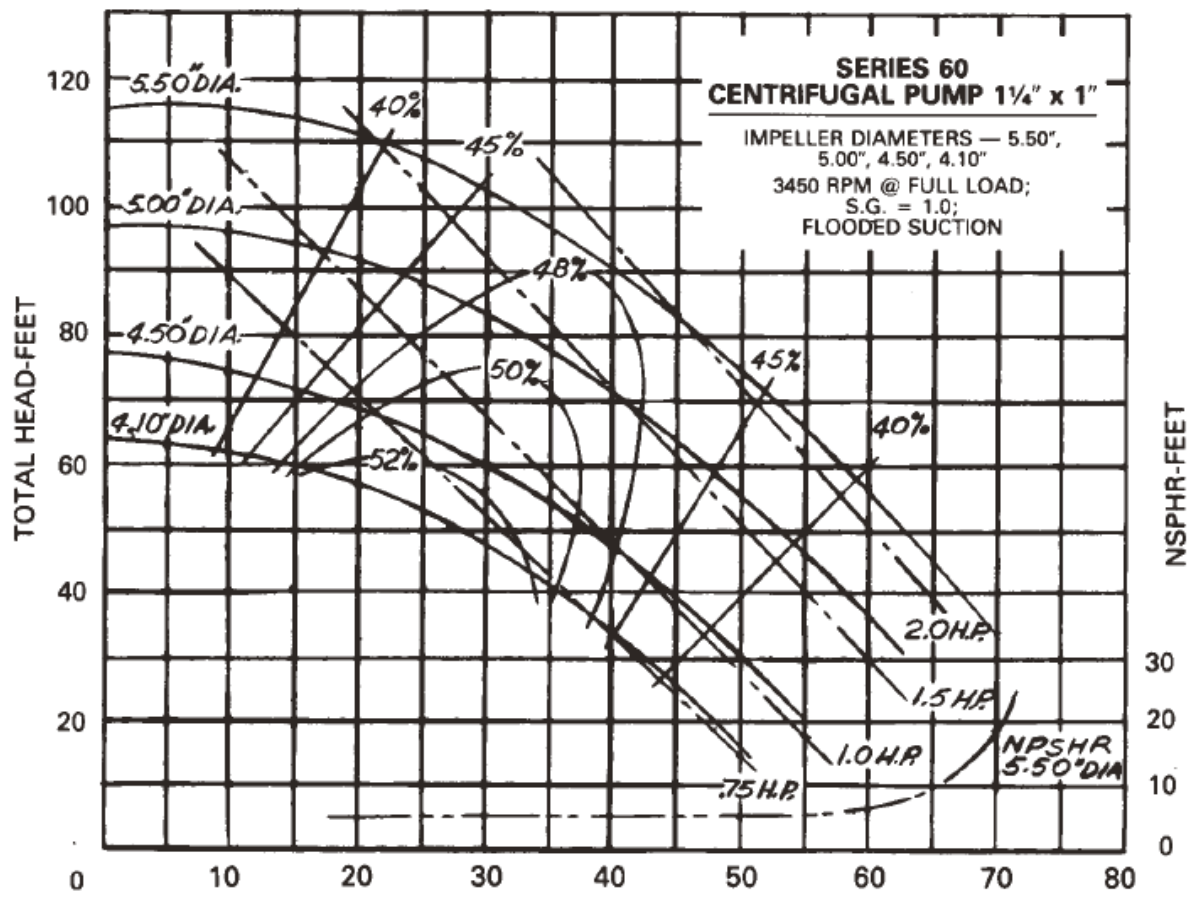

Low flow, high pressure pump curve 


\section{Appendix D - Neoprene Specifications}

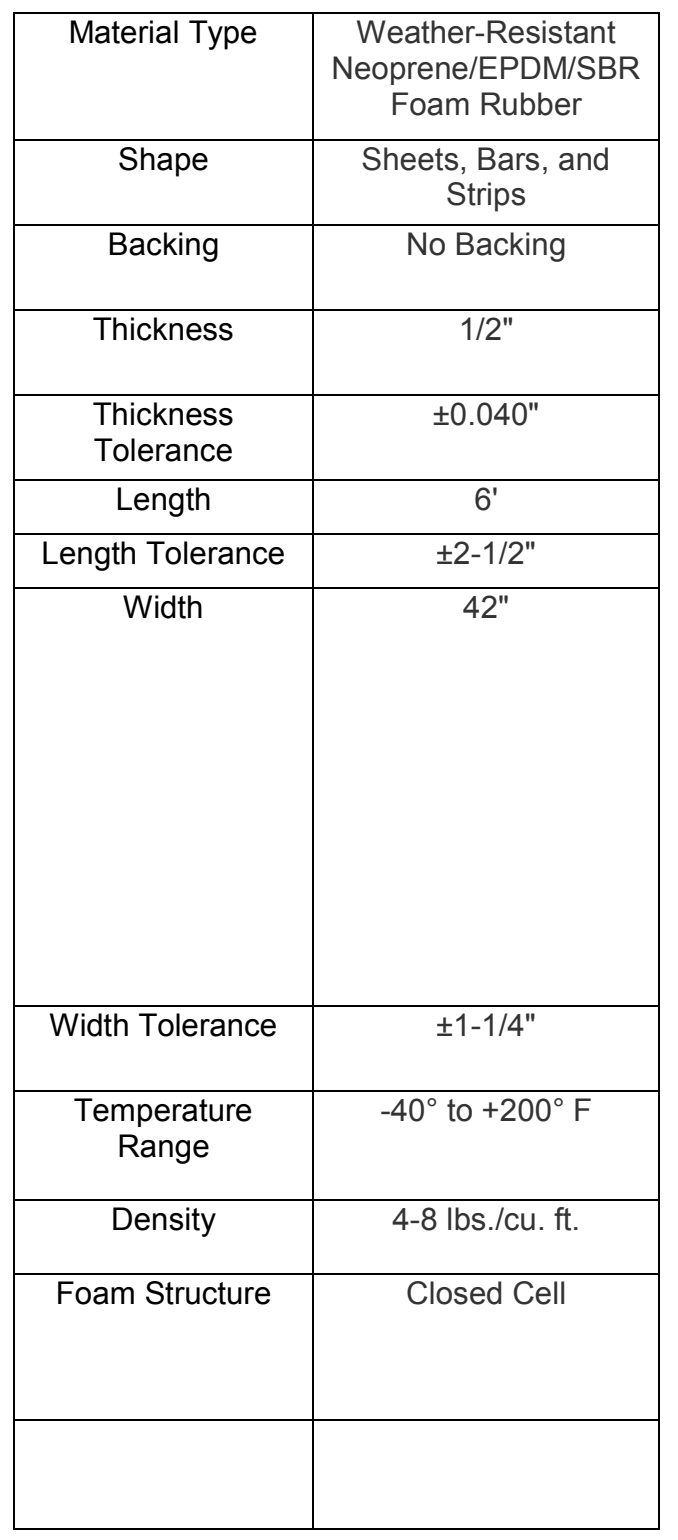

\begin{tabular}{|c|c|}
\hline Texture Type & Fine Cell \\
\hline $\begin{array}{c}\text { Foam } \\
\text { Firmness }\end{array}$ & Extra Soft \\
\hline Firmness, psi & $\begin{array}{c}2-5(25 \% \\
\text { Deflection) }\end{array}$ \\
\hline $\begin{array}{c}\text { Compression } \\
\text { Recovery }\end{array}$ & Fair \\
\hline Color & Black \\
\hline Finish & Textured \\
\hline Tolerance & Standard \\
\hline $\begin{array}{c}\text { Specifications } \\
\text { Met }\end{array}$ & $\begin{array}{c}\text { American } \\
\text { Society for } \\
\text { Testing and } \\
\text { Materials } \\
\text { (ASTM), } \\
\text { Military } \\
\text { Specifications } \\
\text { (MIL), } \\
\text { Underwriters } \\
\text { Laboratories } \\
\text { (UL) }\end{array}$ \\
\hline $\begin{array}{c}\text { ASTM } \\
\text { Specification }\end{array}$ & ASTM D1056 \\
\hline $\begin{array}{c}\text { MIL } \\
\text { Specification }\end{array}$ & $\begin{array}{c}\text { MIL-C-3133C } \\
\text { MIL-STD- } \\
670 B\end{array}$ \\
\hline $\begin{array}{c}\text { UL } \\
\text { Specification }\end{array}$ & UL 94HF1 \\
\hline Properties & $\begin{array}{c}\text { Weather } \\
\text { Resistant, } \\
\text { Flame } \\
\text { Resistant }\end{array}$ \\
\hline Notes & $\begin{array}{c}\text { Material does } \\
\text { not have a } \\
\text { skin }\end{array}$ \\
\hline
\end{tabular}




\section{Appendix E - Slippage Data}

\section{Concrete, 5 psi Plug Pressure}
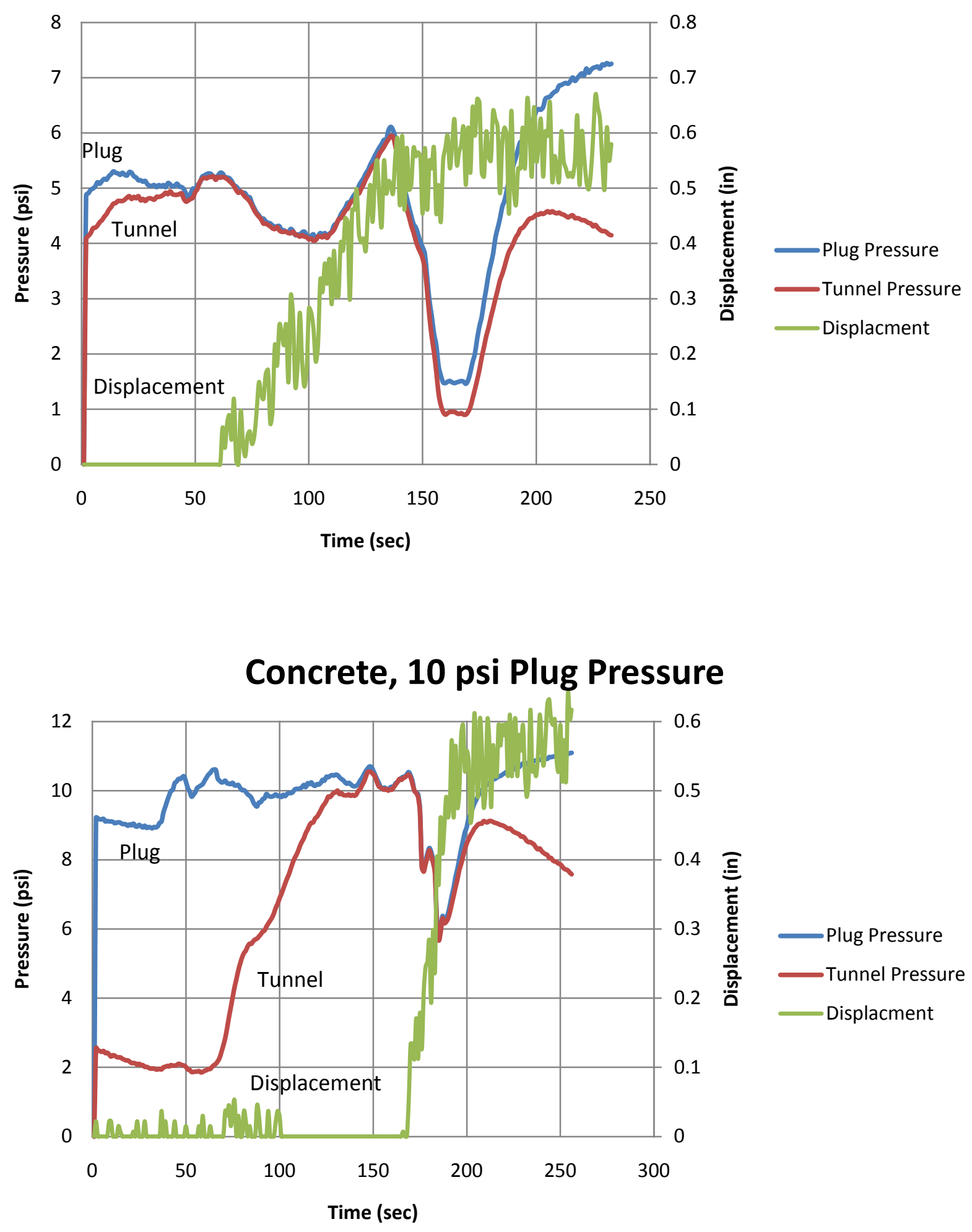
Concrete, 15 psi Plug Pressure

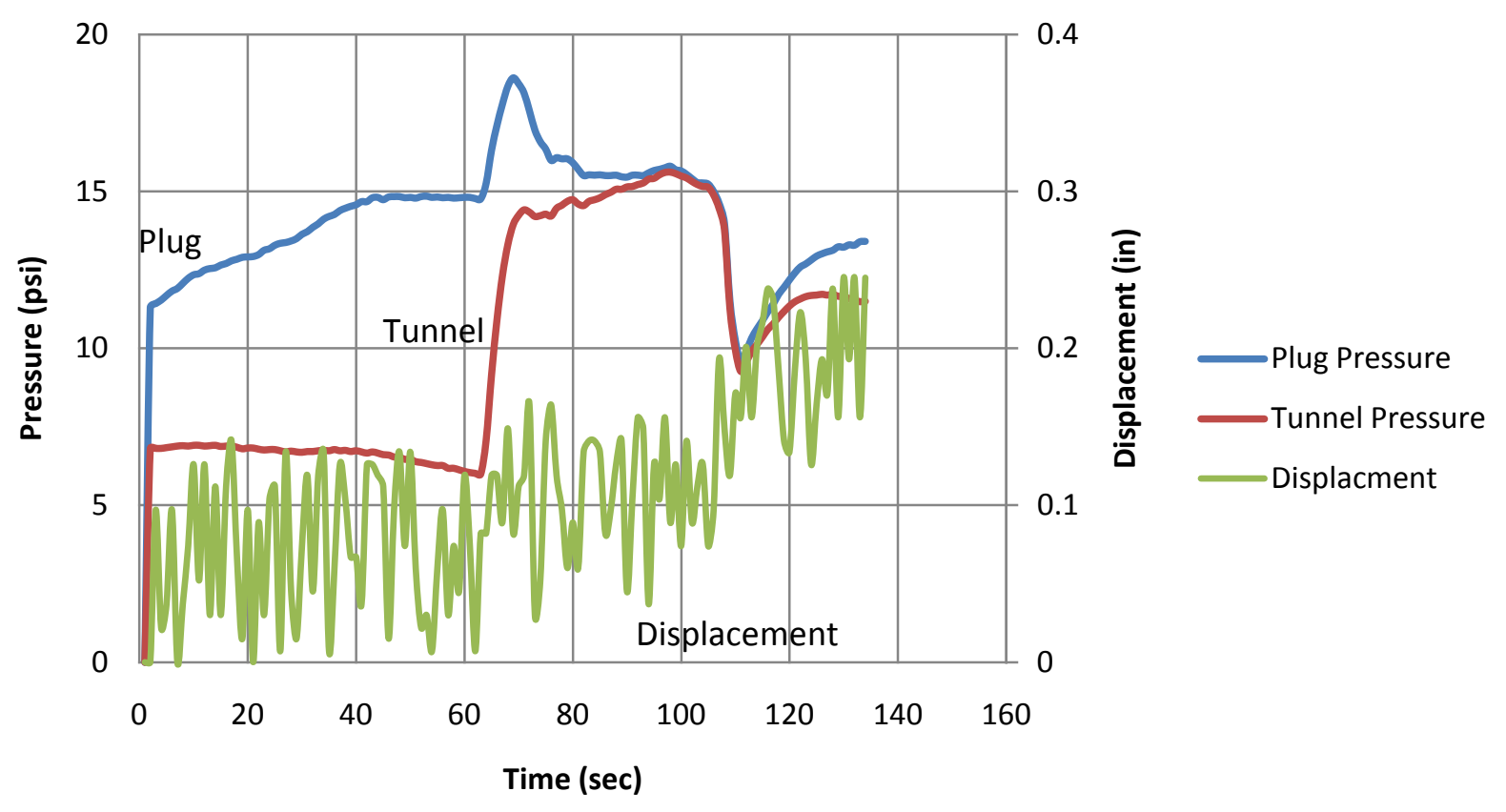

\section{Concrete, 20 psi Plug Pressure}

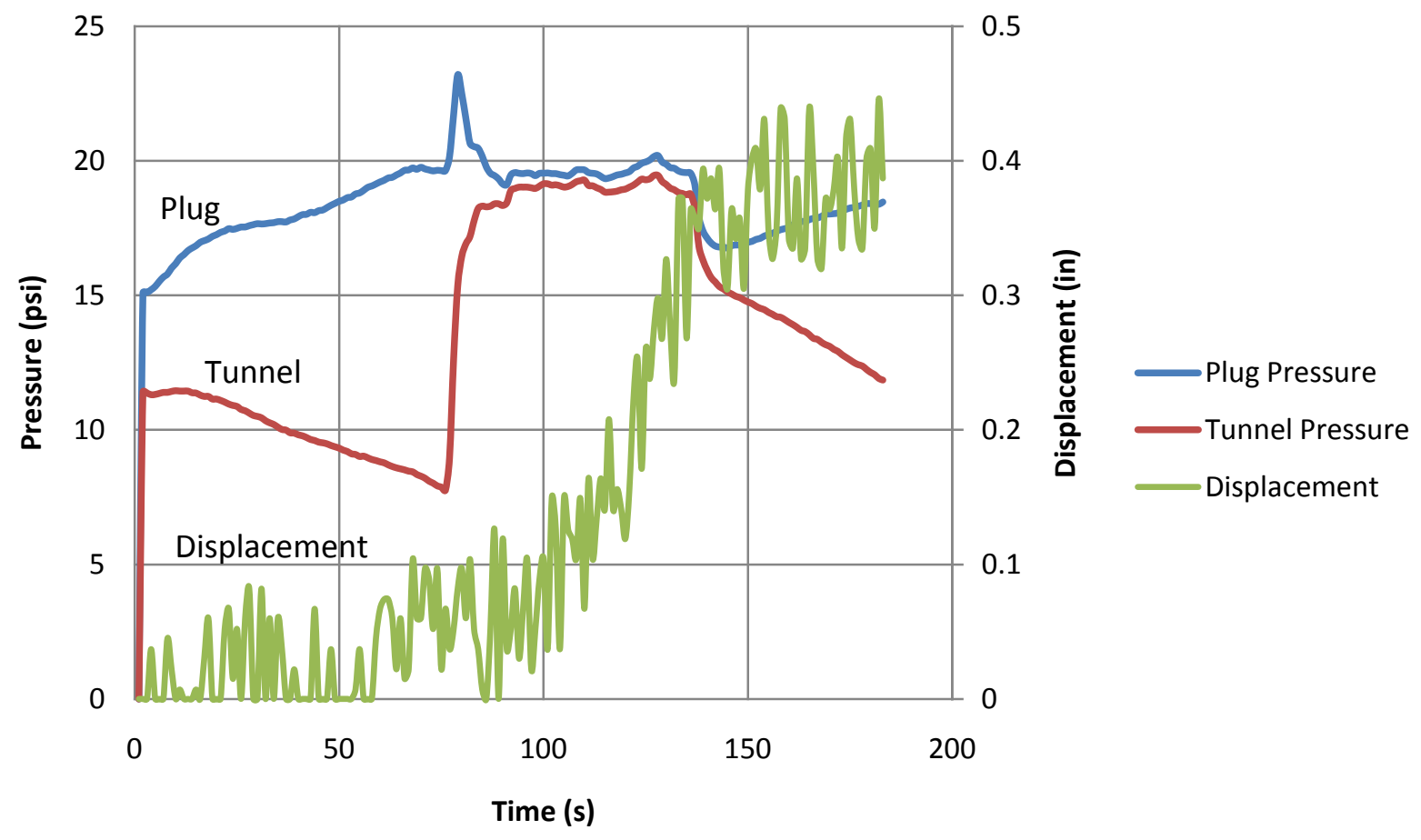


Concrete, 25 psi Plug Pressure

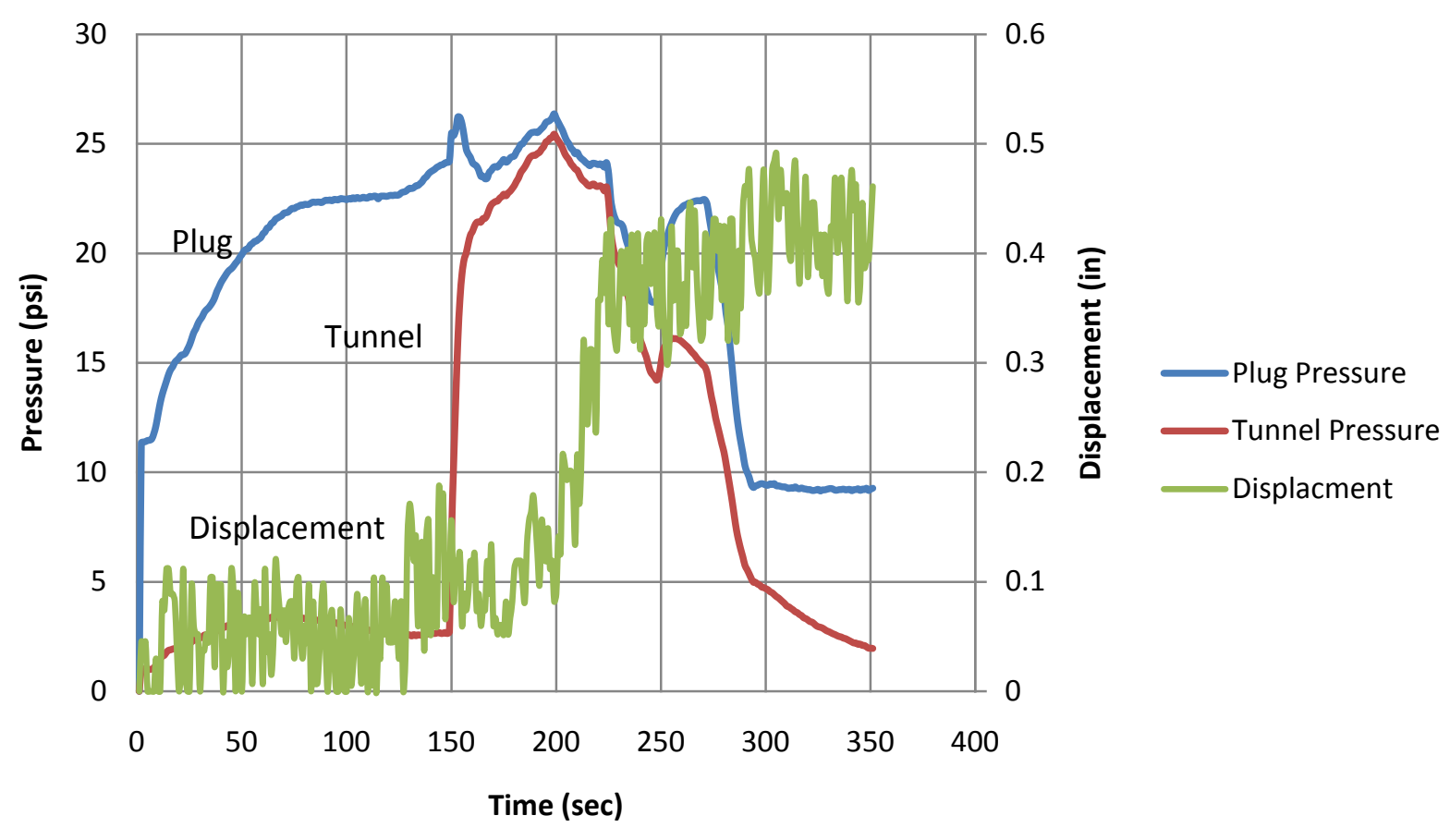

Neoprene, 5 psi Plug Pressure

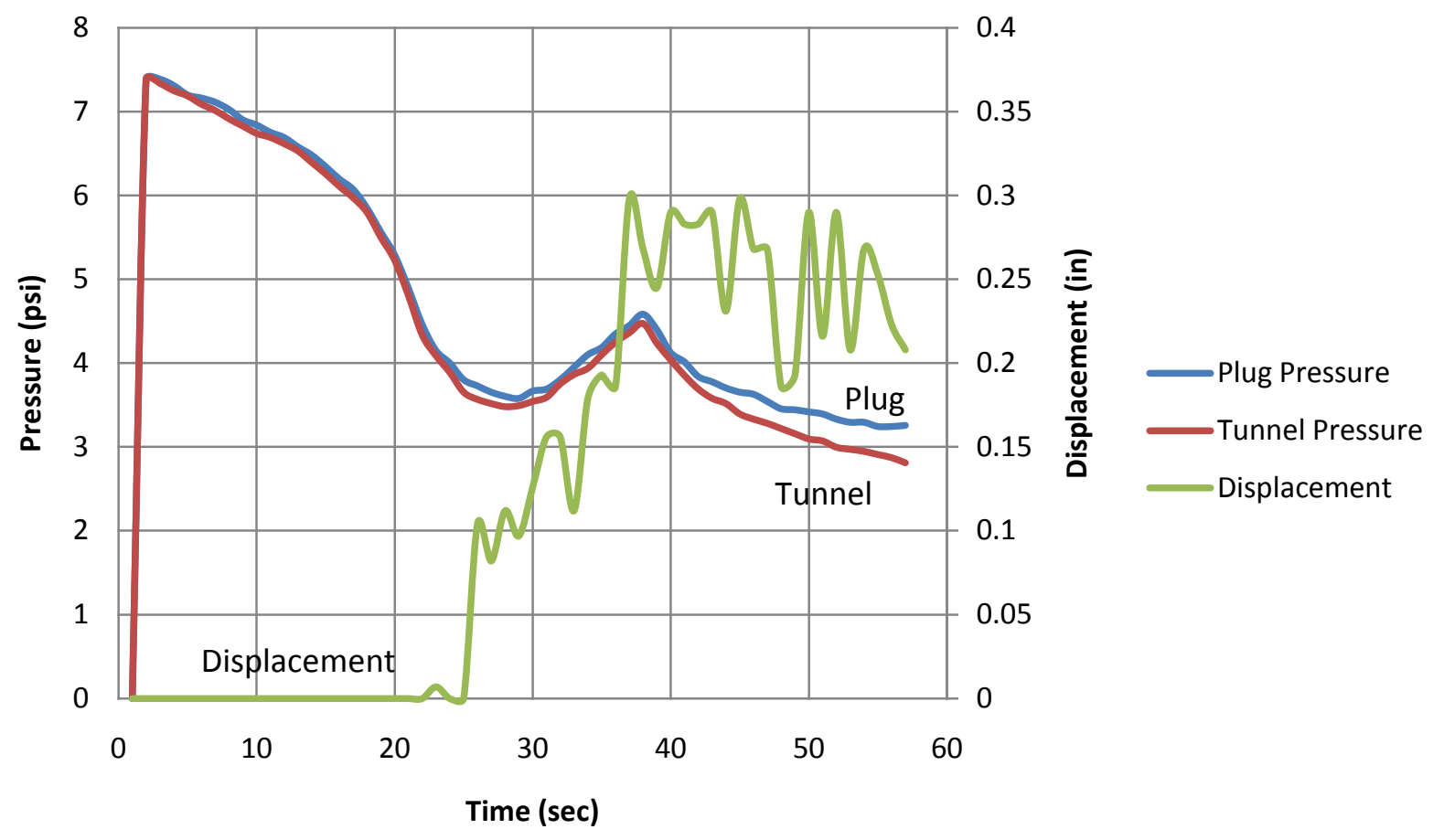


Neoprene, 10 psi Plug Pressure

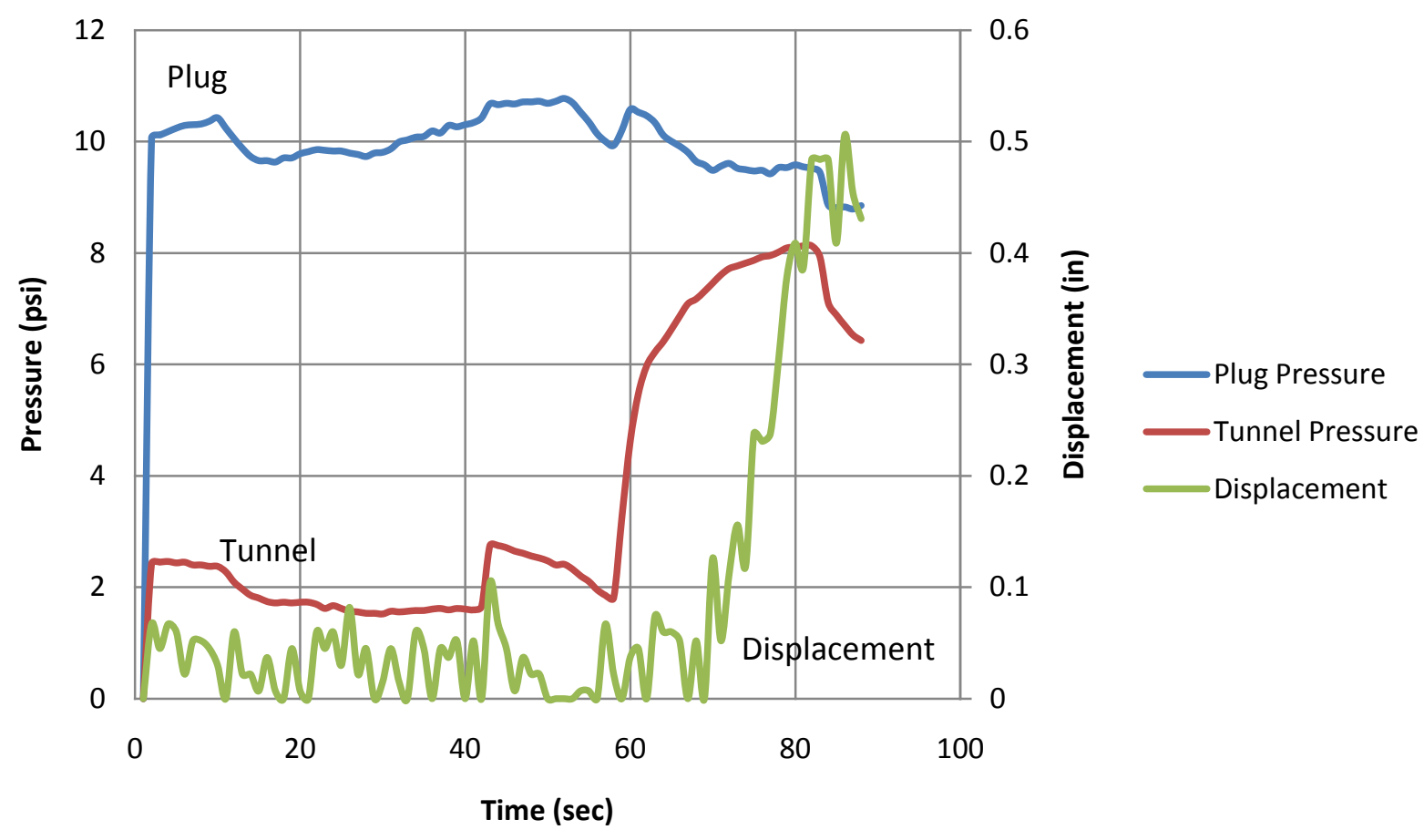

Neoprene, 15 psi Plug Pressure

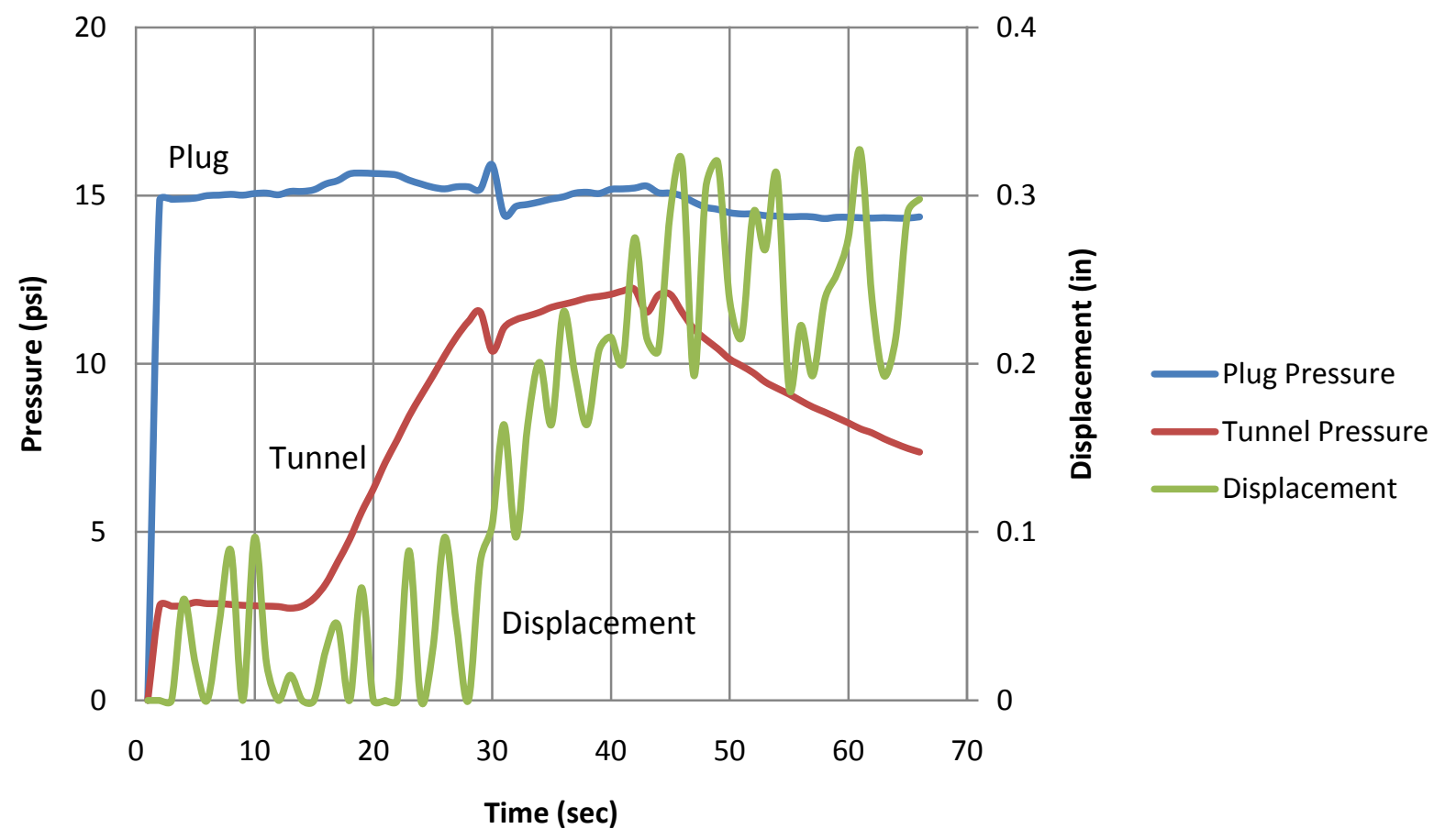


Neoprene, 20 psi Plug Pressure

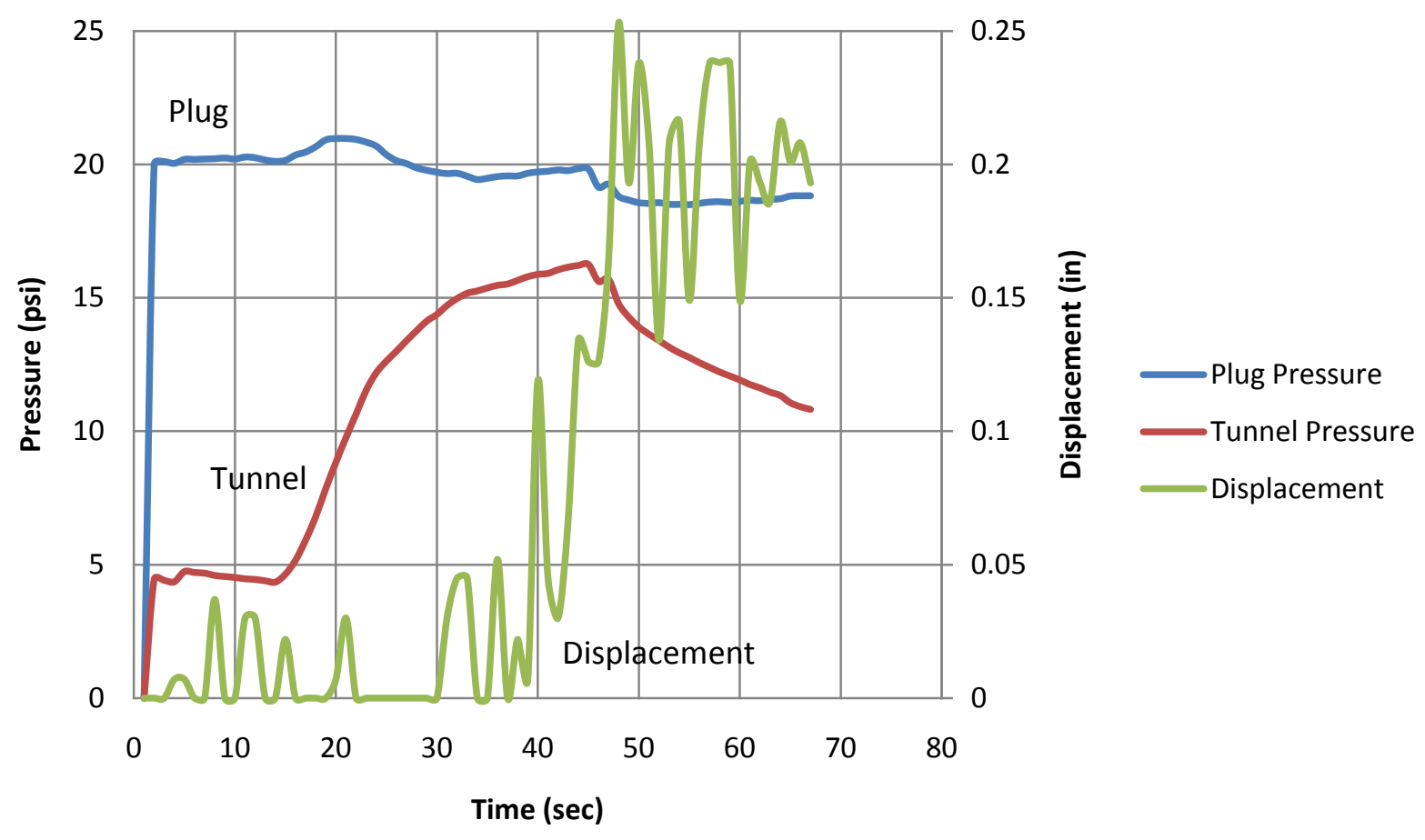

Neoprene, 25 psi Plug Pressure

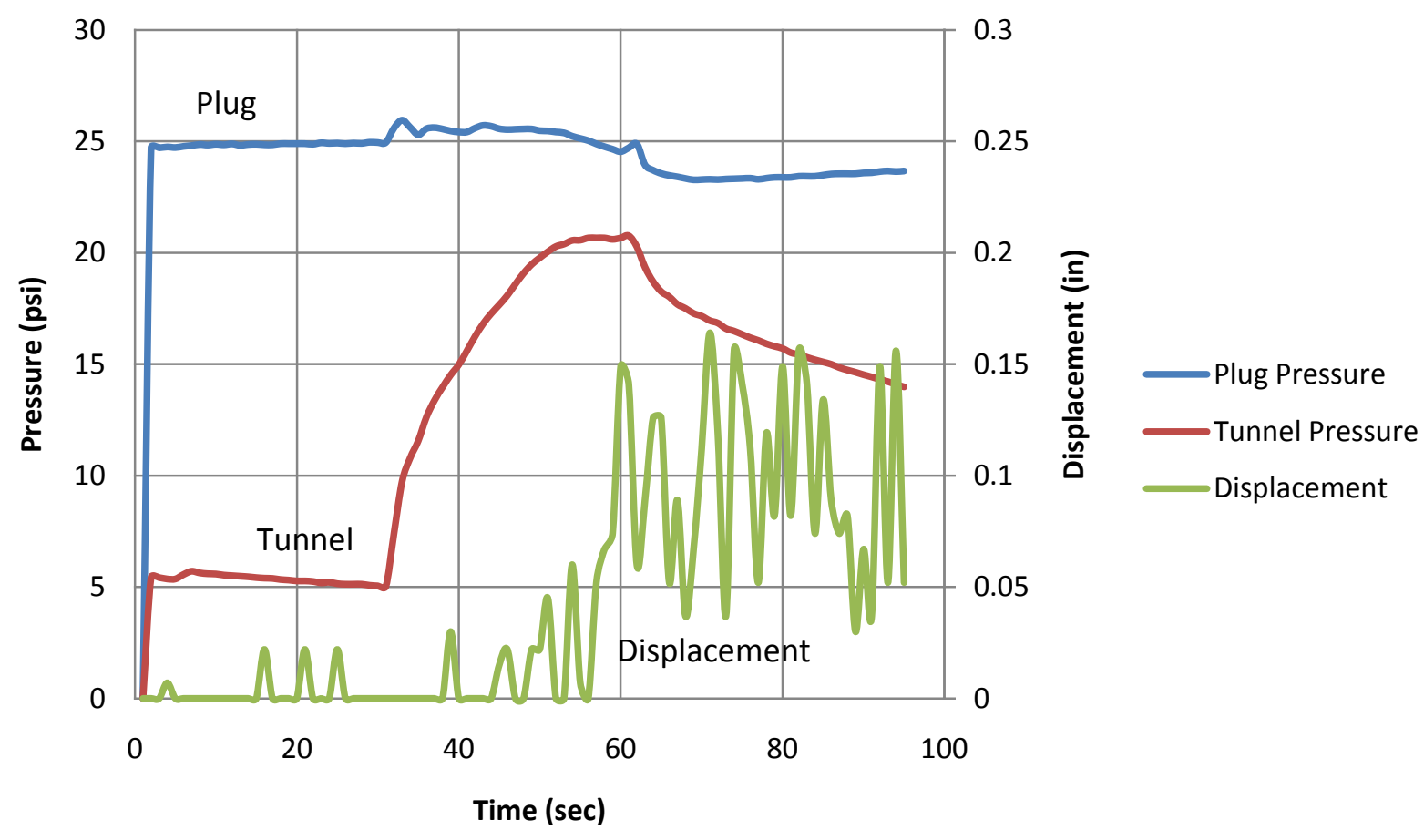




\section{Vinyl, 5 psi Plug Pressure}

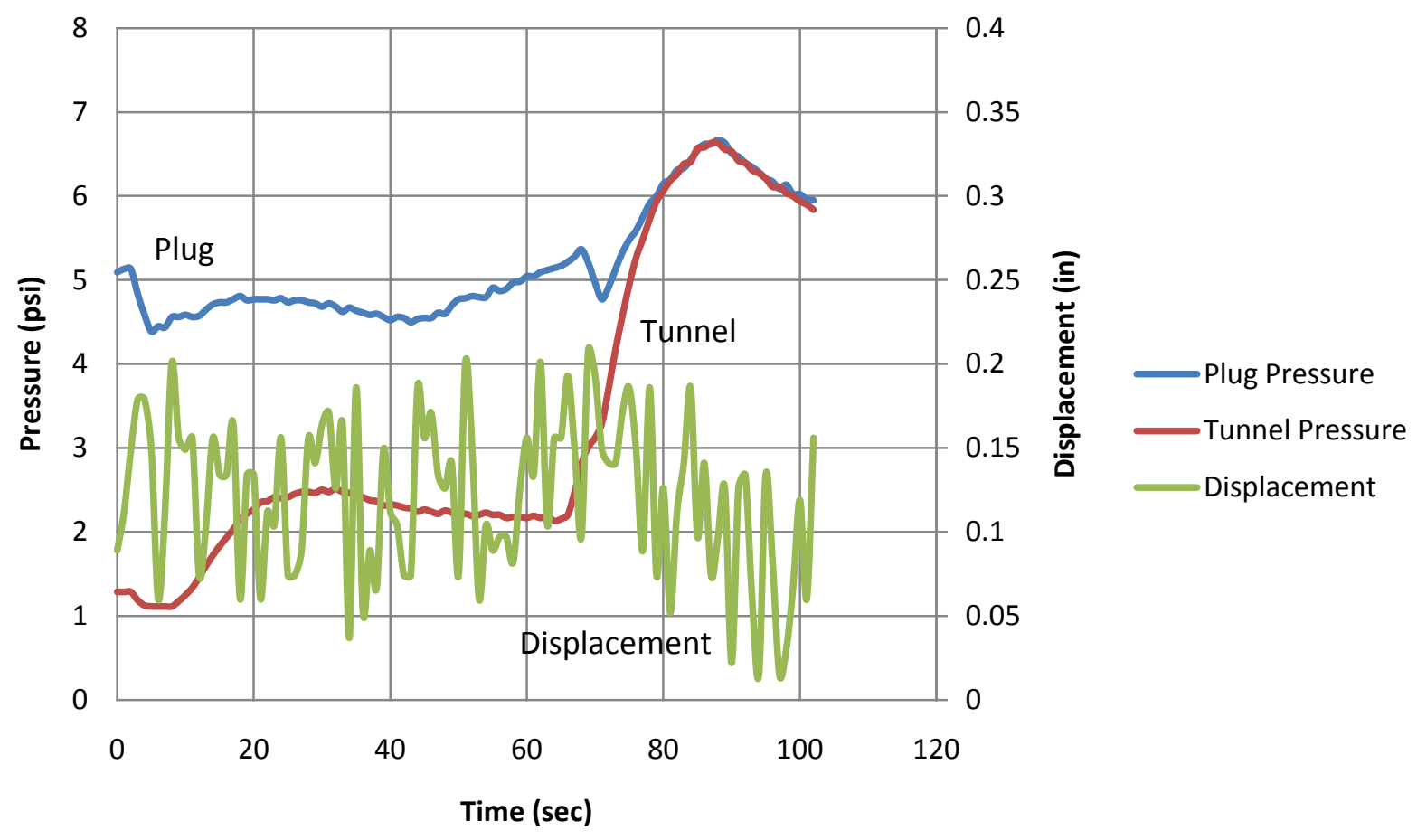

\section{Vinyl, 10 psi Plug Pressure}

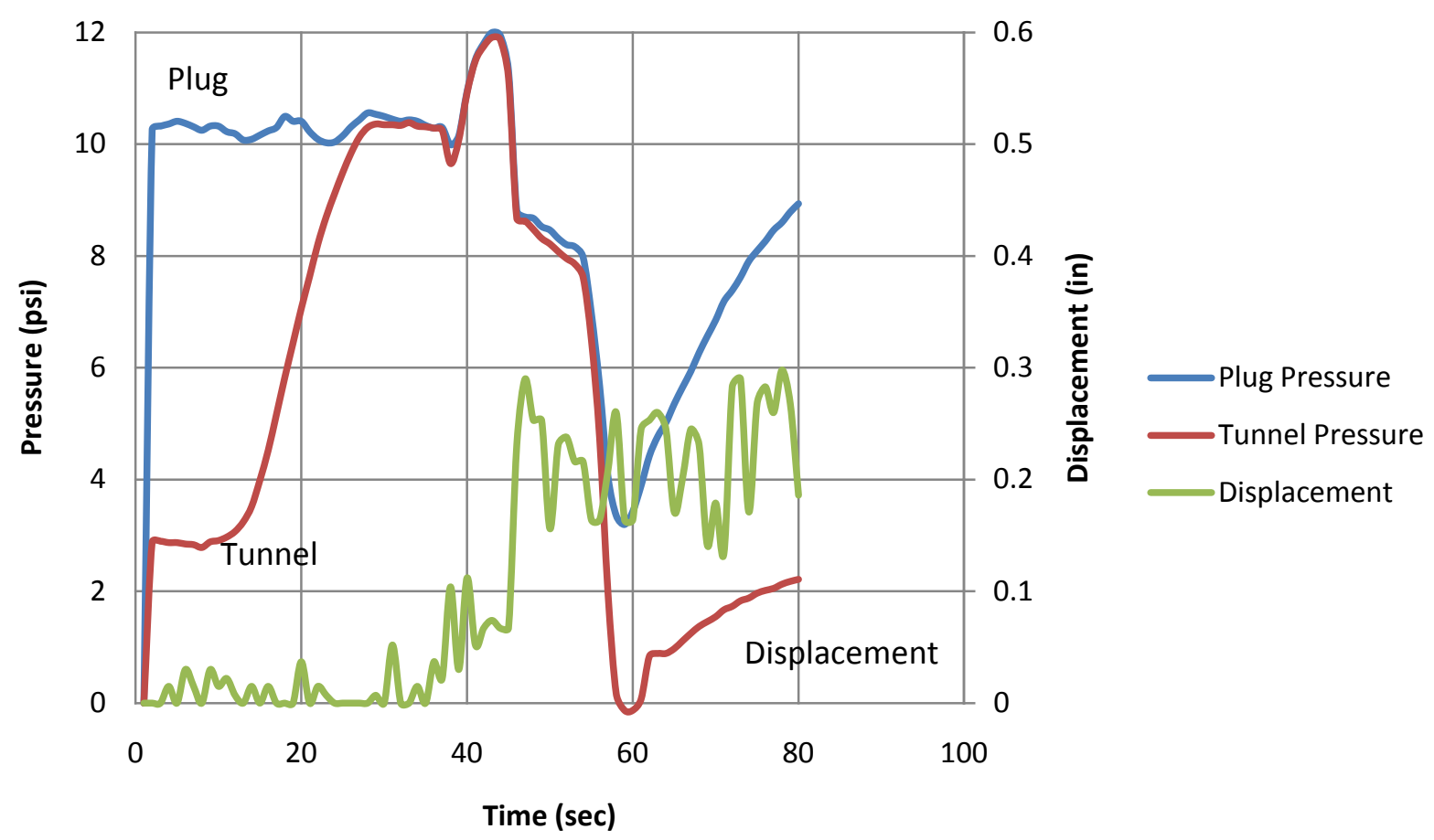



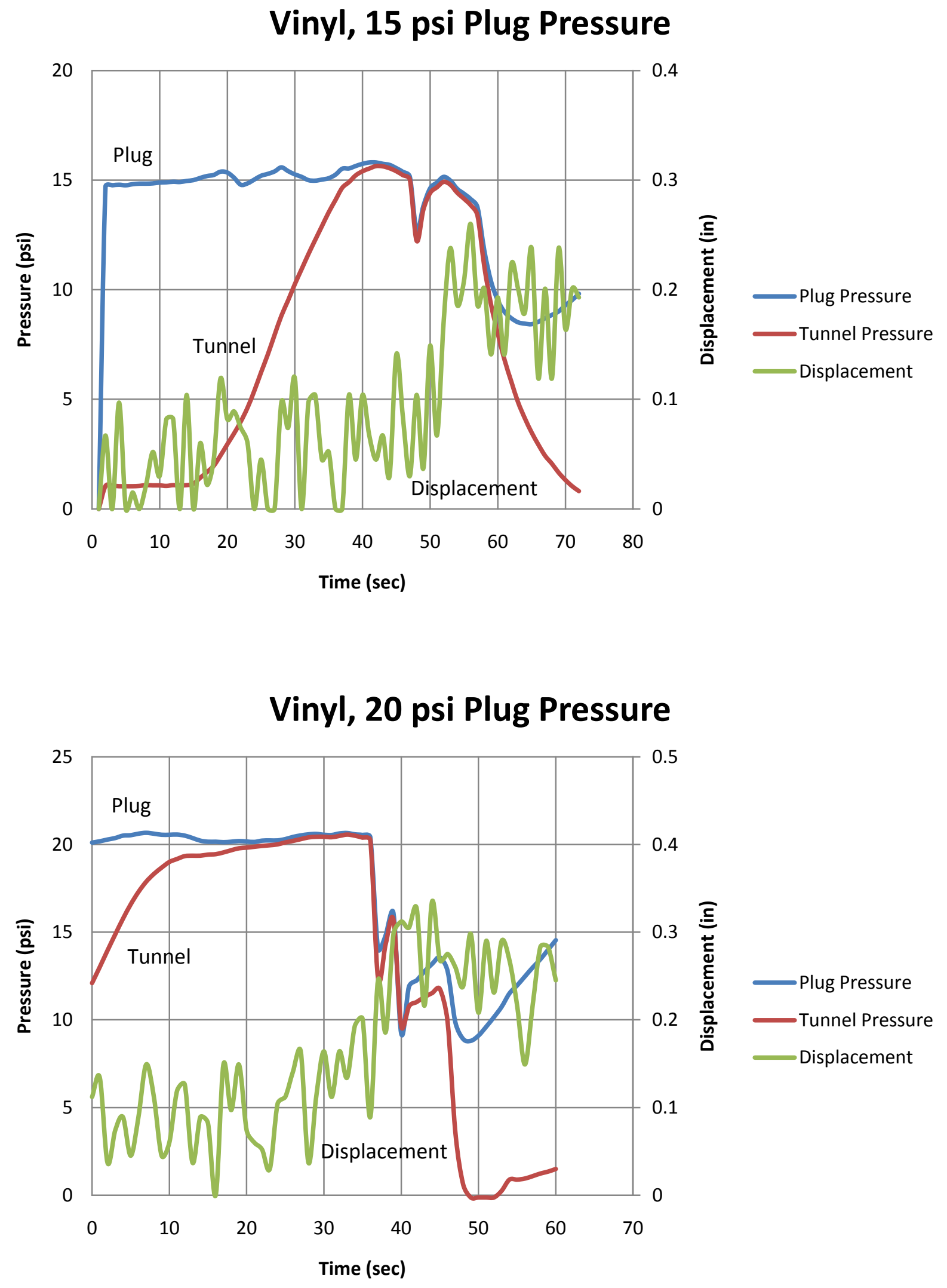

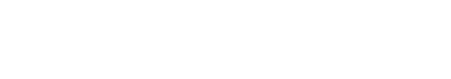

